Florida International University FIU Digital Commons

$5-27-2014$

\title{
Confirmation bias in witness interviewing: Can interviewers ignore their preconceptions?
}

Jillian R. Rivard

Florida International University, jrowb001@fiu.edu

DOI: $10.25148 /$ etd.FI14071109

Follow this and additional works at: https://digitalcommons.fiu.edu/etd

\section{Recommended Citation}

Rivard, Jillian R., "Confirmation bias in witness interviewing: Can interviewers ignore their preconceptions?" (2014). FIU Electronic Theses and Dissertations. 1445.

https://digitalcommons.fiu.edu/etd/1445 


\title{
FLORIDA INTERNATIONAL UNIVERSITY \\ Miami, Florida
}

\section{CONFIRMATION BIAS IN WITNESS INTERVIEWING: CAN INTERVIEWERS}

IGNORE THEIR PRECONCEPTIONS?

\author{
A dissertation submitted in partial fulfillment of \\ the requirements for the degree of \\ DOCTOR OF PHILOSOPHY \\ in \\ PSYCHOLOGY
}

by

Jillian R. Rivard

2014 
To: $\quad$ Interim Dean Michael R. Heithaus

College of Arts and Sciences

This dissertation, written by Jillian R. Rivard, and entitled Confirmation Bias in Witness Interviewing: Can Interviewers Ignore their Preconceptions?, having been approved in respect to style and intellectual content, is referred to you for judgment.

We have read this dissertation and recommend that it be approved.

Ronald Fisher

Lindsay Malloy

Rob Guerette

Nadja Schreiber Compo, Major Professor

Date of Defense: May 27, 2014

The dissertation of Jillian R. Rivard is approved.

Interim Dean Michael R. Heithaus

College of Arts and Sciences

Dean Lakshmi N. Reddi

University Graduate School

Florida International University, 2014 


\section{DEDICATION}

I dedicate this dissertation to my incredibly patient husband. I could not have done this without you. 


\section{ACKNOWLEDGMENTS}

First, I would like to thank my major advisor, Nadja Schreiber Compo, for her encouragement, support, and enthusiasm for this research. Together, we transformed an idea into an exciting line of research and a massive dissertation project. Her excitement about this idea and invaluable guidance throughout the process made this all possible. I am eternally grateful for her mentorship.

I wish to thank my committee members Ronald P. Fisher, Rob Guerette, and Lindsay Malloy for their support, ideas, and constructive feedback throughout this process. Their guidance is deeply appreciated.

I would also like to thank all of the undergraduate research assistants that made this project possible. They are too many too name but their persistence, reliability, and dedication were fundamental to the success of this project.

I would also like to thank my friends and colleagues, Daniella, Jenna, Andrea, and Dana who provided moral support and consistent encouragement throughout the entire process.

Lastly I would like to thank the American Psychology-Law Society (AP-LS). This project was supported, in part, by the AP-LS Grants-in-Aid award, awarded in 2010. 


\title{
ABSTRACT OF THE DISSERTATION \\ CONFIRMATION BIAS IN WITNESS INTERVIEWING: CAN INTERVIEWERS \\ IGNORE THEIR PRECONCEPTIONS?
}

\author{
by
}

\author{
Jillian R. Rivard \\ Florida International University, 2014 \\ Miami, Florida \\ Professor Nadja Schreiber Compo, Major Professor
}

Basic research on expectancy effects suggests that investigative interviewers with pre-conceived notions about a crime may negatively influence the interview process in meaningful ways, yet many interviewing protocols recommend that interviewers review all available information prior to conducting their interviews. Previous research suggests that interviewers with no pre-interview knowledge elicit more detailed and accurate accounts than their informed counterparts (Cantlon, et al., 1996; Rivard et al., under review). The current study investigated whether (a) the benefit of blind versus informed interviewing is moderated by cautionary interviewer instructions to avoid suggestive questions and (b) whether any possible effects of pre-interview information extend beyond the immediate context of the forensic interview.

Paired participants $(\mathrm{N}=584)$ were assigned randomly either to the role of interviewer or witness. Witnesses viewed a mock crime video and were interviewed one week later by an interviewer who received either correct, incorrect, or no information about the crime event. Half of the interviewers were assigned randomly to receive additional instructions to avoid suggestive questions. All participants returned 1 week 
after the interview to recall the crime video (for the witness) or the information recalled by the witness during the interview (for the interviewer). All interviews and delayed recall measures were scored for the quantity and accuracy of information reported. Results replicate earlier findings that blind interviewers elicit more information from witnesses, without a decrease in accuracy rate. However instructions to avoid suggestive questions did not moderate the effect of blind versus informed interviewing on witness recall during the interview. Results further demonstrate that the effects of blind versus non-blind interviewing may extend beyond the immediate context of the interview to a later recall attempt. With instructions to avoid suggestive questions, witnesses of blind interviewers were more accurate than witnesses of incorrectly informed interviewers when recalling the event 1 week later. In addition, blind interviewers had more accurate memories for the witnesses' account of the event during the interview compared to non-blind interviewers. 


\section{TABLE OF CONTENTS}

CHAPTER

PAGE

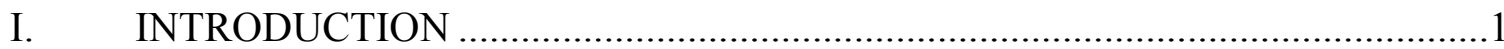

Pre-interview Preparation ......................................................................

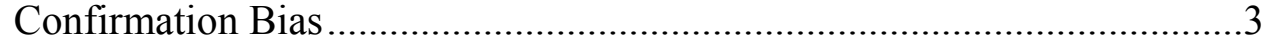

Theoretical Mechanisms .......................................................................

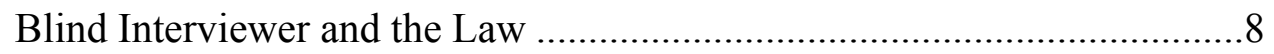

Previous Research on Blind Interviewing ..................................................9

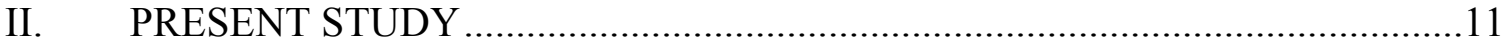

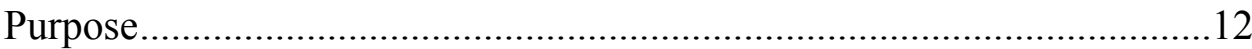

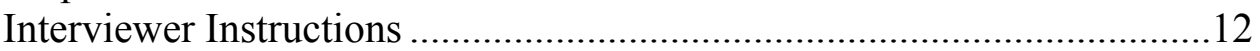

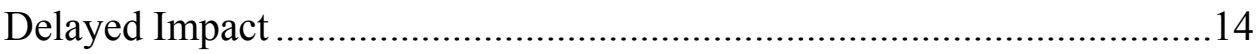

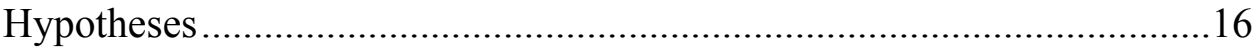

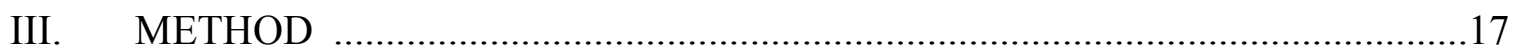

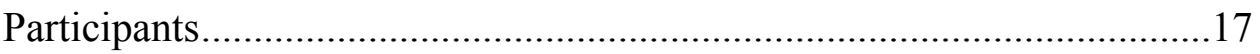

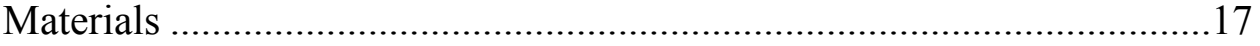

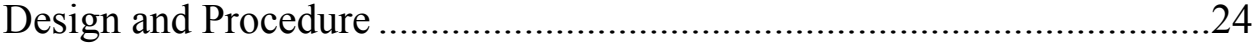

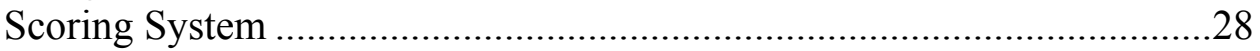

Dependent Measures: Time 2 Interview ....................................................30

Dependent Measures: Time 3 Written Recall...............................................32

Dependent Measures: Source Memory …………………..........................33

Dependent Measures: Across Time ……………………………..............34

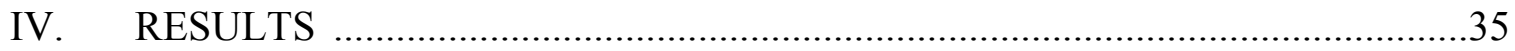

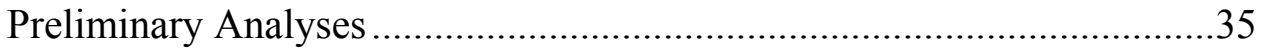

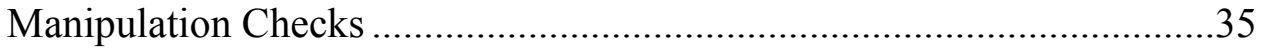

Time 2 Primary Witness Variables .........................................................41

Time 2 Secondary Witness Variables .....................................................43

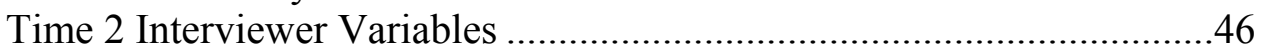

Time 3 Primary Witness Variables ..........................................................49

Time 3 Secondary Witness Variables ....................................................51

Time 3 Primary Interviewer Variables ...................................................54

Time 3 Secondary Interviewer Variables ………………........................56

Witness Memory Across Time …………………….............................58

Time 3 Source Memory …………………………………....................59

Time 3 Post-experiment Questionnaire ………………………………....65

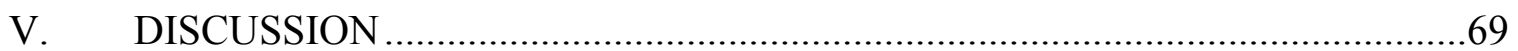

Time 2 Interview .............................................................................

Delayed Impact of Pre-interview Information ..........................................73

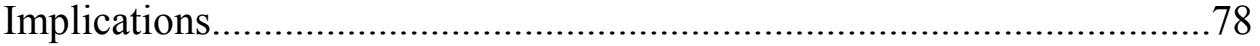




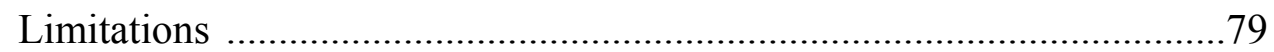

Conclusions and Future Directions ...................................................8 80

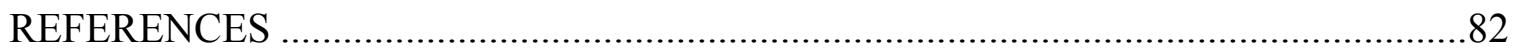

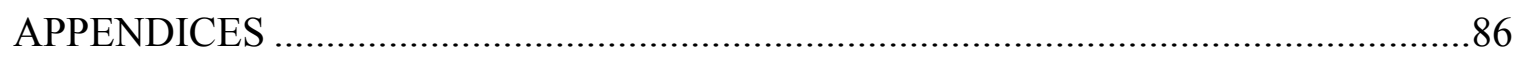

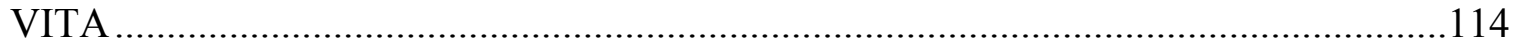




\section{LIST OF TABLES}

TABLE

PAGE

1. Average inter-rater agreement (ICC) for each scored dependent variable.

2. Means and standard deviations for participant motivation and perceptions of incentives

3. F values, $p$ values and effect sizes for participant motivation and interviewer perceptions of incentives. .40

4. Means and standard deviations for primary witness variables at Time 2

4a. Means and standard deviations for secondary witness variables at Time 2 44

5. F values, $\mathrm{p}$ values and effect sizes for all witness Time 2 variables. .45

6. Means and standard deviations for interviewer variables at Time 2 .48

7. F values, $p$ values and effect sizes for all interviewer variables at Time 2

8. Means and standard deviations for primary witness variables at Time 3 ...............51

8a. Means and standard deviations for secondary witness variables at Time $3 \ldots \ldots . . . . .52$

9. F values, $p$ values and effect sizes for all witness Time 3 Variables ........................53

10. Means and standard deviations for primary interviewer variables at Time 3 .55

10a. Means and standard deviations for secondary Interviewer variables at Time 3 .57

11. F values, $\mathrm{p}$ values and effect sizes for all interviewer Time 3 variables. .58

12. Means and standard deviations for witness variables across time .59

13. F values, $\mathrm{p}$ values and effect sizes for witness memory over time

14. Means and standard deviations for witness source memory decisions

15. F values, $p$ values and effect sizes for witness source memory decisions .62

16. Means and standard deviations for interviewer source memory decisions .64

17. F values, $\mathrm{p}$ values and effect sizes for interviewer source memory decisions .64 
18. Means and standard deviations for witness perceptions of the interviewer 65

19. F values, $p$ values and effect sizes for witness perceptions of the interviewer .......66

20. Means and standard deviations for Interviewer perceptions of the witness and

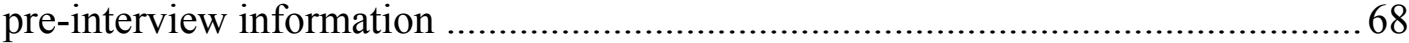

21. F values, $p$ values and effect sizes for Interviewer perceptions of the witness and pre-interview information 68 


\section{I: INTRODUCTION}

Confirmation bias in witness interviewing: Can interviewers ignore their preconceptions?

Obtaining information from witnesses is the first and perhaps most critical step in criminal investigations. It is extremely important that an investigator obtains the most accurate and detailed description possible from each witness. An eyewitness' statements, if elicited through poor investigative interviewing strategies (e.g. suggestive or repeated questions), can lead an investigation astray and result in the wrongful conviction of an innocent person.

\section{Pre-Interview Preparation}

The National Institute of Justice (NIJ) organized a technical working group of social science researchers, law enforcement officials and attorneys, which has produced a handbook of best practice guidelines in collecting eyewitness evidence in order to enhance witness recall while avoiding techniques that may bias the witness' memory or an interviewer's interpretation of that memory (Technical Working Group, 1999). These guidelines suggest that investigative interviewers "review all available witness and case information prior to conducting a witness interview" (p. 21, Technical Working Group, 1999). This pre-interview preparation is thought to foster witness participation in the interview process and enable the interviewer to be more efficient (e.g., aiding in an understanding of the events and the witness). This recommendation is in line with schematic principles of memory and comprehension, in that information is easier to process and remember if we have a scaffold with which to interpret and organize incoming information (MacCoun, 1998). 
The necessity of pre-interview preparation may depend on the context of the investigation. That is, specific interviewing contexts, such as suspect interviews, may benefit from interviewers' knowledge of case facts more than others. In suspect interviews, investigators must make important judgments of interviewee trustworthiness and deception and therefore, being as knowledgeable as possible about pre-existing case facts is necessary to compare interviewee's accounts to established facts of the case. Preinterview preparation may also be critical with certain vulnerable witness populations such as children (Poole \& Lamb, 1998). Typically, child forensic interviewers are encouraged to gather all relevant information including allegation information, familiarity with topics that interest the child, and any information that may be helpful in clarifying details, such as family names and caretaking routines. This is thought to enhance comprehension of the child's responses, foster more effective rapport building, and aid in introducing the topic of abuse (Poole \& Lamb, 1998). It has also been argued that preinterview information may be necessary given sexually abused children's reluctance to disclose spontaneously in an interview situation (Saywitz, Goodman, Nicholas, \& Moan, 1991). As such, reluctant children may benefit from direct questioning fostered by knowledge of the circumstances surrounding the allegation or a previous disclosure from the child.

There may be contexts, however, where pre-interview knowledge is not necessary and may actually be harmful to the interview process, such as with cooperative adult witnesses. A wealth of cognitive and social psychological research on confirmation bias and expectancy effects suggests that the recommendation to review pre-interview information may be at odds with the equally important recommendation to avoid biasing 
the interview (e.g., Rosenthal \& Rubin, 1978; Snyder \& Swann, 1978; Rosenthal, 1994). That is, interviewers who have information about the crime may be guided, and hence biased, in the direction of the information. The usefulness of pre-interview preparation may thus depend on the quality/veracity of case information available to the interviewer.

\section{Confirmation Bias}

The idea that pre-interview information may bias an investigative interview is derived from the empirically demonstrated human tendency to confirm rather than disconfirm a hypothesis, known as the 'confirmation bias' or confirmatory hypothesis testing (Wason, 1968; Rosenthal, 1994; Nickerson, 1998; Jones \& Sugden, 2001). In addition, a plethora of research demonstrates that an initial hypothesis can transform an interaction such that individuals actually behave in ways consistent with the hypothesis (e.g., Synder \& Swann, 1978; Nisbett \& Ross, 1980; Rosenthal, 1994). In the earliest laboratory experiments investigating this phenomenon, Rosenthal and colleagues tested the effect of confirmation bias in an experimental setting. Experimenters who were led to expect an arbitrary result obtained outcomes consistent with their expectations, despite the fact that the expectations were artificially implanted at random (Rosenthal, 1994). This phenomenon, termed the "Rosenthal Effect" or interpersonal expectancy effect, occurs when ambiguous situations or behaviors are interpreted in the direction of previously held expectations. In order to minimize both intentional and unintentional experimenter cues and expectancy effects, experimental research designs now incorporate a 'double-blind' procedure in which the experimenter and the participant have no knowledge of the study's hypotheses and the participant's group assignment. Thus the 
Rosenthal effect has led to arguably one of the broadest and most significant advances in the field of experimental psychology design.

The current body of research on confirmation bias and interpersonal expectancy effects spanning over 50 years demonstrates the robustness of the effect in a variety of different contexts extending well beyond the scope of experimental designs (e.g., Snyder \& Swann, 1978; Kassin, Goldstein \& Savisky, 2003; Dror, Péron, Hind \& Charlton, 2005 Rosenthal, 1994). For example, in a classic experiment by Rosenthal and Rubin (1978), grade-school teachers were arbitrarily told that a random selection of their students scored above average on an intelligence test and would thus be expected to show significant intellectual growth. Results demonstrated that those students who were expected to achieve intellectual growth, showed a significantly greater gain than the students who were not named as the "high-scoring" students. Similarly, in another classic series of experiments by Synder and Swann (1978) participant interviewers were led to believe that an individual they were about to interview was either an extrovert or an introvert. Results revealed that interviewers (a) selected questions consistent with the hypothesis given, (b) elicited answers that were consistent with their original hypotheses and (c) the confirmatory pattern was observed irrespective of perceived likelihood of the preconception being correct or an incentive to be accurate. These early findings show just how powerful the confirmation bias is: It occurs regardless of whether another strategy would be more efficient and regardless of whether the initial hypothesis is based on strong or weak evidence. In addition, confirmation bias has a substantial, observable impact on the outcome of the interaction through a form of self-fulfilling prophecy (Rosenthal, 1994). 
Recently, the concept of confirmatory hypothesis testing has been examined within the context of legal issues and researchers have demonstrated the need to protect police procedures from investigative biases. Kassin, Goldstein and Savisky (2003) showed that student interrogators who were led to believe a suspect was guilty prior to interviewing a suspect were more likely to interpret the suspect's behavior as being indicative of guilt, and were more likely to use guilt-presumptive questions and interrogation tactics in an attempt to elicit a confession. The guilt presumptive techniques in turn caused the suspects to appear more defensive and therefore "guilty" to an outside observer, particularly when the suspect was actually innocent (Kassin et al., 2003). In addition, research on lineup administration procedures has shown that under some circumstances, lineup administrators' hypotheses regarding the presence and position of a suspect in a lineup can influence participant witnesses' lineup identifications (Phillips, McAuliff, Kovera \& Cutler, 1999), post-identification recall and confidence ratings (Garrioch \& Brimacombe, 2001). Analyses of non-verbal behavior revealed subtle differences between blind and non-blind lineup administrators' eye contact, emphasis of speech, facial expressions, and body language (Garrioch \& Brimacombe, 2001). The double-blind paradigm has been proposed to combat lineup administrator bias, with the hope that if both the witness and the lineup administrator are unaware of who the suspect is and his or her location in the lineup, expectancy effects will be reduced (Phillips et al., 1999; Wells, Small, Penrod, Malpass, Fulero \& Brimacombe, 1998).

\section{Theoretical Mechanisms}

There are a number of cognitive and motivational explanations for why confirmatory hypothesis testing occurs. Of particular relevance to the context of 
investigative interviews, one such explanation is that confirmation bias results from a form of heuristic processing whereby the hypothesis tester uses information readily available (Synder \& Swann, 1978). Considerable evidence suggests that individuals use an 'availability heuristic' when estimating frequencies whereby the ease with which one is able to recall an event determines the frequency with which one thinks it occurs (Tversky \& Kahneman, 1973). Information relevant to testing a hypothesis is salient and easily accessible (e.g., directly stated) in comparison to information relevant to disproving a hypothesis, which would take an extra cognitive step to infer (Wason, 1968; Synder \& Swann, 1978). In addition, according to schematic principles of memory, confirmation bias occurs because preconceived notions about the world serve as a filter through which we attend to and interpret information in our environment (MacCoun, 1998). When a hypothesis activates a schema, a form of automatic processing occurs whereby one's attention is filtered through the schema and information gathered is interpreted through the lens of the schema (Alba \& Hasher, 1983; MacCoun, 1998; Nisbett \& Ross, 1980). Information consistent with the schema is easily incorporated with pre-existing beliefs whereas schema-inconsistent information may be overlooked, minimized or transformed with respect to the schema or in this case, the original hypothesis. This restricted way of processing information with respect to the salient hypothesis in turn influences and restricts the type of evidence that can be gathered. Such a directed strategy may increase efficiency in circumstances in which an interviewer has limited time and resources and may be beneficial when pre-interview information is accurate. However, in circumstances in which the goal is to maximize the amount of information obtained from witnesses (e.g., in the exploratory stages on an investigation) 
and the veracity of previously gathered information is unknown, this restricted strategy may limit the generation of viable leads and could bias the interviewer in the direction of confirming inaccurate information.

Taken together, the continually growing body of research on confirmation biases and expectancy effects shows that the danger of preconceptions in interpersonal interactions may be two-fold. First, preconceptions may drive the 'hypothesis-tester' to selectively seek out confirming evidence, giving more weight to confirming evidence and less weight to disconfirming evidence, and to interpret cues within the framework of the hypothesis through 'top-down' information processing (Nickerson, 1998). Although this type of confirmatory hypothesis testing is more cognitively efficient and may save an interviewer valuable time and resources (Snyder \& Swann, 1978; Jones \& Sugden, 2001), the process of searching for disconfirming evidence in a 'bottom-up' approach may maximize the accuracy of the information obtained - an important objective in legal settings. Second, the process of seeking and interpreting confirming cues can result in a unique feedback loop in which disproportionately sought-after confirming evidence transforms the interaction such that the respondent adjusts his/her behavior to confirm the other person's expectation. Applied to the investigative interviewing context, the power of such expectancy effects and confirmation biases suggests that their risks may outweigh the proposed benefits of pre-interview preparation. That is, interviewers who have reviewed all relevant information may (a) ask questions aimed at confirming initial information gathered about the crime which may or may not be accurate, (b) overlook or give less weight to information that is inconsistent with the information or (c) stop short of collecting all possible information by simply confirming what is already known. In 
turn, this could result in interviewees who (falsely) conform to the interviewers' hypotheses because they are constrained or influenced by the types of questions asked. When the quality of pre-interview information is unknown or poor, this confirmatory strategy may be particularly harmful.

\section{Blind Interviewing and the Law}

A few child interviewing agencies (e.g., in Idaho, Arizona, Wisconsin, and Pennsylvania) have adopted an interviewing strategy reducing the amount of preinterview information known to the interviewer, referred to as "allegation-blind" or "blind" interviewing (Rivard \& Schreiber Compo, in preparation). In a blind interview, the investigative interviewer knows very limited information about the event and is "blind" to all allegations or event information prior to conducting the forensic interview. The idea is that without pre-interview knowledge, the interviewer is free to explore all potential hypotheses, will be less likely to adopt a biased questioning strategy, will be better able to remain neutral and will be less able to introduce information into the interview.

The courts have not addressed the issue of pre-interview information with adult witnesses, but have indirectly addressed this topic in at least one known case of child sexual abuse. In Idaho v. Wright (1990), a woman was charged with sexually abusing her 2 1/2-year-old daughter. The key evidence in this case was the child's statement to a pediatrician regarding the abuse. Because the child was deemed incapable of testifying on her own behalf at the time of trial, the pediatrician's testimony was instrumental to the prosecution's case and his interview techniques came under question. As a result, the conviction was reversed and the appeal made it all the way to the United States Supreme 
Court, which ruled that the doctor had conducted the interview without procedural safeguards sufficient to guarantee trustworthiness and therefore, the admittance of his testimony violated the defendant's $6^{\text {th }}$ Amendment right to due process. These errors included failing to videotape the interview and the use of leading questions (e.g. "Did daddy touch your pee-pee?"). Of particular importance to the current research, the court also noted that having a preconceived idea of the allegation the child should be disclosing was also a contributing factor to the untrustworthiness of the child's statements. That is, the pediatrician was aware that the child's sister recently disclosed sexual abuse by their father, which appeared to be the basis of the pediatrician's suggestive questions specifically targeting the alleged perpetrator. Although the Supreme Court has not provided specific guidelines with respect to reliability and trustworthiness, the final opinion in Idaho $v$. Wright (1990) suggests that being blind to allegation information may serve as a legally sound safeguard against interviewer bias.

\section{Previous Research on Blind Interviewing}

Few studies to date have addressed the topic of blind interviewing empirically and all have focused on child witnesses. Only one study has directly investigated the effects of pre-interview information in a field setting (Cantlon, Payne, \& Erbaugh, 1996) by comparing the effectiveness of allegation-blind versus non-blind interview techniques on alleged child abuse victims' disclosure rates. Real-world interviewers either did or did not have any pre-interview information before interviewing a child witness. Results showed that the allegation-blind technique resulted in a significantly higher disclosure rate compared to non allegation-blind interviews. One possible explanation suggested by the researchers is that allegation-blindness resulted in more attentive and patient 
interviewers. However, there are considerable limitations in interpreting the results of the aforementioned study because it lacked random assignment and the possibility to assess statement veracity.

Recently, Rivard, Schreiber Compo, and Pena (under review) conducted a laboratory study with adult witnesses to investigate whether pre-interview knowledge can influence lay interviewers' questioning strategies and the quality and quantity of witness recall, using newly developed stimulus material. Participants were randomly assigned to the role of interviewer or witness. Witnesses watched a mock crime video of a laptop being stolen and were then interviewed either after a 10 minute filler task or a 1-week delay by an interviewer who had either correct, incorrect, or no information about the crime. Results revealed that witnesses of blind interviewers reported more details and more correct details than witnesses of both correctly and incorrectly informed interviewers. Differences in witness recall across the groups were mirrored and possibly elicited by interesting differences in interviewer behavior across the three groups: Blind interviewers asked more questions than the informed interviewers, conducting slightly longer interviews, but only in the immediate condition. Blind interviewers were also more likely to begin the interview with an open-ended question compared to informed interviewers. In contrast, informed interviewers were more likely to begin the interview with a suggestive question compared to blind interviewers. This initial laboratory study provides support for the notion that interviewers' pre-interview knowledge of case facts can influence the effort expended and output elicited during an eyewitness memory recall task. 


\section{II: THE PRESENT STUDY}

Taken together, both past and current findings on the expectancy effect and its resulting theoretical explanations support the notion that blind interviewers' naïve approach may be beneficial in reducing the use of suggestive questions and/or enhancing quantity (and potential accuracy) of information elicited from a witness. In addition, the observed differences between experimental groups in Rivard et al.'s study demonstrate that the newly developed stimulus materials and procedure were sufficiently sensitive to detect the effect of pre-interview information in a laboratory setting, even with lay interviewers. However, there are two additional components of real-world interviewing that should be considered when evaluating the effects of pre-interview preparation that remain untested. First, real world interviewers are typically instructed to avoid suggestive questions and may thus respond to and incorporate pre-interview information differently than the lay interviewers in Rivard et al.'s study. Second, real world interviewers have vested interest in the outcome of the witness interview. That is, they are motivated by external pressure to identify the perpetrator of a given crime and close the case, which may influence the way interviewers use pre-interview information both in their questioning strategy and in the way they interpret the witness' statement. The delayed impact of pre-interview information on interviewers' interpretation and memory for the interview remains untested. Finally, and perhaps most importantly, in the Rivard et al. study, the influence of pre-interview information on witness' memory was tested only within the context of the interview itself. As witnesses are often asked to recall the event on more than one occasion after the investigative interview (e.g., courtroom testimony), the influence of pre-interview information on witness memory remains unknown. That is, 
the greatest problem with pre-informed interviewing may arguably present itself at a later time, when both the interviewer and the witness may recall the interview or original event falsely incorporating pre-interview information.

\section{Purpose}

To address these gaps in the literature on pre-interview information, the current study investigated: (1) whether interviewer instructions to avoid suggestive interviewing techniques moderated the effect of pre-interview information on both interviewer and interviewee behavior and (2) whether the effects of pre-interview information extended beyond the immediate context of the forensic interview to later recall attempts. Although it is difficult to approximate in the lab the pressure and motivations of real-world investigators in the context of criminal investigations, the present study aimed to improve the ecological validity of Rivard et al.'s design by adding incentives for lay interviewers to generate detailed reports.

\section{Interviewer Instructions}

At first glance, cautionary instructions to avoid suggestive questions may allow interviewers to question the witness more effectively, thereby eliminating the effect of pre-interview information. Lay interviewers, with no restrictions, may have assumed it was appropriate to introduce information into the interview. Therefore, instructions to avoid suggestive questions could sufficiently deter interviewer bias. However, previous research suggests that confirmation bias and expectancy effects persist despite knowledge that the preconception may be inaccurate (Synder \& Swann, 1991) and despite explicit instructions to avoid bias (Garrioch \& Brimacombe, 2001; Petit et al., 1991; Phillips et al., 1991) and ethical obligations to avoid bias (e.g., Rosenthal, 1994). Research suggests 
that, alternatively, cautionary interviewer instructions may only slightly decrease this effect, perhaps because the underlying mechanisms of confirmatory hypothesis testing reflect automatic versus deliberate mental processes. That is, if pre-interview information is salient, easily accessible or activates a schema, the underlying cognitive mechanisms may occur beyond the interviewers' conscious awareness. This type of heuristic processing may be particularly prominent in real-world criminal investigations in which the demands of the investigation (e.g., time constraints, a need for fine-grained level of detail or safety concerns) may outweigh attempts to remain neutral and non-suggestive. In addition, interviewing crime victims is a complex task, which involves much more than simply listening to the witness describe an event. Interviewers continually search their memories in order to (a) formulate forensically-relevant questions, (b) clarify inconsistencies in the witness' statement, (c) decide when sufficient information has been obtained, (d) monitor the witness for indices of credibility or deception and in the case of informed interviewers, and (e) monitor the witness' consistency with the pre-interview information. Basic cognitive research on working memory suggests that individuals have limited amount cognitive resources to allocate to competing mental tasks at any given time (Baddeley \& Hitch, 1974; Baddeley, 2001; Teasdale et al., 1995). When or if neutral, open-ended questions do not yield the level of detail necessary to meet the investigation's needs or pre-conceived notions of the alleged events, the instruction to avoid suggestive questions may become increasingly difficult. These instructions may also require an additional level of self-monitoring for those interviewers who have preinterview knowledge because they must suppress the tendency to simply confirm their preconception with a direct and potentially leading question. Researchers investigating 
cues to deception have posited that suppressing guilty knowledge adds an additional cognitive burden on liars compared to truth tellers because they must avoid selfincrimination (e.g., Vrij, Granhag, Mann, \& Leal, 2011). Similarly, informed interviewers asked to avoid suggestive questions, which introduce information, may experience more cognitive demands when generating questions compared to interviewers who have no previous knowledge to suppress. Thus, cautionary instructions may be more beneficial to blind interviewers compared to correctly and incorrectly informed interviewers.

\section{Delayed Impact}

A second goal of the proposed study is to explore the effects and possible theoretic underpinnings of pre-interview information's effect beyond the immediate context of the forensic interview. That is, in addition to changing the interviewer's behavior at the time of the interview, pre-interview information may also have a longterm effect on how both interviewer and witness will recall the event at a later time. This is because memory is an active constructive and reconstructive process that is guided by our knowledge and expectations both at encoding and retrieval (Alba \& Hasher, 1983; Neisser, 1996). As such, memories are formed, interpreted, shaped and possibly distorted as new information is introduced and we are asked to recall the event more than once. An extensive body of psychological research has established that exposure to post-event information has a powerful effect on individuals' memory for the original event (e.g., Loftus \& Palmer, 1974; Loftus 1975; Loftus, Miller, \& Burns. 1978; McCloskey \& Zaragoza, 1985). Witnesses can be exposed to information in various ways, one of which is the exposure to suggestive questions (both correct and incorrect) in an interview 
context. For example, participants who are asked a suggestive question such as "How fast were the cars going when they smashed into each other?" gave higher speed estimates than those who were asked "How fast were the cars going when they hit each other?" The slight variation in the verb from 'hit' to 'smashed' influenced participants' interpretation of the cars' speed and also increased the likelihood that participants would (falsely) report having seen broken glass (Loftus \& Palmer, 1974). When the interjected information is incorrect, the resulting memory distortion is known as one of the many forms of the 'misinformation effect.'

According to the source monitoring framework, the misinformation effect occurs because individuals who have been exposed to different sources of information must evaluate the source of their memories when remembering in order to discriminate between memories originating from source A or source B (e.g., the event or suggestive question; Johnson, Hashtroudi and Lindsay, 1993). Source monitoring errors (and thus misinformation effects) occur when a newly introduced piece of information is wrongly attributed to the original event. In the context of blind versus informed interviewing, preinterview information, if introduced into the interview through the use of suggestive questions or statements, could be falsely attributed to the original event when a witness is trying to remember the event at a later time. Similarly, interviewers may falsely attribute a memory as originating from the witness' account when it was contained only in the preinterview report. In sum, pre-interview information may act as misinformation beyond its immediate effect on the investigative interview such that (a) it is incorporated into a nonblind interviewer's memory via source attribution errors (pre-interview report vs. witness statement) at a later recall attempt and (b) incorporated into the witness' memory of the 
actual event via source attribution errors (original event vs. interviewer suggestion) at a later recall attempt. Arguably, this type of possible misinformation effect may be even more detrimental than succumbing to interviewer suggestions at time of the interview. That is, whereas acquiescing to interviewer suggestions could theoretically be disregarded if interviews are videotaped, this delayed effect of non-blind interviewing may render both witnesses and interviewers unable to disentangle which recalled information originated from which source at a later time.

\section{Hypotheses}

Findings of previous research and the underlying theoretical mechanisms discussed above resulted in the formulation of the following hypotheses: (1) Blind interviewers would perform better quality interviews (e.g., containing fewer suggestive questions, more open-ended questions) compared to both correctly and incorrectly informed interviewers, (2) Witnesses interviewed by blind interviewers would provide more information than witnesses of both incorrectly and correctly informed interviewers, (3) Witnesses interviewed by blind interviewers would be more accurate than witnesses

of incorrectly informed interviewers, (4) Instructions to avoid suggestive questions would decrease the number of suggestive questions asked, particularly when interviewers are informed compared to blind; and finally, (5) after a brief delay, (a) blind interviewers' recall of the witness' account would be more accurate than correctly and incorrectly informed interviewers' and (b) witnesses of blind interviewers would have more accurate and detailed memories of the originally witnessed event than witnesses of incorrectly informed interviewers and more detailed memories than witnesses of correctly informed 
interviewers. See Appendix A for a summary of the research questions, hypotheses, and subsequent findings.

\section{METHOD}

\section{Participants}

Five hundred and eighty-four male and female undergraduate students (292 pairs) from Florida International University were recruited for a study on 'Impressions of Social Interactions.' Forty-four pairs were excluded because they (a) recognized the actors in the mock-crime video, (b) failed to follow directions (e.g., conducted an interrogation or pretended they were an actor in the video rather than an outside observer), or (c) admitted to speaking to one another in between sessions. The final sample included five hundred and two participants (251 pairs) with a mean age of 23 years (ranging from 18 to 60 years). Three-hundred and seventy-one were female (74\%) and the remaining 131 were male (26\%). Participants were primarily Hispanic (62\%), followed by African Americans (16\%), Caucasians (12\%), other or mixed ethnicities (7\%), and Asians/Pacific Islanders $(3 \%)$.

\section{Materials}

Distractor Video and Questionnaire. The true purpose of the experiment was disguised to better approximate incidental versus intentional encoding of the crime event. Therefore, participants were first shown a neutral video of an interpersonal interaction (approximately $2-3$ minutes in length), which served as a distractor video. The video depicted two graduate students entering a room and discussing an upcoming research paper assignment. At the conclusion of the distractor video, participant-witnesses were asked 3 questions related to their impressions of the social interaction. Participants' 
responses were recorded but not analyzed. See Figure 1 for a flow chart of the experimental procedure and dependent measures administered.

Figure 1. Flow chart of experimental procedure and dependent measures for interviewers and witnesses.

\section{Interviewer}

\section{TIME 1}

- Consent

- Interviewer instructions

TIME 2

- General instructions

- Suggestive questions instruction: Yes vs. No

- Pre-interview information: Correct vs. Incorrect vs. None

- Participate in Interview

- Demographics Questionnaire

\section{TIME 3}

- Free Recall of witness interview

- Cued Recall of witness interview

- Source Memory Questionnaire

- Post-Experiment Questionnaire

- Debriefing Questionnaire

\section{Witness}

TIME 1

- Consent

- Distractor Video

- Distractor Questionnaire

- Stimulus Mock Crime video

TIME 2

- General instructions

- Participate in Interview

- Demographics Questionnaire

TIME 3

- Free Recall of crime video

- Cued Recall of crime video

- Source Memory Questionnaire

- Post-Experiment Questionnaire

- Debriefing Questionnaire

Video Stimulus. The mock-crime video was 1 of 2 versions of a mock-crime video used as the stimulus materials in Rivard et al. (under review). Both mock crime videos depicted the theft of a laptop from the viewpoint of an eyewitness. They were created to allow for a counterbalancing of stimulus events and to manipulate the correct 
versus incorrect report type, while keeping the type and length of the crime constant. The crime videos were approximately 1.5 minutes long and varied in approximately 15 identifiable details related to the item(s) stolen, the setting, the perpetrator and the sequence of events. However, the videos both depicted a theft of a laptop and contained the following same core details: (a) a Hispanic, male perpetrator, (b) a Hispanic male bystander who was present in the room but did not actually see the crime occur, (c) a female witness who left the room before the crime occurred, (d) location in the DM building, (e) a laptop being stolen, and (f) the bystander calling security to report it.

Pre-interview Reports. The pre-interview information was provided to participant-interviewers in the form of a brief, written, narrative police report ( 9 sentences) designed to reflect a case summary that could have been collected by a first responder (e.g., a 911 operator). The source and veracity of the information was not disclosed to test accurately the effects of general information on the interviewers' subsequent approach to interviewing an eyewitness. The reports included details regarding what type of crime occurred (e.g., theft of a laptop), where and when the crime occurred (e.g., time of day, room number, time of year), description of the perpetrator (e.g., height, weight, ethnicity, clothing), and some general action details (e.g., sequence of people entering the room). Correct reports matched the video viewed by the witness (correct pre-informed condition) whereas incorrect reports matched the alternate version (incorrect pre-informed condition). Each report contained 27 details: 12 correct details contained in both versions of the video and 15 details that were either correct because they matched the video watched by the witness or incorrect because they matched the 
alternate version of the video. ${ }^{1}$ The incorrect report included both correct and incorrect information to increase believability of this condition and to prevent both interviewers and witnesses from detecting the true objective of the study during the interview. See Appendix B for a table of the details contained in the pre-interview report.

Demographics Questionnaire. All participants filled out a basic demographic questionnaire in which they indicated their age, sex, ethnic background, whether they had a pre-existing relationship with the other participant, and for witnesses, whether they recognized any of the actors in the mock-crime video. See Appendix C for a copy of the demographic questionnaire. For a summary of the dependent measures and time of administration, see Figure 1.

Time 2 Witness Interview. One week after witnessing the stimulus mock crime video, a participant interviewer was assigned to interview the witness about the event. All interviews were audio and video recorded.

Time 3 Free Recall Questionnaire. One week after participating in the interview, witnesses' memories for the original event and interviewers' memories for the witness' version of the event were tested via written free-recall. Witnesses responded to the open-ended prompt, "In as much detail as possible, please describe exactly what you saw in the mock-crime video 2 weeks ago." Interviewers in turn responded to the following prompt, "Please place yourself in the shoes of a police investigator who must

\footnotetext{
${ }^{1}$ It should be noted that 3-4 of the details that were classified as 'incorrect' in the reports were actually somewhat similar in the videos (e.g., perpetrator height: $5^{\prime} 7$ vs. $5^{\prime} 8$ ) and could have arguably been scored as 'correct' too - depending on the degree of leniency allowed in a specific scoring system. In the present study however, for the purpose of establishing the ground truth of the reports (independent of witness memory), even minor differences were considered to be incorrect details.
} 
write an official report about what the witness said in his/her statement. Based on the interview you conducted 1 week ago, please write the most accurate and detailed report possible."

Time 3 Interviewer Recall for the Pre-Interview Information. All interviewers who read a pre-interview summary were also asked to complete an additional free recall questionnaire targeting their memories for the pre-interview information. The informed interviewers were asked to write down as many details from the police report as they could remember.

Time 3 Cued Recall Questionnaire. Following the free recall questionnaire, witnesses' memory for the original event and interviewers' memories for the witness interview were then tested via a cued-recall questionnaire. The questionnaires consisted of 34 fill-in-the-blank prompts regarding specific details about the perpetrator's appearance (e.g., ethnicity, hair color, clothing etc.), as well as the victim's appearance, bystander's appearance, setting characteristics (e.g., room type, room number, items in room etc.), and the sequence of events (e.g., order of entering/leaving room, victim actions, bystander actions etc.). For each category, participants could also provide additional details via an "other" prompt. See Appendix D for a copy of the cued recall questionnaire.

Time 3 Source Memory Questionnaire. To assess witness and interviewer source memory, all participant witnesses and all pre-informed participant-interviewers filled out 1 of 4 versions of a multiple choice, source memory questionnaire. The four versions differed in the order in which items were presented to control for order effects. Each source memory questionnaire presented participants with 36 details from either (a) 
video 1 only (or pre-interview report 1 only), (b) video 2 only (or pre-interview report 2 only), (c) both videos (overlapping details), or (d) neither (i.e., new details not contained in either video or report). Witnesses were asked to determine from which of the following sources (if any) they remember this information: (a) the video only, (b) the interviewer only, (c) both the video and the interviewer, (d) neither the video nor the interviewer, or (e) I don't know. Similarly, pre-informed interviewers who had read either a correct or incorrect crime summary before interviewing the witness responded to the same 36 details and were asked to determine from which of the following sources (if any) they remember the information from: (a) the report only, (b) the witness only, (c) both the report and the witness, (d) neither the report nor the witness, or (e) I don't know. Participant responses were compared to a transcript of the witness interview and an answer key for either the appropriate video or pre-interview report. Responses were classified as either correct, incorrect, or don't know decisions. Incorrect decisions were further classified as either pure source confusions (e.g., attributing the detail to the interviewer when it was actually learned only from the video), omitted source errors (e.g., attributing to only 1 source when it should have been both sources), or added source errors (e.g., attributing to both sources when it should have been only 1 source). See Appendix E for a copy of the witness source memory questionnaire.

Witness Post-experiment Questionnaire. The witness post-experiment questionnaire consisted of Likert scale questions assessing the witness' perceptions of the interviewer. Witnesses rated how effective the interviewer was, how good of a listener the interviewer was, how comfortable the interviewer made them feel, and how much pressure they felt to provide details they didn't know on a scale of 1 to $10(1=$ not at all 
to 10 extremely or completely). Witnesses also indicated whether or not they believed that the interviewer had prior information about the incident (Yes or No) and rated the extent to which they thought this prior knowledge was accurate on a scale of 1 to $10(1=$ not at all accurate to $10=$ completely accurate). See Appendix F for a copy of the witness post-experiment questionnaire.

Interviewer Post-experiment Questionnaire. The interviewer post-experiment questionnaire consisted of Likert scale questions assessing the interviewer's perceptions of the witness and if applicable, the interviewer's perceptions of the pre-interview information. Specifically, interviewers rated how accurate and how credible they believed the witness to be. Interviewers also indicated whether or not they believed they had introduced information into the interview on a scale of 1 to $10(1=$ not at all to $10=$ extremely or completely). Finally, interviewers responded to 2 manipulation check questions in which they were asked to indicate which of the following instructions they had received prior to interviewing the witness: (a) gather as much information as possible, (b) avoid leading or suggestive questions, (c) both a and b or (d), none of the above. Responses were classified as correct if participant-interviewers in the no additional instruction condition selected option 'a' (gather as much information as possible) and participant-interviewers in the additional instruction condition selected option 'c' (gather as much information as possible and avoid suggestive or leading questions). Finally, interviewers were asked to identify an example of a suggestive question from a list of alternatives to assess their comprehension of the instruction manipulation. See Appendix G for a copy of the interviewer post-experiment questionnaire. 
Debriefing Questionnaire. Finally, all participants completed a debriefing questionnaire in which they were asked a Likert scale question about how seriously they took their role in the experiment $(1=$ not at all seriously to $10=$ extremely seriously). All participants were also asked to indicate whether they had spoken to the other participant in between appointments and if so, what specifically they discussed. Additionally, a series of Likert scale questions assessed interviewers' motivation in the interview task on a scale of 1 to $10(1=$ not at all to $10=$ extremely $)$. Specifically, interviewers were asked how much effort they put into conducting their interviews, how motivated they were to conduct the best interview possible, and how concerned they were with gathering accurate and plentiful information. See Appendix $\mathrm{H}$ for a copy of the debriefing questionnaire.

\section{Design and Procedure}

Time 1: Encoding Task. The study employed a 3 (pre-interview information type: none vs. correct vs. incorrect) by 2 (interviewing instruction: yes or no) between participants design. Two participants signed up independently for the study and entered the lab at Time 1, during which time they were assigned randomly either to the role of interviewer or witness. Interviewers read brief instructions indicating that their role in the study would be to return in 1 week to interview a witness to a crime. Interviewers were dismissed and told not to discuss the study with anyone, including the other participant with whom they were paired. After the interviewer left, participant witnesses were then told that they would watch a series of videos of social interactions and be asked questions about the interactions. Witnesses first watched the distractor video and answered 3 questions posed by the researcher regarding the interactions. After the researcher 
recorded the witness' responses on a questionnaire, witnesses were instructed to watch another video. They were then presented with one of two versions of the videotaped staged crime. At the conclusion of the stimulus video, the true purpose of the experiment was revealed and witnesses were told that for the remainder of the experiment, they should place themselves in the shoes of an outside witness (separate from the actors in the video) who was present at the time of the event. Witnesses were told that when they returned in 1 week, they would be interviewed about the crime event that they just witnessed and that they should not discuss the study or the events with anyone, including the participant with whom they were paired.

Time 2: Interview Task. At Time 2, one week later, both interviewers and interviewees arrived at the lab at the same time but were separated to receive individual instructions. All witnesses were again told to place themselves in the shoes of a witness who viewed the crime in the video, is shocked, and is about to be interviewed by police. Witnesses were told to answer only the questions they were asked and to answer all questions to the best of their ability.

All interviewers were told that they were about to interview a witness to crime and that their task was to gather as much information as possible - that every detail counted. Specifically, they were told to find out what type of crime took place and the details of the crime, when and where exactly the crime took place, the sequence of events, who exactly was involved, a detailed description of all people involved, and any other details they deem important to successfully solve the crime.

Half of the interviewers were assigned randomly to receive additional instructions to avoid suggestive questions. Specifically, they were told that in addition to gathering as 
much information as possible, their second goal was to avoid suggestive questions. Interviewers were further informed that a suggestive question was defined as one which either suggests the answer to a question (e.g., You drove to school today, didn't you?) or introduces information not yet mentioned by the witness (e.g., What color is your car? when the witness has not mentioned he/she has a car). All interviewers were instructed to take as much time as they needed to gather the most detailed and informative statement possible. Additionally, all interviewers were given an incentive to conduct a good interview and a consequence for conducting a poor interview. Interviewers were told that at the conclusion of the study, their interview would be evaluated and they could earn an additional extra credit point for themselves and the witnesses if the research team concluded that they had gathered sufficient information to successfully solve the crime. However, if the research team concluded that they did not gather sufficient information, they would not receive the extra credit point, would have to explain to the study supervisor why they failed, and would be asked to write a 200 -word essay outlining this explanation. See Appendix I for the two versions of interviewer instructions.

The above instructions were first read out loud to the participant interviewers and then given to them to read quietly to themselves. After reading the instructions again, interviewers completed an instruction comprehension quiz in which they were asked to provide short answer responses regarding (a) their goals as an interviewer, (b) how much time they have to conduct the interview, (c) if applicable, the definition of a suggestive question, (d) the categories of information they should obtain from the witness, (e) the consequences for performing a good versus poor interview. The researcher then went through each individual response and corrected the participant response when necessary, 
reiterating the instructions one last time. See Appendix J for a copy of the instruction comprehension quiz.

The participant-interviewers were further randomly assigned to one of three preinterview preparation conditions: review of correct case summary (matched the crime video viewed by the witness), review of incorrect case summary (matched the alternate version) or no pre-interview information (blind). In the pre-informed conditions, interviewers were handed the respective written report, which was said to "contain information gathered about the crime" and were asked to read it quietly before interviewing the witness. To test the pure effect of pre-interview knowledge as opposed to biases associated with the trustworthiness of the source of pre-interview information, participant-interviewers received no specific instructions regarding the source or veracity of the case information. Finally, the researcher left the room while the participants conducted the interview, which was audio and video-recorded.

Time 3: Delayed Recall Task. All participant witnesses and interviewers returned 1 week later at Time 3 ( 2 weeks from initial encoding of the video and 1 week after the interview) and were asked to fill out questionnaires regarding their recollections of either the crime video (for the witness) or the witness' version of events during the interview (for the interviewer). Memory was assessed via written recall rather than an interview format, to more feasibly code the data at the conclusion of the 3-week experiment. Participants were given the Time 3 measures one at a time, completing the free recall questionnaire first, followed by the cued questionnaire, the source memory questionnaire, the post-experiment questionnaire, and lastly, the debriefing questionnaire. See Figure 1 for a flow chart of the procedure and dependent measures administered. 


\section{Scoring System}

All witness interviews were videotaped and transcribed. The interviewee and interviewer portion of each transcript were then divided into units, defined as the smallest piece of information that could stand alone as a verifiable detail, e.g., he was wearing a black shirt. Similarly, the delayed written recall measures (witness free and cued recall, interviewer free and cued recall, and interviewer free recall of the pre-interview information) were broken into units of information for scoring purposes. Each unit was scored according to a detailed set of scoring rules by a carefully trained coder who was blind to experimental condition. Given the extensive amount of coding necessary to test the primary hypotheses, 3 teams consisting of 2 to 4 coders were assigned to score each of the primary outcome measures: (1) Interview behavior at Time 2 (interviewer behavior and witness memory), (2) Witness memory at Time 3, (3) Interviewer memory at Time 3, and (4) Witness and interviewer source memory at Time 3. Across the first 3 teams (witness and interviewer memory and behavior at Times $2 \& 3$ ), coding was equally split and coders overlapped on approximately $15 \%$ of all data, which was used to calculate inter-rater agreement. For the final team (source monitoring), coding was completed by 1 primary coder and $15 \%$ of the data was co-scored by a second coder. See Table 1 for a detailed break-down of the inter-rater agreement calculations for each dependent measure. Average inter-rater agreement on all dependent measures was an intraclass correlation (ICC) of 0.858 (ranging from .525-.999). 
Table 1.

Average inter-rater agreement (ICC) for each scored dependent variable.

\begin{tabular}{|c|c|c|}
\hline Variable Type & Variable Name & $\begin{array}{l}\text { Avg } \\
\text { ICC }\end{array}$ \\
\hline \multirow[t]{2}{*}{ Witness Time 2 Primary } & Number of total details & .899 \\
\hline & Accuracy rate & .766 \\
\hline \multirow{10}{*}{ Witness Time 2 Secondary } & Correct details & .875 \\
\hline & Incorrect details & .728 \\
\hline & Don't know responses & .874 \\
\hline & False acquiesces & .541 \\
\hline & Other errors & .778 \\
\hline & Perpetrator details & .890 \\
\hline & Victim details & .958 \\
\hline & Bystander details & .951 \\
\hline & Setting details & .788 \\
\hline & Crime action details & .673 \\
\hline \multirow{7}{*}{ Interviewer Time 2 Primary } & Total questions & .992 \\
\hline & Open ended questions & .728 \\
\hline & Cued questions & .864 \\
\hline & Yes/No questions & .976 \\
\hline & Multiple-choice questions & .900 \\
\hline & Suggestive Questions & .788 \\
\hline & Facilitators & .890 \\
\hline \multirow[t]{2}{*}{ Witness Time 3 Primary } & Total Details & .616 \\
\hline & Accuracy rate & .867 \\
\hline \multirow{6}{*}{ Witness Time 3 Secondary } & Correct details & .654 \\
\hline & Incorrect details & .838 \\
\hline & Don't know responses & .985 \\
\hline & Additions & .881 \\
\hline & Modifications & .852 \\
\hline & False incorporations & .525 \\
\hline \multirow[b]{2}{*}{ Interviewer Time 3 Primary } & Total details & .894 \\
\hline & Accuracy rate & .923 \\
\hline \multirow{6}{*}{ Interviewer Time 3 Secondary } & Correct details & .921 \\
\hline & Incorrect details & .889 \\
\hline & Don't know responses & .940 \\
\hline & Report related errors & .745 \\
\hline & Other errors & .878 \\
\hline & Omissions & .893 \\
\hline \multirow[t]{3}{*}{ Witness Source Memory } & Correct decisions & .960 \\
\hline & Incorrect decisions & .918 \\
\hline & Don't know decisions & .976 \\
\hline
\end{tabular}




\begin{tabular}{|l|l|l|}
\hline \multirow{4}{*}{ Interviewer Source Memory } & Pure source confusions & .884 \\
\cline { 2 - 3 } & Misattribute to both sources & .830 \\
\cline { 2 - 3 } & Misattribute to only 1 source & .862 \\
\hline & Correct decisions & .990 \\
\cline { 2 - 3 } & Incorrect decisions & .972 \\
\cline { 2 - 3 } & Don't know decisions & .999 \\
\cline { 2 - 3 } & Pure source confusions & .937 \\
\cline { 2 - 3 } & Misattribute to both sources & .926 \\
\cline { 2 - 3 } & Misattribute to only 1 source & .910 \\
\hline
\end{tabular}

\section{Dependent Measures: Time 2 Interview}

Witness Variables: Time 2 Interview. Primary witness outcome variables for the Time 2 interview included the quantity of information reported (i.e., the number of details recalled), the quality of witness information reported (the number of correct, incorrect, and don't know responses), and the accuracy rate (the proportion of all scorable responses that are correct).

Incorrect Witness Details. Incorrect witness details were further classified into one of two broad error types: (1) interviewer generated (a false acquiescence to an interviewer suggestive utterance) or (2) witness generated or "other false" error. A false acquiescence was defined as an instance in which the witness incorrectly agreed with the interviewer or provided an incorrect answer in response to a suggestive question. Another false error was defined as an error not elicited through interviewer influence. See Figure 2 below for a flow chart of incorrect witness unit classifications. 
Figure 2. Classification of Incorrect Witness Units: Time 2 Interview

Witness Unit Classifications

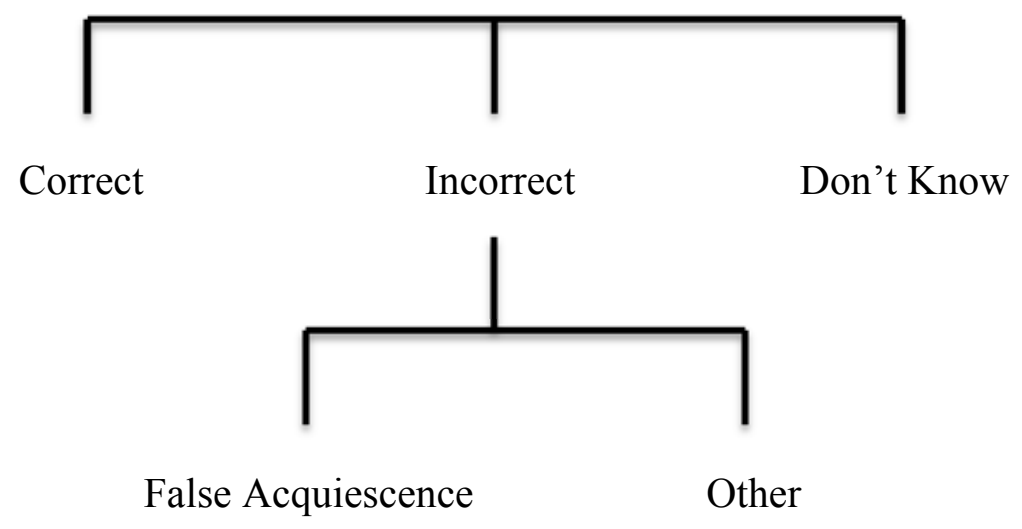

Relevant Witness Details. To approximate a quality measure of the witnesses' statements, an exhaustive list of 74 possible "relevant" video-based details (e.g., details that could be recalled and are important to solving the crime) was generated and at each time point, coders checked for the presence of these details in each witness statement. These relevant details were broadly classified into the following descriptive categories: (a) perpetrator (e.g., physical description), (b) victim (physical description), (c) bystander (physical description and actions), (d) setting (e.g., time of day, items in the room etc.), and (e) crime action details (e.g., what was stolen, how stolen, where were stolen items placed etc.). The purpose of the relevant detail list was to simplify an exhaustive and detailed comparison of witness memory across time while capturing the content of details recalled, without individually classifying each witness unit. See Appendix K for a list of the relevant details. 
Interviewer Variables: Time 2 Interview. Primary outcome variables for interviewers during the Time 2 witness interview included the number of questions asked, types of questions asked, and the number of suggestive questions asked.

Question Types. Interviewer question types were classified as (1) an open-ended narrative question, which requests a narrative answer (e.g., What happened?), (2) an open ended cued question that requests a short, (typically 1-2-word answer) answer (e.g., How did he steal it?), (3) a multiple-choice question that gives the witness several options to choose from (e.g., Was it in the morning, afternoon or night?), (4) a Yes/No question that can only be answered "yes" or "no" (e.g., Were the lights on?), or (5) or a facilitator defined as a restatement of a previous witness utterance or general, non-suggestive word of encouragement (e.g., "Ok”, “Mhmm”).

Suggestive Questions. Suggestive questions were defined as those that either introduced information not yet mentioned by the witness or suggested the answer to the question. For example, if the interviewer asked, "Did you see him take the laptop?" and the witness hadn't yet mentioned the perpetrator's gender or what was stolen, this was classified as a suggestive question.

\section{Dependent Measures: Time 3 Written Recall}

Witness Variables: Time 3 Recall. Primary witness outcome variables for the Time 3 written recall measures included the quantity of information reported (i.e., the number of details recalled) and the quality of witness information reported (the number of correct, incorrect, and don't know responses), and the accuracy rate (the proportion of all scorable responses that are correct). Incorrect witness details were further classified as additions, modifications, or false incorporations of interviewer suggestive questions. 
False incorporations were instances in which witnesses recalled a detail incorrectly and the interviewer had introduced that incorrect detail during the Time 2 interview.

Interviewer Variables: Time 3 Recall. Primary interviewer outcome variables for the Time 3 written recall measures (for the witness' version of events during the interview and when applicable, the pre-interview information) included the quantity of information reported (i.e., the number of details recalled), the quality of information reported (the number of correct, incorrect, and don't know responses), and the accuracy rate (the proportion of all scorable responses that are correct). Responses were classified as correct if the witness stated them during the Time 2 interview. Responses were classified as incorrect if they did not originate from the witness during the interview. Incorrect interviewer details were further classified into the following error types: reportrelated errors, other errors and omissions. Report-related errors included both additions and modifications and were defined as the interviewer committing an error by changing or adding a detail that originated from the report. Other errors included additions and modifications not related to the report. Omissions were calculated only for the relevant detail list. That is, each relevant detail reported by the witnesses at Time 2 was compared to the relevant details recalled by interviewers at Time 3 . If the interviewer forgot to mention at Time 3 a relevant detail recalled by the witness at Time 2, this was classified as an omission.

\section{Dependent Measures: Source Memory Questionnaires}

Primary outcome measures for interviewer and witness source memory included the number of correct, incorrect, and don't know decisions. Decisions were classified by comparing the participants' questionnaire response to the transcript of the witness 
interview and an answer key listing the details contained either in the pre-interview report (for the interviewers) or in the mock crime video (for the witnesses). Incorrect source decisions were further classified into 3 different types: (a) pure source confusions (e.g., reporting a detail was contained in the video when it was introduced only by the interviewer), (b) misattributing to only 1 source when it was presented by both sources (e.g., reporting it was mentioned only by the witness when it was both mentioned by the witness and written in the pre-interview report), and (c) misattributing to both sources when it was presented by only one source (e.g., reporting it was mentioned by the interviewer and seen in the video but it was only mentioned by the interviewer).

\section{Dependent Measures: Across Time}

Primary outcome measures for witness memory over time were (1) the change in quantity of details recalled across time (e.g., Time 2 interview vs. Time 3 free and cued recall), (2) the change in accuracy of witness information recalled across time (e.g., Time 2 interview vs. Time 3 free and cued recall), and (3) the consistency of information recalled across time for the "relevant" detail list described above. Specifically, for all relevant details, the number of omissions, contradictions and consistent statements from the Time 2 interview to the Time 3 were compared and scored. A detail was classified as consistent (either correctly consistent or incorrectly consistent) if the same relevant detail was recalled at both Time 2 and Time 3 (e.g., the perpetrator was wearing a black shirt). A detail was classified as a contradiction if the detail changed over time (e.g., the perpetrator was wearing a white shirt at Time 2 and a black shirt at Time 3). A detail was classified as an omission if it was recalled at Time 2 but not Time 3. Reminiscences were not captured for the purpose of this experiment. 


\section{RESULTS}

\section{Preliminary Analyses}

Removal of Outliers. Preliminary analyses revealed one extreme outlier more

than 3 standard deviations above the mean for a primary dependent measure (total witness details recalled during the Time 2 interview). This participant pair was excluded from all further analyses.

Pre-existing relationship. Forty-one pairs of participants knew each other prior to participating in the experiment (25 pairs of classmates, 2 pairs of acquaintances, 12 pairs of friends, and 1 romantic partnership). When the variable of pre-existing relationship was added as a covariate in the primary Time 2 analyses, there was no effect of pre-existing relationship on witness quantity, $F(1,240)=.044, p=.834, \eta_{\mathrm{p}}{ }^{2}=.013$ or witness accuracy rate, $F(1,240)=.083, p=.774, \eta_{\mathrm{p}}{ }^{2}=.000$ and the main pattern of results did not differ. Thus, all subsequent analyses include participant pairs with preexisting relationships.

\section{Manipulation checks}

Interviewer Instructions. To evaluate whether interviewers' remember their instructions and the primary goals of the Time 2 interview task, all participant interviewers were asked at Time 3 to indicate which of the following instructions they had received prior to interviewing the witness: (a) gather as much information as possible, (b) avoid leading or suggestive questions, (c) both a and b or (d), none of the above. Due to attrition and missing data, participant responses to this question were calculated for 228 of the interviewers. Overall, $86 \%$ correctly identified their instructions. (e.g., those instructed to avoid suggestive questions selected choice c and those who were 
not instructed selected choice a). A Chi-square test for independence indicated a significant difference between the two instruction types in participants' ability to correctly identify their instructions, $\chi^{2}(1, n=228)=10.45, p=.001$, phi $=.21$. Interviewers who had received the instructions to avoid suggestive questions correctly identified their instructions more often $(93.8 \%)$ than those who did not receive the instructions $(79.1 \%)$. This may be because many participants $(18 \%)$ in the "no instruction" condition mistakenly assumed they were also supposed to avoid suggestive questions when presented with that option choice at Time 3.

Instructions to Avoid Suggestive Questions. To examine the effectiveness of the instructions to avoid suggestive questions manipulation, all participant interviewers also responded to a multiple choice question about a suggestive question as part of the Time 3 post-interview questionnaire. Specifically, interviewers were asked the following question: Assume you know nothing about a crime other than one occurred. Which of the following is an example of a suggestive question given that you have no information? (a) When did this occur?, (b) Who was there?, (c) How did he steal the laptop?, or (d) What was the suspect wearing? Due to attrition and missing data, participant responses to this question were calculated for 231 of the interviewers. Seventy-seven percent of the participant interviewers correctly identified the suggestive question as answer choice c. A Chi-square test for independence indicated a significant difference between the two instruction types in participants' ability to correctly identify the suggestive question, $\chi^{2}$ $(1, n=231)=25.57, p<.001, \mathrm{phi}=.33$. Interviewers who had received the instructions to avoid suggestive questions at Time 2 correctly identified the suggestive question at Time 3 more often $(91.2 \%)$ than those who did not receive the instructions $(63.2 \%)$. In 
addition, primary analyses (see below) revealed that interviewers who were instructed to avoid suggestive questions tended to asked fewer suggestive questions overall $(M=2.11$, $S D=2.98)$ than those who did not receive the instructions $(M=2.91, S D=4.10), F(1$, 244) $=3.15, p=.077, \eta_{\mathrm{p}}{ }^{2}=.013$; see results section for all Time 2 interviewer variables). Participants' responses to both instruction manipulation check questions suggest that the large majority of participants (a) remember the goal of the interview task and (b) read and understood the instructions to avoid suggestive/leading questions, including identifying what constitutes a suggestive question.

Participant Motivation. To ensure that participants were taking the experimental tasks seriously, all participants were asked how seriously they took their role as witness or interviewer on a scale of 1 to $10(1=$ not at all seriously to $10=$ extremely seriously $)$. Overall, participants indicated that they took the task very seriously (interviewers: $M=$ $8.64, S D=1.40$; witnesses: $M=8.66, S D=1.38$ ). A 3 (interviewer type: correctly informed vs. incorrectly informed vs. blind) X 2 (instructions to avoid suggestive questions: yes vs. no) Multivariate Analysis of Variance (MANOVA) examined whether there were any differences in participant motivation (interviewer and witness) as a function of interviewer type or suggestibility instruction type. Analyses revealed no significant differences in how seriously participants' took their role in the study as a function of experimental group. See Table 2 for means and standard deviations and Table 3 for inferential statistics.

All participant-interviewers were additionally asked about their motivation to conduct a good interview (e.g., How much effort did you put into conducting the interview?; How motivated were you to conduct the best interview possible?; How 
concerned were you with gathering accurate information?; How concerned were you with gathering a lot of information?) on a scale of 1 to $10(1=$ not at all; $10=$ extremely $)$.

Overall, interviewers indicated high motivation in the experimental tasks (all $M$ 's $>8$; see Table 2 for means and standard deviations).

To assess whether there were any differences in perceptions of the incentives across experimental groups, a 3 (interviewer type: correctly informed vs. incorrectly informed vs. blind) X 2 (instruction to avoid suggestive questions: yes vs. no) MANOVA was conducted on participants' responses to 4 above-mentioned, Likert scale questions regarding interviewer motivation. Analyses revealed no differences in self-reported motivation as a function of experimental group. See Table 2 for means and standard deviations and Table 3 for inferential statistics.

Perceptions of Incentives. Because one of the aims of the present study was to improve on the ecological validity of Rivard et al.'s original design, incentives were given to participant interviewers in the form of (1) an extra credit point for conducting a sufficient interview and (2) a consequence (e.g., writing a 200-word essay and providing an oral explanation to the study supervisor). To assess the effectiveness of these incentives, at the conclusion of the study, interviewers were asked (a) whether they believed they would have to write the 200 word essay (Yes or No), and on a scale of 1 to $10(1=$ not at all to $10=$ extremely $)$, how concerned they were about (b) having their interview evaluated, (c) having to write the essay, and (d) earning the extra credit point. Overall, $70 \%$ of interviewers believed they would have to write the 200 -word essay. In addition, interviewers were highly concerned about earning the extra credit point $(M=$ 
$8.82, S D=2.01)$ and about having their interview evaluated $(M=7.90, S D=2.90)$, but less concerned about having to write the essay $(M=6.37, S D=3.32)$.

To assess whether there were any differences in perceptions of the incentives across experimental groups, a 3 (interviewer type: correctly informed vs. incorrectly informed vs. blind) X 2 (instructions to avoid suggestive questions: yes vs. no) MANOVA was conducted on participants' concerns regarding the extra credit, essay and interview evaluation. Analyses revealed no differences in self-reported motivation as a function of experimental group. With respect to all manipulation check questions, participants seemed highly motivated and interviewers indicted they were appropriately concerned about the incentives. See Table 2 for means and standard deviations and Table 3 for inferential statistics.

Table 2.

Means and standard deviations for participant motivation and perceptions of incentives.

\begin{tabular}{|c|c|c|c|c|}
\hline Manipulation Check Variable & $\begin{array}{l}\text { Suggestibility } \\
\text { Instruction }\end{array}$ & Interviewer Type & Mean & $\mathrm{SD}$ \\
\hline \multirow{6}{*}{ Witness task seriousness } & \multirow{3}{*}{ Yes } & Blind & 8.67 & 1.21 \\
\hline & & Correct-Informed & 8.70 & 1.32 \\
\hline & & Incorrect-Informed & 8.82 & 1.82 \\
\hline & \multirow{3}{*}{ No } & Blind & 8.61 & 1.35 \\
\hline & & Correct-Informed & 8.55 & 1.27 \\
\hline & & Incorrect-Informed & 8.64 & 1.42 \\
\hline \multirow{6}{*}{ Interviewer task seriousness } & \multirow{3}{*}{ Yes } & Blind & 8.68 & 1.47 \\
\hline & & Correct-Informed & 8.57 & 1.41 \\
\hline & & Incorrect-Informed & 8.93 & 1.30 \\
\hline & \multirow{3}{*}{ No } & Blind & 8.44 & 1.48 \\
\hline & & Correct-Informed & 8.77 & 1.22 \\
\hline & & Incorrect-Informed & 8.74 & 1.31 \\
\hline \multirow{9}{*}{$\begin{array}{l}\text { Interviewer effort to conduct } \\
\text { good interview }\end{array}$} & \multirow{3}{*}{ Yes } & Blind & 8.55 & 1.65 \\
\hline & & Correct-Informed & 8.63 & 1.23 \\
\hline & & Incorrect-Informed & 8.91 & 1.23 \\
\hline & \multirow{3}{*}{ No } & Blind & 8.83 & 1.06 \\
\hline & & Correct-Informed & 8.61 & 1.33 \\
\hline & & Incorrect-Informed & 8.62 & 1.27 \\
\hline & \multirow{3}{*}{ Yes } & Blind & 8.68 & 1.70 \\
\hline & & Correct-Informed & 8.43 & 1.48 \\
\hline & & Incorrect-Informed & 8.85 & 1.37 \\
\hline
\end{tabular}




\begin{tabular}{|c|c|c|c|c|}
\hline \multirow{3}{*}{$\begin{array}{l}\text { Interviewer concern with } \\
\text { conducting best interview } \\
\text { possible }\end{array}$} & \multirow{3}{*}{ No } & Blind & 9.03 & 1.18 \\
\hline & & Correct-Informed & 8.66 & 1.26 \\
\hline & & Incorrect-Informed & 8.68 & 1.27 \\
\hline \multirow{6}{*}{$\begin{array}{l}\text { Interviewer concern with } \\
\text { gathering accurate } \\
\text { information }\end{array}$} & \multirow{3}{*}{ Yes } & Blind & 8.68 & 1.80 \\
\hline & & Correct-Informed & 8.98 & 1.10 \\
\hline & & Incorrect-Informed & 9.21 & 1.34 \\
\hline & \multirow{3}{*}{ No } & Blind & 8.78 & 1.77 \\
\hline & & Correct-Informed & 9.05 & 1.23 \\
\hline & & Incorrect-Informed & 9.02 & 1.15 \\
\hline \multirow{6}{*}{$\begin{array}{l}\text { Interviewer concern with } \\
\text { gathering a lot of information }\end{array}$} & \multirow{3}{*}{ Yes } & Blind & 8.74 & 1.65 \\
\hline & & Correct-Informed & 8.60 & 1.55 \\
\hline & & Incorrect-Informed & 9.0 & 1.50 \\
\hline & \multirow{3}{*}{ No } & Blind & 8.94 & 1.55 \\
\hline & & Correct-Informed & 8.92 & 1.30 \\
\hline & & Incorrect-Informed & 8.53 & 1.86 \\
\hline \multirow{6}{*}{$\begin{array}{l}\text { Interviewer concern about } \\
\text { having interview evaluated }\end{array}$} & \multirow{3}{*}{ Yes } & Blind & 7.77 & 2.80 \\
\hline & & Correct-Informed & 7.90 & 2.47 \\
\hline & & Incorrect-Informed & 8.72 & 3.70 \\
\hline & \multirow[t]{3}{*}{ No } & Blind & 7.64 & 2.84 \\
\hline & & Correct-Informed & 7.89 & 2.47 \\
\hline & & Incorrect-Informed & 7.54 & 2.80 \\
\hline \multirow{6}{*}{$\begin{array}{l}\text { Interviewer concern over } \\
\text { writing the essay }\end{array}$} & \multirow{3}{*}{ Yes } & Blind & 5.32 & 3.65 \\
\hline & & Correct-Informed & 7.08 & 3.08 \\
\hline & & Incorrect-Informed & 7.18 & 3.05 \\
\hline & \multirow{3}{*}{ No } & Blind & 5.64 & 3.17 \\
\hline & & Correct-Informed & 7.13 & 3.13 \\
\hline & & Incorrect-Informed & 5.81 & 3.47 \\
\hline \multirow{6}{*}{$\begin{array}{l}\text { Interviewer concern over } \\
\text { extra credit point }\end{array}$} & \multirow{3}{*}{ Yes } & Blind & 8.90 & 1.85 \\
\hline & & Correct-Informed & 8.52 & 2.16 \\
\hline & & Incorrect-Informed & 9.12 & 1.89 \\
\hline & \multirow{3}{*}{ No } & Blind & 8.61 & 2.49 \\
\hline & & Correct-Informed & 9.07 & 1.32 \\
\hline & & Incorrect-Informed & 8.78 & 2.16 \\
\hline
\end{tabular}

Table 3.

$F$ values, $p$ values and effect sizes for participant motivation and interviewer perceptions of incentives.

\section{Manipulation Check Variable}

Witness task seriousness

Interviewer task seriousness

Interviewer effort to conduct good interview

Interviewer concern with best interview

\begin{tabular}{|c|c|c|c|c|c|}
\hline \multicolumn{3}{|c|}{ Interview Type } & \multicolumn{3}{|c|}{ Instruction Type } \\
\hline $\mathrm{F}$ & $p$ & $\eta_{\mathrm{p}}^{2}$ & $\mathrm{~F}$ & $p$ & $\eta_{\mathrm{p}}^{2}$ \\
\hline .118 & .889 & .001 & .454 & .501 & .002 \\
\hline .693 & .502 & .007 & .127 & .712 & .001 \\
\hline .254 & .776 & .002 & .002 & .967 & .000 \\
\hline 998 & 370 & .009 & .552 & 458 & .003 \\
\hline
\end{tabular}




$\begin{array}{llllllll}\text { Interviewer concern with accuracy } & 1.43 & .241 & .013 & .000 & .986 & .000 \\ \text { Interviewer concern for quantity } & .058 & .944 & .001 & .009 & .926 & .000 \\ \begin{array}{l}\text { Interviewer concern for evaluation } \\ \text { Interviewer concern for essay }\end{array} & .376 & .687 & .004 & 1.26 & .263 & .006 \\ \text { Interviewer concern for extra credit point } & .180 & .835 & .002 & .009 & .924 & .000\end{array}$

\section{Time 2 Interview: Primary Witness Variables}

To examine whether interviewers' pre-interview knowledge of the crime and/or instructions to avoid suggestive questions had any influence on witness memory during the Time 2 interview, separate Analyses of Variance (ANOVAs) first examined whether interviewer type and instruction type influenced (1) the total number of crime-relevant details recalled during the interview (combined correct and incorrect details) and (2) the accuracy rate (the total number of correct details divided by the total number of details).

Total Details Recalled. A 3 (interviewer type: correctly informed vs. incorrectly informed vs. blind) X 2 (instructions to avoid suggestive questions: yes vs. no) ANOVA was conducted on the total number of details witnesses recalled, revealing a marginal effect of interviewer type, $F(2,244)=2.68, p=.071, \eta_{\mathrm{p}}{ }^{2}=.021$ (See Figure 4). Post hoc analyses indicated that witnesses of blind interviewers recalled significantly more details $(M=41.45, S D=22.63)$ than witnesses of incorrectly informed interviewers $(M=34.48$, $S D=16.76$ ), but not significantly more than witnesses of correctly informed interviewers $(M=36.79, S D=17.35)$. Witnesses of correctly and incorrectly informed interviewers did not differ from one another. There was no effect of instruction type and no significant interviewer type by instruction type interaction. See Table 4 for means and standard deviations for the primary dependent measures and Table 5 for inferential statistics. 


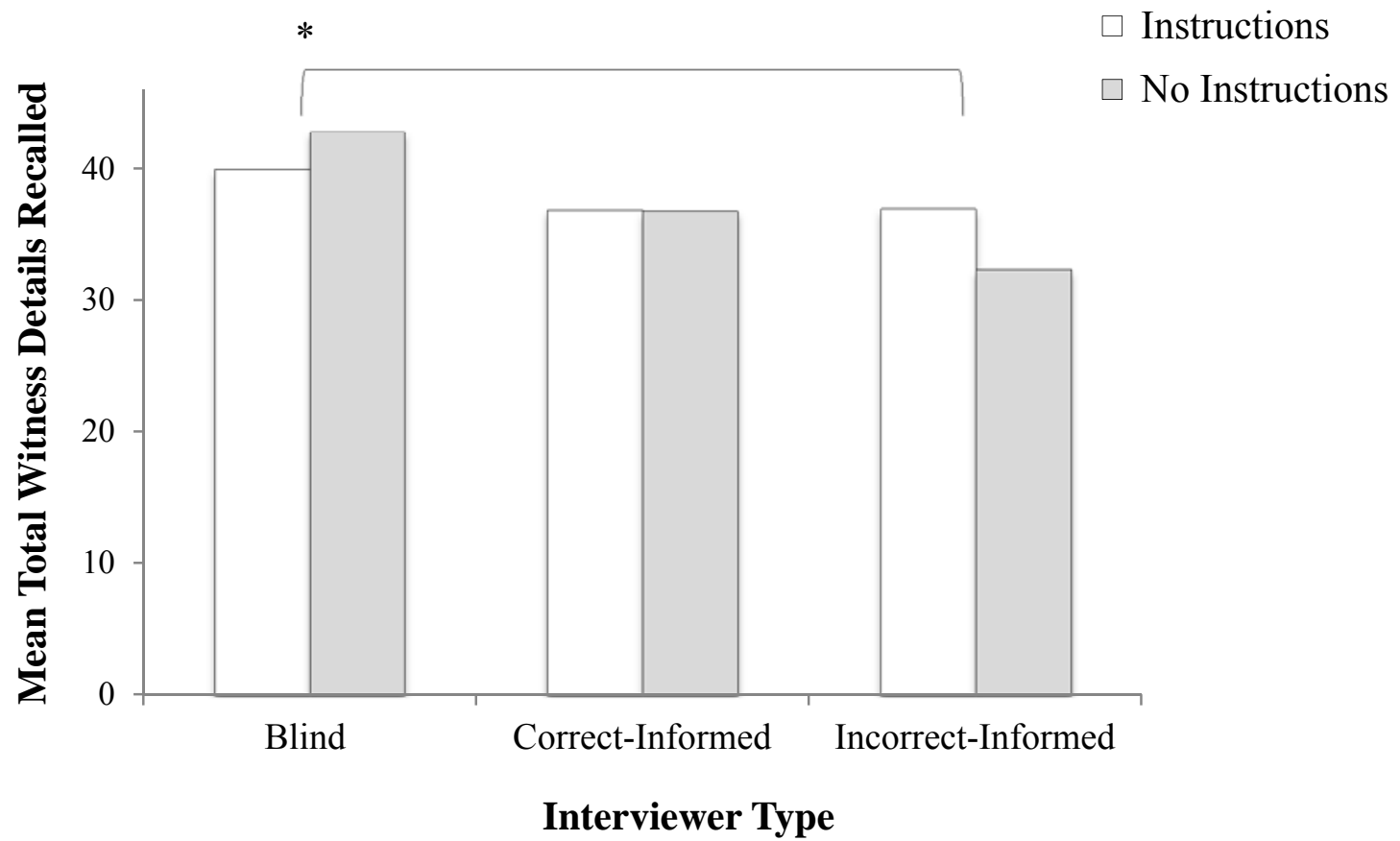

Figure 4. Mean total witness details recalled as a function of interviewer type and instruction type. Note. ${ }^{*}$ Denotes a marginal difference at $p=.07$.

Witness Accuracy. A 3 X 2 ANOVA then examined the effects of interviewer type and instruction type on witness accuracy rate (i.e. correct details recalled divided by the total details recalled) and revealed no effects of interviewer type or instruction type and no interviewer type by instruction type interaction. See Table 4 for means and standard deviations and Table 5 for inferential statistics.

Table 4.

Means and standard deviations for Time 2 primary witness variables.

\begin{tabular}{|c|c|c|c|c|}
\hline $\begin{array}{c}\text { Primary Witness Variables: } \\
\text { Time } 2\end{array}$ & $\begin{array}{l}\text { Suggestibility } \\
\text { Instruction }\end{array}$ & Interviewer Type & Mean & SD \\
\hline \multirow{6}{*}{ Total Details } & \multirow{3}{*}{ Yes } & Blind & 39.92 & 23.75 \\
\hline & & Correct-Informed & 36.84 & 17.08 \\
\hline & & Incorrect-Informed & 36.92 & 18.06 \\
\hline & \multirow{3}{*}{ No } & Blind & 42.84 & 21.76 \\
\hline & & Correct-Informed & 36.74 & 17.83 \\
\hline & & Incorrect-Informed & 37.27 & 18.86 \\
\hline \multirow[b]{3}{*}{ Accuracy rate } & \multirow{3}{*}{ Yes } & Blind & .89 & 0.07 \\
\hline & & Correct-Informed & .88 & 0.09 \\
\hline & & Incorrect-Informed & .89 & 0.08 \\
\hline
\end{tabular}




\begin{tabular}{|l|l|l|l|l|}
\hline \multirow{2}{*}{ No } & Blind & .89 & 0.07 \\
\cline { 3 - 5 } & & Correct-Informed & .88 & 0.07 \\
\cline { 3 - 5 } & & Incorrect-Informed & .85 & 0.10 \\
\hline
\end{tabular}

\section{Time 2 Interview: Secondary Witness Variables}

To examine further the effect of pre-interview knowledge and instructions to avoid suggestive questions on witness memory during the Time 2 interview, several Multivariate Analyses of Variance (MANOVAs) investigated the effect of interviewer type and instruction type on witness memory with respect to a number of secondary outcomes of interest: (1) the quality of witness statements (the number of correct details, incorrect details, and don't know responses), (2) the types of errors witnesses made when recalling details (falsely acquiescing to an interviewer suggestive utterance or 'other' witness error), (3) the content of witness statements as they related to the pre-interview summaries (report-related details or 'other' details), and (4) the types of details witnesses recalled (e.g., perpetrator, victim, bystander, setting, or crime action).

Correct, Incorrect, and Don't Know Responses. A 3 (interviewer type: correctly informed vs. incorrectly informed vs. blind) X 2 (instructions to avoid suggestive questions: yes vs. no) MANOVA was conducted on (1) the number of correct details recalled, (2) the number of incorrect details recalled, and (3) the number of don't know responses recalled. The MANOVA indicated no effects of interviewer or instruction type and no interviewer by instruction type interaction on any of the variables. See Table 4a for means and standard deviations and Table 5 for inferential statistics.

Witness Error Types. To examine whether interviewer type or instruction type had any effect on the types of errors witnesses made (interviewer-generated vs. witnessgenerated errors), a second 3 X 2 MANOVA was conducted on: (1) the number of false 
acquiesces to an interviewer suggestive utterance (interviewer-generated errors) and (2) 'other' witness errors (witness-generated errors). Analyses revealed a significant effect of instruction type on the number of interviewer-generated errors, $F(1,243)=6.12, p=$ $.014, \eta_{\mathrm{p}}^{2}=.024$. When interviewers were instructed to avoid suggestive questions, witnesses were significantly less likely to falsely acquiesce to an interviewer's suggestive question $(M=0.23, S D=0.64)$ compared to when no such instructions were given $(M=$ $0.48, S D=0.90)$. There were no other main effects or interactions. See Table 4a for means and standard deviations and Table 5 for inferential statistics.

Detail Types. To assess further the quality of witnesses' statements, another $3 \mathrm{X}$ 2 MANOVA was conducted on the 5 categories of relevant details recalled (e.g., perpetrator, victim, bystander, setting, and crime action details). Analyses revealed no significant main effects or interactions, all $p s>.05$. See Table 4a for means and standard deviations and Table 5 for inferential statistics.

Table 4a.

Means and standard deviations for secondary witness variables at Time 2.

\begin{tabular}{|c|c|c|c|c|}
\hline Secondary Witness Variables: Time 2 & Suggestibility Instruction & Interviewer Type & Mean & SD \\
\hline \multirow{6}{*}{ Number of correct details } & \multirow{3}{*}{ Yes } & Blind & 35.31 & 21.45 \\
\hline & & Correct-Informed & 32.63 & 15.88 \\
\hline & & Incorrect-Informed & 33.08 & 16.62 \\
\hline & \multirow{3}{*}{ No } & Blind & 37.93 & 18.46 \\
\hline & & Correct-Informed & 32.14 & 15.75 \\
\hline & & Incorrect-Informed & 27.80 & 13.82 \\
\hline \multirow{6}{*}{ Number of incorrect details } & \multirow{3}{*}{ Yes } & Blind & 4.62 & 3.62 \\
\hline & & Correct-Informed & 4.21 & 3.01 \\
\hline & & Incorrect-Informed & 3.85 & 3.32 \\
\hline & \multirow{3}{*}{ No } & Blind & 4.91 & 4.50 \\
\hline & & Correct-Informed & 4.60 & 3.37 \\
\hline & & Incorrect-Informed & 4.52 & 3.19 \\
\hline \multirow{5}{*}{ Number of don't know responses } & \multirow{3}{*}{ Yes } & Blind & 4.64 & 5.71 \\
\hline & & Correct-Informed & 4.86 & 4.31 \\
\hline & & Incorrect-Informed & 6.41 & 7.95 \\
\hline & \multirow[b]{2}{*}{ No } & Blind & 5.86 & 5.48 \\
\hline & & Correct-Informed & 5.54 & 6.53 \\
\hline
\end{tabular}




\begin{tabular}{|c|c|c|c|c|}
\hline & & Incorrect-Informed & 3.31 & 5.40 \\
\hline \multirow{6}{*}{ Number of false acquiesce errors } & \multirow{3}{*}{ Yes } & Blind & 0.13 & 0.34 \\
\hline & & Correct-Informed & 0.35 & 0.92 \\
\hline & & Incorrect-Informed & 0.21 & 0.47 \\
\hline & \multirow{3}{*}{ No } & Blind & 0.56 & 0.98 \\
\hline & & Correct-Informed & 0.45 & 1.04 \\
\hline & & Incorrect-Informed & 0.41 & 0.62 \\
\hline \multirow{6}{*}{ Number of other errors } & \multirow{3}{*}{ Yes } & Blind & 4.18 & 3.49 \\
\hline & & Correct-Informed & 3.84 & 2.74 \\
\hline & & Incorrect-Informed & 3.54 & 3.19 \\
\hline & \multirow{3}{*}{ No } & Blind & 4.33 & 4.24 \\
\hline & & Correct-Informed & 3.95 & 3.32 \\
\hline & & Incorrect-Informed & 4.11 & 3.13 \\
\hline \multirow{6}{*}{$\begin{array}{l}\text { Number of perpetrator } \\
\text { details }\end{array}$} & \multirow{3}{*}{ Yes } & Blind & 4.63 & 2.98 \\
\hline & & Correct-Informed & 5.12 & 2.70 \\
\hline & & Incorrect-Informed & 5.05 & 2.99 \\
\hline & \multirow{3}{*}{ No } & Blind & 5.12 & 3.35 \\
\hline & & Correct-Informed & 5.81 & 2.84 \\
\hline & & Incorrect-Informed & 4.95 & 3.15 \\
\hline \multirow{6}{*}{ Number of victim details } & \multirow{3}{*}{ Yes } & Blind & 1.92 & 1.53 \\
\hline & & Correct-Informed & 1.86 & 1.56 \\
\hline & & Incorrect-Informed & 2.13 & 1.70 \\
\hline & \multirow{3}{*}{ No } & Blind & 2.84 & 1.59 \\
\hline & & Correct-Informed & 1.93 & 1.74 \\
\hline & & Incorrect-Informed & 1.77 & 1.43 \\
\hline \multirow{6}{*}{ Number of bystander details } & \multirow{3}{*}{ Yes } & Blind & 4.42 & 3.20 \\
\hline & & Correct-Informed & 4.38 & 2.29 \\
\hline & & Incorrect-Informed & 4.54 & 2.56 \\
\hline & \multirow{3}{*}{ No } & Blind & 5.46 & 3.20 \\
\hline & & Correct-Informed & 4.12 & 2.29 \\
\hline & & Incorrect-Informed & 4.28 & 2.56 \\
\hline \multirow{6}{*}{ Number of setting details } & \multirow{3}{*}{ Yes } & Blind & 1.45 & 1.03 \\
\hline & & Correct-Informed & 1.62 & 1.27 \\
\hline & & Incorrect-Informed & 1.59 & 1.15 \\
\hline & \multirow{3}{*}{ No } & Blind & 1.79 & 1.10 \\
\hline & & Correct-Informed & 1.52 & 1.25 \\
\hline & & Incorrect-Informed & 1.81 & 1.23 \\
\hline \multirow{6}{*}{ Number of crime action details } & \multirow{3}{*}{ Yes } & Blind & 2.37 & 1.46 \\
\hline & & Correct-Informed & 2.88 & 1.86 \\
\hline & & Incorrect-Informed & 2.26 & 1.23 \\
\hline & \multirow{3}{*}{ No } & Blind & 2.84 & 1.54 \\
\hline & & Correct-Informed & 2.81 & 1.40 \\
\hline & & Incorrect-Informed & 2.53 & 1.35 \\
\hline
\end{tabular}

Table 5.

$F$ values, $p$ values and effect sizes for all witness Time 2 variables.

Witness

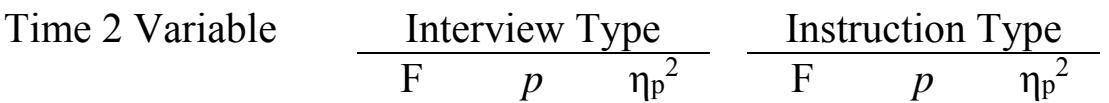

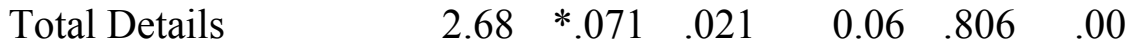




$\begin{array}{lcccccc}\text { Accuracy Rate } & 0.57 & .568 & .005 & 1.84 & .176 & .008 \\ \text { Correct Details } & 2.81 & .062 & .023 & 0.23 & .629 & .001 \\ \text { Incorrect Details } & 0.56 & .573 & .005 & 1.02 & .314 & .004 \\ \text { Don't Know Responses } & 0.11 & .894 & .001 & 0.30 & .586 & .001 \\ \text { False Acquiesces } & 0.30 & .739 & .002 & 6.12 & * .014 & .024 \\ \text { Other Errors } & 0.38 & .686 & .003 & 0.42 & .516 & .002 \\ \text { Perpetrator Details } & .088 & .416 & .007 & 0.88 & .350 & .004 \\ \text { Victim Details } & 2.00 & .137 & .016 & 0.93 & .335 & .004 \\ \text { Bystander } & 1.54 & .216 & .013 & 0.27 & .606 & .001 \\ \text { Setting } & 0.53 & .590 & .004 & 0.68 & .412 & .003 \\ \text { Crime Action } & 1.89 & .153 & .015 & 1.41 & .237 & .006\end{array}$

Note. $*$ Denotes significant or marginal effect at $p<.08$.

\section{Time 2 Interview: Interviewer Variables}

To examine whether the pre-interview information or instructions to avoid suggestive questions influenced interviewer behavior during the Time 2 interview, separate ANOVAs first examined the effects of interviewer type and instruction type on (1) the total number of questions asked (all open, cued, yes/no, multiple choice) and (2) the duration of the interview. A MANOVA then investigated the effect of interviewer type and instruction type on interviewer utterances (e.g., question types).

Total Questions. A 3 (interviewer type: correctly informed vs. incorrectly informed vs. blind) X 2 (instructions to avoid suggestive questions: yes vs. no) ANOVA on the total number of questions asked revealed no effects of interviewer type, instruction 
type and no interviewer type by instruction type interaction. See Table 6 for means and standard deviations for interviewer Time 2 primary dependent variables and see Table 7 for inferential statistics.

Interview Length. A 3 X 2 ANOVA on interview length revealed a marginal effect of suggestibility instructions on the length of the witness interviews, $F(1,244)=$ $3.57, p=.06, \eta_{\mathrm{p}}{ }^{2}=.014$. When interviewers received instructions to avoid suggestive questions, they tended to conduct longer interviews $(M=6.70, S D=5.51)$ compared to when no instructions were given $(M=5.56, S D=3.84)$. There was no effect of interviewer type and no instruction by interviewer type interaction. See Table 6 for means and standard deviations and Table 7 for inferential statistics.

Question Types. To further examine whether interviewer type or suggestibility instructions influenced interviewer behavior during the witness interview, a 3 X 2 MANOVA examined the effects of interviewer type and instruction type on the various types of interviewer utterances: (1) the number of open-ended questions, (2) the number of cued questions, (3) the number of yes/no questions, (4) the number of multiple choice questions, (5) the number of facilitators (e.g., mhmm, okay), and (6) the number of suggestive questions or statements. Analyses revealed significant effects of suggestibility instructions on the number of suggestive questions asked, $F(1,244)=3.15, p=.077, \eta_{\mathrm{p}}{ }^{2}=$ .013 and the number of cued questions asked, $F(1,244)=4.74, p=.030, \eta_{\mathrm{p}}{ }^{2}=.019$. Follow-up comparisons revealed that interviewers who were instructed to avoid suggestive questions asked fewer suggestive questions $(M=2.12, S D=2.98)$ than those who were not given the instruction $(M=2.91, S D=4.10)$. Instructed interviewers also asked more cued questions $(M=11.12, S D=8.40)$ than those who did not receive the 
instructions $(M=9.05, S D=6.36)$. There were no other effects of interviewer type or instruction type and no interviewer type by instruction type interactions on any of the other interviewer utterance types. See Table 6 for means and standard deviations and Table 7 for inferential statistics.

Table 6.

Means and standard deviations for interviewer dependent variables at Time 2.

\begin{tabular}{|c|c|c|c|c|}
\hline $\begin{array}{c}\text { Primary Interviewer } \\
\text { Variables: Time } 2\end{array}$ & $\begin{array}{l}\text { Suggestibility } \\
\text { Instruction }\end{array}$ & Interviewer Type & Mean & SD \\
\hline \multirow{6}{*}{ Total Questions } & \multirow{3}{*}{ Yes } & Blind & 34.00 & 30.66 \\
\hline & & Correct-Informed & 32.26 & 24.10 \\
\hline & & Incorrect-Informed & 32.72 & 27.03 \\
\hline & \multirow{3}{*}{ No } & Blind & 33.28 & 22.82 \\
\hline & & Correct-Informed & 30.26 & 20.88 \\
\hline & & Incorrect-Informed & 25.91 & 17.26 \\
\hline \multirow{6}{*}{ Interview Length } & \multirow{3}{*}{ Yes } & Blind & 6.45 & 5.32 \\
\hline & & Correct-Informed & 6.47 & 4.76 \\
\hline & & Incorrect-Informed & 7.20 & 6.51 \\
\hline & \multirow{3}{*}{ No } & Blind & 6.03 & 3.94 \\
\hline & & Correct-Informed & 5.82 & 4.47 \\
\hline & & Incorrect-Informed & 4.86 & 2.97 \\
\hline \multirow{6}{*}{ Open-Ended Questions } & \multirow{3}{*}{ Yes } & Blind & 5.51 & 4.76 \\
\hline & & Correct-Informed & 4.77 & 3.54 \\
\hline & & Incorrect-Informed & 5.51 & 4.49 \\
\hline & \multirow{3}{*}{ No } & Blind & 5.49 & 3.95 \\
\hline & & Correct-Informed & 3.86 & 3.06 \\
\hline & & Incorrect-Informed & 4.23 & 2.50 \\
\hline \multirow{6}{*}{ Cued Questions } & \multirow{3}{*}{ Yes } & Blind & 10.66 & 9.17 \\
\hline & & Correct-Informed & 11.56 & 8.12 \\
\hline & & Incorrect-Informed & 11.13 & 8.41 \\
\hline & \multirow{3}{*}{ No } & Blind & 10.61 & 6.73 \\
\hline & & Correct-Informed & 9.14 & 6.03 \\
\hline & & Incorrect-Informed & 7.67 & 6.25 \\
\hline \multirow{6}{*}{ Yes/No Questions } & \multirow{3}{*}{ Yes } & Blind & 15.46 & 17.14 \\
\hline & & Correct-Informed & 14.49 & 13.68 \\
\hline & & Incorrect-Informed & 14.97 & 16.15 \\
\hline & \multirow{3}{*}{ No } & Blind & 15.28 & 15.05 \\
\hline & & Correct-Informed & 14.95 & 13.01 \\
\hline & & Incorrect-Informed & 12.11 & 9.72 \\
\hline \multirow{7}{*}{ Multiple-Choice Questions } & \multirow{3}{*}{ Yes } & Blind & 2.26 & 3.93 \\
\hline & & Correct-Informed & 1.44 & 1.83 \\
\hline & & Incorrect-Informed & 1.23 & 1.66 \\
\hline & \multirow{4}{*}{ No } & Blind & 2.21 & 2.22 \\
\hline & & Correct-Informed & 2.31 & 2.55 \\
\hline & & Incorrect-Informed & 1.84 & 2.02 \\
\hline & & Blind & 2.46 & 4.22 \\
\hline
\end{tabular}




\begin{tabular}{|c|c|c|c|c|}
\hline \multirow{5}{*}{ Facilitators } & \multirow[t]{2}{*}{ Yes } & Correct-Informed & 4.72 & 7.18 \\
\hline & & Incorrect-Informed & 4.08 & 5.60 \\
\hline & \multirow{3}{*}{ No } & Blind & 3.51 & 5.24 \\
\hline & & Correct-Informed & 3.36 & 5.80 \\
\hline & & Incorrect-Informed & 3.22 & 4.11 \\
\hline \multirow{6}{*}{ Suggestive Questions } & \multirow{3}{*}{ Yes } & Blind & 1.25 & 1.62 \\
\hline & & Correct-Informed & 2.35 & 3.19 \\
\hline & & Incorrect-Informed & 2.72 & 3.59 \\
\hline & \multirow{3}{*}{ No } & Blind & 2.58 & 4.61 \\
\hline & & Correct-Informed & 3.26 & 4.01 \\
\hline & & Incorrect-Informed & 2.91 & 3.72 \\
\hline
\end{tabular}

Table 7.

$F$ values, $p$ values and effect sizes for all interviewer variables at Time 2.

Interviewer

Time 2 Variable

\begin{tabular}{|c|c|}
\hline Interview Type & Instruction Type \\
\hline F $\quad p \quad \eta_{\mathrm{p}}{ }^{2}$ & \\
\hline
\end{tabular}

Total Questions

$\begin{array}{lll}0.67 & .297 & .004\end{array}$

$\begin{array}{lll}1.09 & .691 \quad .005\end{array}$

Interview Length

$\begin{array}{lll}0.04 & .959 \quad .000\end{array}$

$3.57 * .060 \quad .014$

Open-Ended Questions

$\begin{array}{lll}1.69 & .128 & .017\end{array}$

$\begin{array}{lll}2.41 & .122 \quad .010\end{array}$

Cued Questions

$\begin{array}{lll}0.59 & .553 \quad 005\end{array}$

$4.74 * .030 \quad .019$

Yes/No Questions

$\begin{array}{lll}0.33 & .717 & .003\end{array}$

$0.22 \quad 642 \quad .001$

Multiple-Choice

$\begin{array}{lll}1.65 & .195 \quad .013\end{array}$

$2.34 \quad .128 \quad .009$

Questions

Suggestive Questions

$\begin{array}{lll}1.69 & .188 & .014\end{array}$

$3.15 * .077 \quad .013$

Facilitators

$\begin{array}{lll}0.81 & .445 \quad .007\end{array}$

$0.60 \quad .440$

.002

Note. ${ }^{*}$ Denotes significant or marginal effect at $p<.08$.

Time 3 Recall: Primary Witness Variables

To examine whether interviewer type and instruction type had any influence on witness recall at Time 3, separate ANOVAs first examined whether interviewer type and instruction type influenced (1) the total details recalled at Time 3 (combined correct and incorrect details) and (2) the percentage accuracy of witness details recalled (the total number of correct details divided by the total number of details recalled). 
Total Details Recalled at Time 3. A 3 (interviewer type: correctly informed vs. incorrectly informed vs. blind) X 2 (instruction to avoid suggestive questions: yes vs. no) ANOVA on the total number of details recalled revealed no effects of interviewer type or instruction type and no interviewer type by instruction type interaction. See Table 8 for means and standard deviations for Time 3 primary witness variables and Table 9 for inferential statistics.

Witness Accuracy at Time 3. A 3 X 2 ANOVA then examined the effect of interviewer type and instruction type on witness accuracy rate and revealed a significant interview type by instruction type interaction, $F(2,244)=3.65, p=.027, \eta_{\mathrm{p}}{ }^{2}=.029$ (See Figure 6). Post-hoc comparisons indicated that when interviewers received no instructions to avoid suggestive questions, witnesses of blind interviewers recalled a higher proportion of correct details $(M=0.86, S D=.06)$ compared to witnesses of incorrectly informed interviewers $(M=0.81, S D=0.12)$. There were no differences across groups when the instructions to avoid suggestive questions were given. There was also a marginal main effect of interviewer type on witness Time 3 accuracy rate, $F(2$, $244)=2.41, p=.092, \eta_{\mathrm{p}}{ }^{2}=.019$. Witnesses of correctly informed interviewers tended to be more accurate $(M=0.85, S D=0.06)$ than witnesses of incorrectly informed interviewers $(M=0.83, S D=0.10)$ but not more accurate than witnesses of blind interviewers $(M=0.85, S D=0.07)$. There was no main effect of instruction type. See Table 8 for means and standard deviations and Table 9 for inferential statistics. 


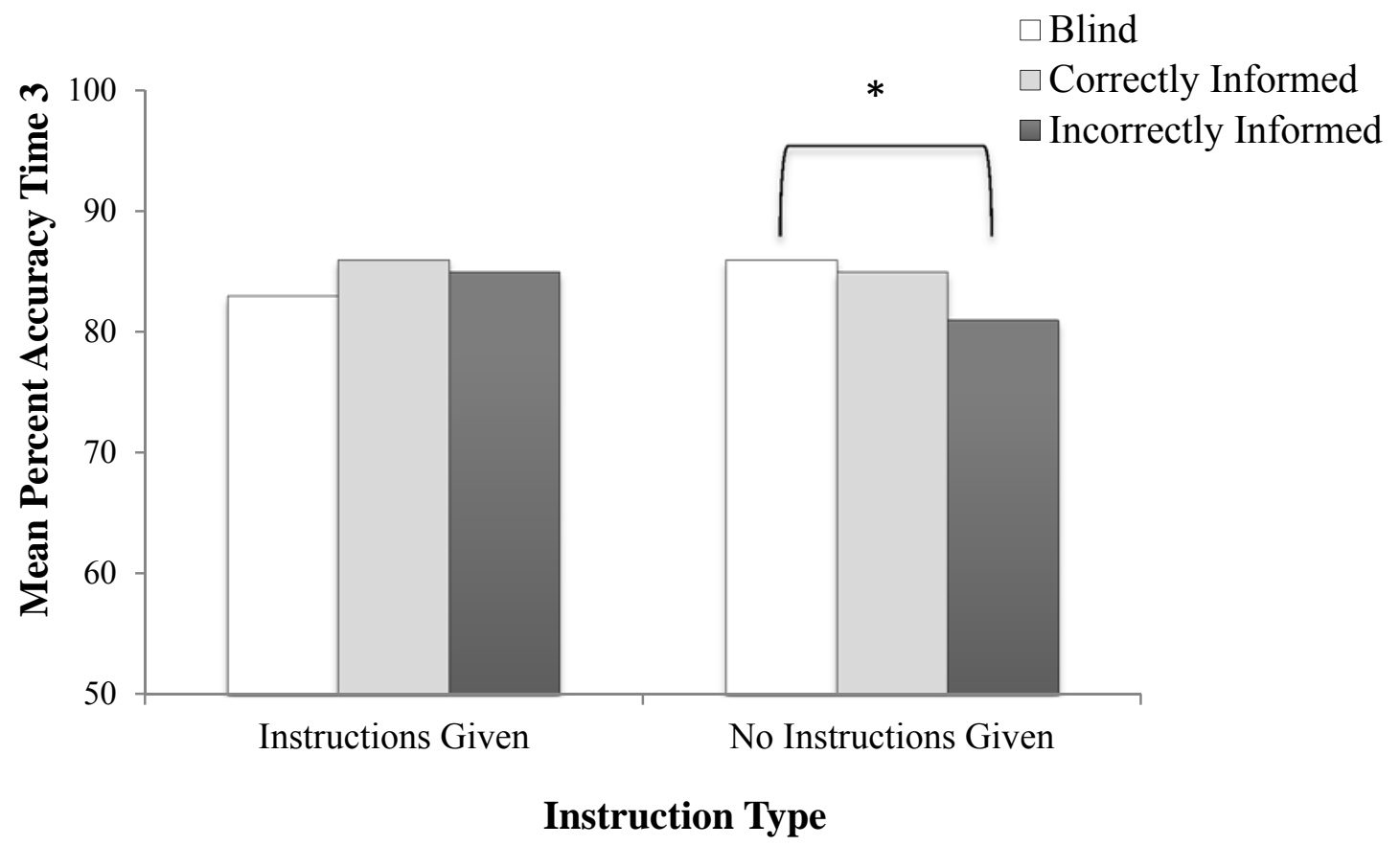

Figure 6. Mean percent witness accuracy at Time 3 as a function of interviewer type and instruction type. Note. ${ }^{*}$ Denotes a significant difference at $p<.05$.

Table 8 .

Means and standard deviations for primary witness dependent variables at Time 3.

\begin{tabular}{|c|c|c|c|c|}
\hline $\begin{array}{c}\text { Primary Witness } \\
\text { Variables: Time } 3\end{array}$ & $\begin{array}{l}\text { Suggestibility } \\
\text { Instruction }\end{array}$ & Interviewer Type & Mean & SD \\
\hline \multirow{6}{*}{ Total Details } & \multirow{3}{*}{ Yes } & Blind & 49.95 & 16.38 \\
\hline & & Correct-Informed & 54.00 & 17.56 \\
\hline & & Incorrect-Informed & 48.46 & 14.99 \\
\hline & \multirow{3}{*}{ No } & Blind & 49.71 & 19.23 \\
\hline & & Correct-Informed & 51.71 & 17.09 \\
\hline & & Incorrect-Informed & 47.22 & 15.63 \\
\hline \multirow{6}{*}{ Accuracy Rate } & \multirow{3}{*}{ Yes } & Blind & 0.83 & 0.07 \\
\hline & & Correct-Informed & 0.86 & 0.08 \\
\hline & & Incorrect-Informed & 0.85 & 0.06 \\
\hline & \multirow{3}{*}{ No } & Blind & 0.86 & 0.06 \\
\hline & & Correct-Informed & 0.85 & 0.07 \\
\hline & & Incorrect-Informed & 0.81 & 0.12 \\
\hline
\end{tabular}

\section{Time 3 Recall: Secondary Witness Variables}

Correct, Incorrect, and Don't Know Responses. To examine further the effects of pre-interview information and the instructions to avoid suggestive questions on the 
quality of delayed witness memory, a 3 (interviewer type: correctly informed vs. incorrectly informed vs. blind) X 2 (instruction to avoid suggestive questions: yes vs. no) between-participants MANOVA examined the effects of interviewer type and instruction type on the following additional witness variables of interest: (1) number of correct details, (2) number of incorrect details, and (3) number of don't know responses. Analyses revealed no main effects of instruction type or interviewer type and no instruction type by interviewer type interaction. See Table 8a for means and standard deviations for all secondary Time 3 witness variables and see Table 9 for inferential statistics.

Witness Error Types. I further examined whether interviewer type and instructions influenced the types of errors that witnesses made during Time 3 recall. Therefore, a second 3 X 2 MANOVA was conducted to examine the effects of interviewer type and instruction type on the three possible witness error types: (1) additions, (2) modifications, and (3) false incorporations of suggested interviewer details. Analyses revealed no effects of interviewer type or instruction type on any of the possible witness error types and no instruction type by interviewer type interaction. See Table $8 \mathrm{a}$ for means and standard deviations and Table 9 for inferential statistics.

Table 8a.

Means and standard deviations for secondary witness dependent variables at Time 3.

\begin{tabular}{|l|l|l|l|l|}
\hline $\begin{array}{c}\text { Secondary Witness } \\
\text { Variables: Time 3 }\end{array}$ & \multicolumn{1}{c|}{$\begin{array}{c}\text { Suggestibility } \\
\text { Instruction }\end{array}$} & \multicolumn{1}{|c|}{ Interviewer Type } & Mean & \multicolumn{1}{c|}{ SD } \\
\hline \multirow{4}{*}{$\begin{array}{l}\text { Yes } \\
\text { Number of Correct } \\
\text { details recalled }\end{array}$} & \multirow{2}{*}{ No } & Blind & 42.20 & 15.99 \\
\cline { 2 - 5 } & & Correct-Informed & 46.90 & 16.93 \\
\cline { 2 - 5 } & & Incorrect-Informed & 41.20 & 13.77 \\
\hline & & Blind & 43.10 & 17.19 \\
\cline { 2 - 5 } & Correct-Informed & 44.07 & 16.28 \\
\cline { 2 - 5 } & Incorrect-Informed & 38.62 & 15.67 \\
\hline
\end{tabular}




\begin{tabular}{|c|c|c|c|c|}
\hline \multirow{5}{*}{$\begin{array}{l}\text { Number of Incorrect } \\
\text { details recalled }\end{array}$} & \multirow[t]{2}{*}{ Yes } & Correct-Informed & 7.10 & 3.71 \\
\hline & & Incorrect-Informed & 7.26 & 3.43 \\
\hline & \multirow{3}{*}{ No } & Blind & 6.65 & 3.12 \\
\hline & & Correct-Informed & 7.64 & 3.66 \\
\hline & & Incorrect-Informed & 7.26 & 3.43 \\
\hline \multirow{6}{*}{$\begin{array}{l}\text { Number of don't know } \\
\text { responses }\end{array}$} & \multirow{3}{*}{ Yes } & Blind & 7.10 & 5.19 \\
\hline & & Correct-Informed & 8.72 & 4.72 \\
\hline & & Incorrect-Informed & 7.73 & 4.70 \\
\hline & \multirow{3}{*}{ No } & Blind & 8.12 & 4.80 \\
\hline & & Correct-Informed & 7.69 & 4.61 \\
\hline & & Incorrect-Informed & 8.69 & 5.74 \\
\hline \multirow{6}{*}{$\begin{array}{l}\text { Number of addition } \\
\text { errors }\end{array}$} & \multirow{3}{*}{ Yes } & Blind & 1.72 & 2.16 \\
\hline & & Correct-Informed & 1.24 & 1.81 \\
\hline & & Incorrect-Informed & 1.92 & 1.95 \\
\hline & \multirow{3}{*}{ No } & Blind & 0.89 & 1.25 \\
\hline & & Correct-Informed & 1.43 & 1.98 \\
\hline & & Incorrect-Informed & 1.60 & 1.93 \\
\hline \multirow{6}{*}{$\begin{array}{l}\text { Number of modification } \\
\text { errors }\end{array}$} & \multirow{3}{*}{ Yes } & Blind & 6.74 & 3.32 \\
\hline & & Correct-Informed & 6.18 & 3.61 \\
\hline & & Incorrect-Informed & 5.92 & 3.05 \\
\hline & \multirow{3}{*}{ No } & Blind & 6.21 & 3.26 \\
\hline & & Correct-Informed & 5.95 & 3.48 \\
\hline & & Incorrect-Informed & 7.26 & 4.12 \\
\hline \multirow{6}{*}{$\begin{array}{l}\text { Number of false } \\
\text { incorporations }\end{array}$} & \multirow{3}{*}{ Yes } & Blind & 0.00 & 0.00 \\
\hline & & Correct-Informed & 0.03 & 0.16 \\
\hline & & Incorrect-Informed & 0.03 & 0.16 \\
\hline & \multirow{3}{*}{ No } & Blind & 0.03 & 0.16 \\
\hline & & Correct-Informed & 0.05 & 0.21 \\
\hline & & Incorrect-Informed & 0.07 & 0.34 \\
\hline
\end{tabular}

Table 9.

$F$ values, $p$ values and effect sizes for all witness Time 3 variables.

Witness

Time 3 Variables

\begin{tabular}{|c|c|c|c|c|c|}
\hline \multicolumn{3}{|c|}{ Interview Type } & \multicolumn{3}{|c|}{ Instruction Type } \\
\hline $\mathrm{F}$ & $p$ & $\eta_{\mathrm{p}}^{2}$ & $\mathrm{~F}$ & & $\eta_{p}^{2}$ \\
\hline 1.88 & .154 & .015 & 0.34 & .562 & .001 \\
\hline 0.80 & .372 & .003 & 2.41 & $* .092$ & .019 \\
\hline 1.49 & .227 & .013 & 0.95 & .332 & .004 \\
\hline 2.48 & .086 & .021 & 0.09 & .763 & .000 \\
\hline 0.64 & .529 & .005 & 0.55 & .460 & .002 \\
\hline 1.51 & .223 & .013 & 1.70 & .193 & .007 \\
\hline 0.50 & .609 & .004 & 0.18 & .675 & .001 \\
\hline
\end{tabular}


Incorporations of 0.59 .553 .005

Note. * Denotes significant or marginal effect at $p<.09$.

\section{Time 3 Recall: Primary Interviewer Variables}

The next set of analyses examined the effects of pre-interview information and instructions to avoid suggestive questions on interviewers' memory for the Time 2 interview. Separate ANOVAs first examined whether interviewer type and instruction type influenced (1) the total details interviewers recalled about the Time 2 interview (combined correct and incorrect details) and (2) the percentage accuracy of the details interviewers recalled (the total number of correct details divided by the total number of details recalled). As a result of study attrition, failure to follow instructions, and some instances of missing data, analyses were performed on 204 of the 251 participant interviewers at Time 3.

Total Interviewer Details Recalled. A 3 (interviewer type: correctly informed vs. incorrectly informed vs. blind) X 2 (instructions to avoid suggestive questions: yes vs. no) ANOVA on the total number of interviewer details recalled revealed no effects of interviewer type or instruction type and no interviewer type by instruction type interaction. See Table 10 for means and standard deviations for primary Time 3 interviewer variables and Table 11 for inferential statistics.

Interviewer Accuracy Rate. A 3 X 2 ANOVA then examined the effect of interviewer type and instruction type on interviewer accuracy rate and revealed a 
significant effect of interviewer type, $F(2,198)=6.20, p=.002, \eta_{\mathrm{p}}{ }^{2}=.059$ (See Figure 7). Post-hoc comparisons indicated blind interviewers recalled a higher proportion of correct details $(M=0.63, S D=0.17)$ compared to correctly informed interviewers $(M=$ $0.57, S D=0.15)$ and incorrectly informed interviewers $(M=0.54, S D=0.16)$. There were no main effects of instruction type and no interviewer type by instruction type interaction. See Table 10 for means and standard deviations and Table 11 for inferential statistics.

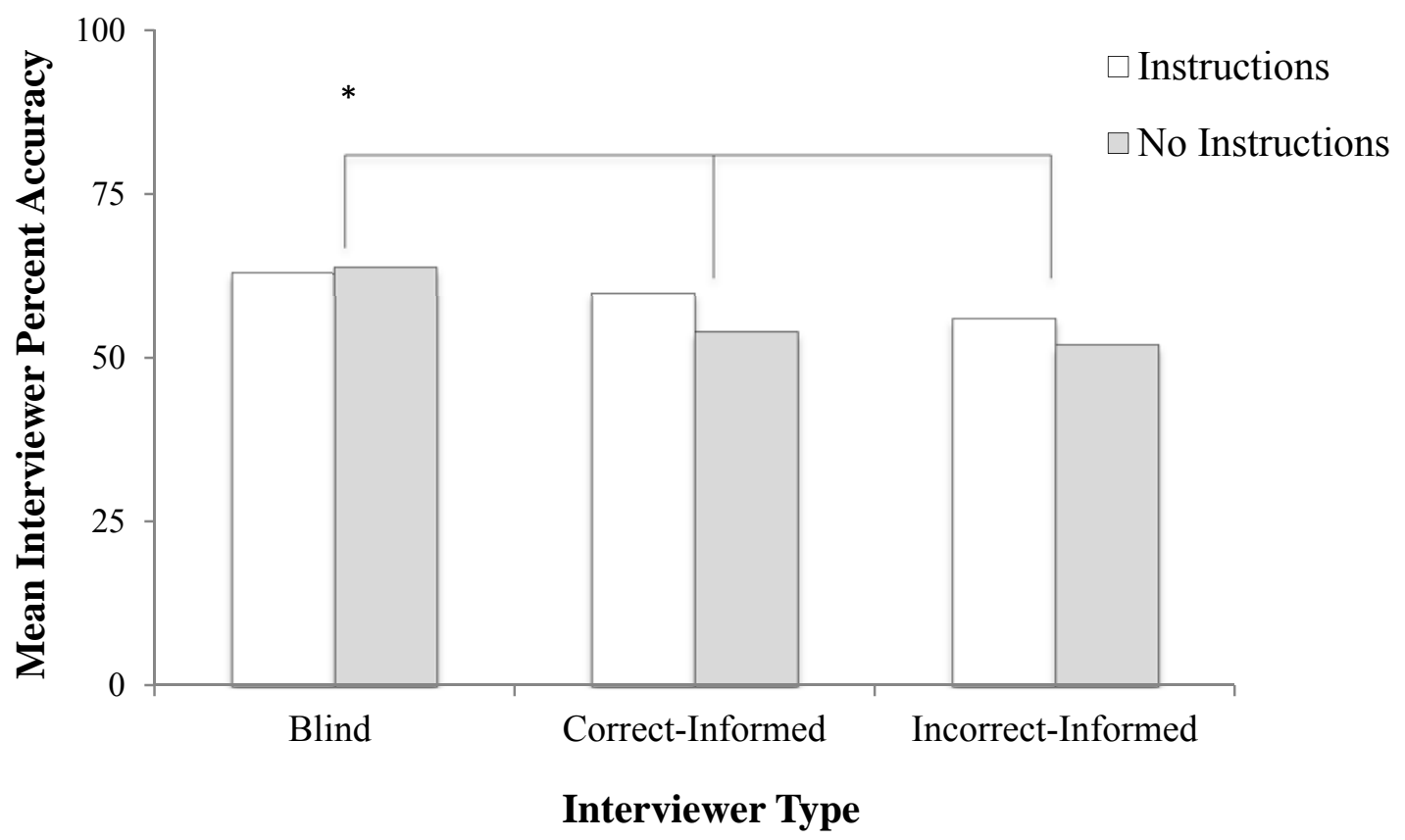

Figure 7. Mean accuracy rate for interviewer memory of the witness interview as a function of interviewer type and instruction type. Note: * Denotes a significant difference at $p<.05$.

Table 10.

Means and standard deviations for primary interviewer variables at Time 3.

\begin{tabular}{|c|c|c|c|c|}
\hline $\begin{array}{c}\text { Witness Variables: } \\
\text { Time } 3\end{array}$ & $\begin{array}{l}\text { Suggestibility } \\
\text { Instruction }\end{array}$ & Interviewer Type & Mean & SD \\
\hline & \multirow{3}{*}{ Yes } & Blind & 32.35 & 13.17 \\
\hline & & Correct-Informed & 37.81 & 15.39 \\
\hline & & Incorrect-Informed & 39.19 & 13.89 \\
\hline
\end{tabular}




\begin{tabular}{|l|l|l|l|l|}
\hline Total Details & \multirow{3}{*}{ No } & Blind & 34.09 & 14.84 \\
\cline { 3 - 5 } & & Correct-Informed & 37.06 & 13.10 \\
\cline { 3 - 5 } & & Incorrect-Informed & 34.54 & 10.38 \\
\hline \multirow{4}{*}{ Accuracy Rate } & \multirow{3}{*}{ Yes } & Blind & 0.63 & 0.19 \\
\cline { 3 - 5 } & & Correct-Informed & 0.60 & 0.15 \\
\cline { 3 - 5 } & \multirow{3}{*}{ No } & Incorrect-Informed & 0.56 & 0.15 \\
\cline { 3 - 5 } & & Blind & 0.64 & 0.16 \\
\cline { 3 - 5 } & & Correct-Informed & 0.54 & 0.14 \\
\cline { 3 - 5 } & Incorrect-Informed & 0.52 & 0.16 \\
\hline
\end{tabular}

\section{Time 3 Recall: Secondary Interviewer Variables}

Correct, Incorrect, and Don't Know Responses. A 3 (interviewer type:

correctly informed vs. incorrectly informed vs. blind) X 2 (instructions to avoid suggestive questions: yes vs. no) between-participants MANOVA examined the effects of interviewer type and instruction type on the secondary interviewer Time 3 variables: (1) number of correct details, (2) number of incorrect details, and (3) number of don't know responses. Analyses revealed a significant effect of interviewer type on the number of incorrect details recalled, $F(2,198)=6.11, p=.003, \eta_{\mathrm{p}}{ }^{2}=.058$. Post-hoc comparisons indicated that blind interviewers recalled significantly fewer incorrect details $(M=12.27$, $S D=8.06)$ than both correctly informed interviewers $(M=16.18, S D=8.37)$ and incorrectly informed interviewers $(M=16.79, S D=7.65)$. There were no other main effects of interviewer type or instruction type, and no interviewer type by instruction type interactions. See Table 10a for means and standard deviations for Time 3 interviewer secondary variables and Table 11 for inferential statistics.

Interviewer Error Types. A second 3 X 2 MANOVA was conducted to examine whether pre-interview information and instructions to avoid suggestive questions influenced the types of possible interviewer errors: (1) report-related errors (e.g., adding or modifying details based on the pre-interview report), (2) other errors (not 
related to the report), and (3) the number of omissions. Analyses revealed a significant effect of interviewer type on the number of report-related errors, $F(2,198)=43.32, p<$ $.001, \eta_{\mathrm{p}}^{2}=0.30$. Blind interviewers were significantly less likely to make a report-related error $(M=0.03, S D=0.18)$ than both correctly informed interviewers $(M=4.03, S D=$ 3.16) and incorrectly informed interviewers $(M=4.15, S D=3.89)$. There were no other main effects or interactions. See Table 10a for means and standard deviations and Table 11 for inferential statistics.

Table 10a.

Means and standard deviations for secondary interviewer variables at Time 3.

\begin{tabular}{|c|c|c|c|c|}
\hline $\begin{array}{c}\text { Interviewer Variables: } \\
\text { Time } 3 \\
\end{array}$ & $\begin{array}{l}\text { Suggestibility } \\
\text { Instruction }\end{array}$ & Interviewer Type & Mean & SD \\
\hline \multirow{6}{*}{$\begin{array}{l}\text { Number of correct } \\
\text { details recalled }\end{array}$} & \multirow{3}{*}{ Yes } & Blind & 20.62 & 12.38 \\
\hline & & Correct-Informed & 22.36 & 9.72 \\
\hline & & Incorrect-Informed & 21.94 & 9.59 \\
\hline & \multirow{3}{*}{ No } & Blind & 21.25 & 9.40 \\
\hline & & Correct-Informed & 20.14 & 8.41 \\
\hline & & Incorrect-Informed & 18.17 & 7.87 \\
\hline \multirow{6}{*}{$\begin{array}{l}\text { Number of incorrect } \\
\text { details recalled }\end{array}$} & \multirow{3}{*}{ Yes } & Blind & 11.73 & 7.58 \\
\hline & & Correct-Informed & 15.44 & 8.63 \\
\hline & & Incorrect-Informed & 17.26 & 8.51 \\
\hline & \multirow{3}{*}{ No } & Blind & 12.84 & 8.62 \\
\hline & & Correct-Informed & 16.92 & 8.15 \\
\hline & & Incorrect-Informed & 16.37 & 6.90 \\
\hline \multirow{6}{*}{$\begin{array}{l}\text { Number of don't know } \\
\text { responses }\end{array}$} & \multirow{3}{*}{ Yes } & Blind & 0.15 & 0.61 \\
\hline & & Correct-Informed & 0.14 & 0.68 \\
\hline & & Incorrect-Informed & 0.23 & 1.09 \\
\hline & \multirow{3}{*}{ No } & Blind & 0.41 & 1.18 \\
\hline & & Correct-Informed & 0.50 & 1.18 \\
\hline & & Incorrect-Informed & 0.14 & 0.43 \\
\hline \multirow{6}{*}{$\begin{array}{l}\text { Number of report- } \\
\text { related errors }\end{array}$} & \multirow{3}{*}{ Yes } & Blind & 0.02 & 0.17 \\
\hline & & Correct-Informed & 4.42 & 3.91 \\
\hline & & Incorrect-Informed & 3.55 & 2.71 \\
\hline & \multirow{3}{*}{ No } & Blind & 0.03 & 0.18 \\
\hline & & Correct-Informed & 3.64 & 2.15 \\
\hline & & Incorrect-Informed & 4.69 & 4.68 \\
\hline \multirow{6}{*}{ Number of other Errors } & \multirow{3}{*}{ Yes } & Blind & 13.11 & 8.12 \\
\hline & & Correct-Informed & 13.42 & 8.10 \\
\hline & & Incorrect-Informed & 16.09 & 8.39 \\
\hline & \multirow{3}{*}{ No } & Blind & 14.09 & 9.41 \\
\hline & & Correct-Informed & 15.36 & 8.00 \\
\hline & & Incorrect-Informed & 14.25 & 6.39 \\
\hline
\end{tabular}




\begin{tabular}{|l|l|l|l|l|}
\hline \multirow{4}{*}{ Number of omissions } & \multirow{3}{*}{ Yes } & Blind & 8.24 & 5.83 \\
\cline { 3 - 5 } & & Correct-Informed & 7.00 & 4.12 \\
\cline { 2 - 5 } & \multirow{3}{*}{ No } & Incorrect-Informed & 7.10 & 3.60 \\
\cline { 2 - 5 } & & Blind & 8.88 & 6.61 \\
\hline & Correct-Informed & 6.61 & 4.20 \\
\cline { 3 - 5 } & Incorrect-Informed & 7.31 & 3.09 \\
\hline
\end{tabular}

Table 11.

$F$ values, $p$ values and effect sizes for all interviewer Time 3 variables.

Interviewer

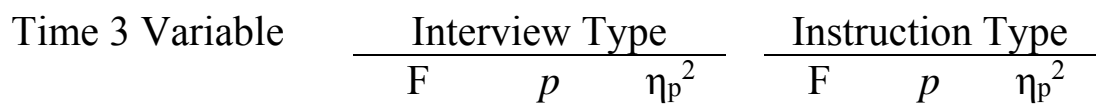

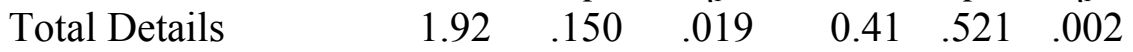

$\begin{array}{lllllll}\text { Accuracy Rate } & 6.20 & * .002 & .059 & 1.45 & .230 & .007\end{array}$

$\begin{array}{llllllll}\text { Correct Details } & & 0.27 & .759 & .003 & 1.72 & .192 & .009\end{array}$

$\begin{array}{llllllll}\text { Incorrect Details } & & 6.11 & * .003 & .058 & 0.25 & .619 & .001\end{array}$

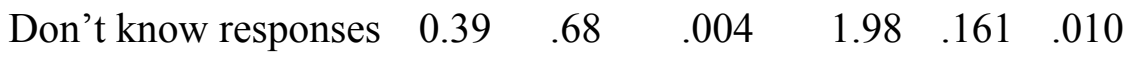

$\begin{array}{lllllll}\text { Report-related Errors } & 43.32 & * .000 & .304 & 0.08 & .767 & .000\end{array}$

$\begin{array}{lllllll}\text { Other Errors } & 0.621 & .538 & .006 & 0.09 & .764 & .000\end{array}$

$\begin{array}{lllllll}\text { Omissions } & 1.56 & .213 & .015 & 0.21 & .646 & .001\end{array}$

Note. * Denotes a significant difference at $p<.05$.

\section{Witness Consistency Across Time}

To examine whether pre-interview information and suggestiveness instructions influenced witness consistency between the Time 2 interview and the Time 3 recall measures, 3 (interviewer type: correctly informed vs. incorrectly informed vs. blind) X 2 (instructions to avoid suggestive questions: yes vs. no) between-participants MANOVA was conducted on the number of witness: (1) consistent statements, (2) contradictions, and (3) omissions. There were no main effects or interactions for any of the variables. See Table 12 for means and standard deviations and Table 13 for inferential statistics. 
Table 12.

Means and standard deviations for witness memory variables across time.

\begin{tabular}{|c|c|c|c|c|}
\hline $\begin{array}{l}\text { Witness Variables } \\
\text { Across Time }\end{array}$ & $\begin{array}{l}\text { Suggestibility } \\
\text { Instruction }\end{array}$ & Interviewer Type & Mean & SD \\
\hline \multirow{6}{*}{$\begin{array}{l}\text { Number of consistent } \\
\text { details recalled }\end{array}$} & \multirow{3}{*}{ Yes } & Blind & 10.23 & 4.67 \\
\hline & & Correct-Informed & 10.97 & 4.54 \\
\hline & & Incorrect-Informed & 11.00 & 5.37 \\
\hline & \multirow{3}{*}{ No } & Blind & 12.46 & 6.20 \\
\hline & & Correct-Informed & 10.73 & 4.51 \\
\hline & & Incorrect-Informed & 10.58 & 5.09 \\
\hline \multirow{6}{*}{$\begin{array}{l}\text { Number of } \\
\text { contradictory details } \\
\text { recalled }\end{array}$} & \multirow{3}{*}{ Yes } & Blind & 0.28 & 0.46 \\
\hline & & Correct-Informed & 0.50 & 0.69 \\
\hline & & Incorrect-Informed & 0.35 & 0.71 \\
\hline & \multirow{3}{*}{ No } & Blind & 0.51 & 1.05 \\
\hline & & Correct-Informed & 0.38 & 0.61 \\
\hline & & Incorrect-Informed & 0.58 & 1.03 \\
\hline \multirow{6}{*}{ Number of omissions } & \multirow{3}{*}{ Yes } & Blind & 2.79 & 2.20 \\
\hline & & Correct-Informed & 3.73 & 3.09 \\
\hline & & Incorrect-Informed & 3.53 & 2.83 \\
\hline & \multirow{3}{*}{ No } & Blind & 4.26 & 3.57 \\
\hline & & Correct-Informed & 3.24 & 2.54 \\
\hline & & Incorrect-Informed & 3.33 & 2.76 \\
\hline
\end{tabular}

Table 13.

$F$ values, $p$ values and effect sizes for witness memory across times 2 and 3.

Witness Variables Across Time

Consistent Details

Contradictory Details

Omissions

\begin{tabular}{ccc}
\multicolumn{4}{c}{ Interview Type } \\
\hline $\mathrm{F}$ & $p$ & $\eta_{\mathrm{p}}{ }^{2}$ \\
0.28 & .753 & .002
\end{tabular}

$\begin{array}{lll}0.17 & .843 \quad .001\end{array}$

$\begin{array}{lll}0.02 & .978 \quad .000\end{array}$ \begin{tabular}{ccc}
\multicolumn{2}{c}{ Instruction Type } \\
\hline $\mathrm{F}$ & $p$ & $\eta_{\mathrm{p}}^{2}$
\end{tabular}

$\begin{array}{lll}0.64 & .424 \quad .003\end{array}$

\section{$\begin{array}{lll}1.19 & .277 \quad .005\end{array}$}

$0.47 \quad .492 \quad .002$

Note. * Denotes a significant effect at $p<.05$.

\section{Time 3: Source Memory}

Next, a series of analyses examined the effects of interviewer type and instruction type on witness and interviewer source memory decisions. Specifically, for both witnesses and interviewers, a MANOVA was conducted on the primary sourcemonitoring outcome measures (the number of correct, incorrect, and don't know source 
monitoring decisions). A second MANOVA examined the different types of possible incorrect source-monitoring decisions by comparing across groups the three possible source-monitoring error types: (1) pure source confusions (e.g., misattributing a detail to one source (i.e. video) when it was presented by the other source (i.e., interviewer)), (2) misattributing to only 1 source when it was presented by both sources, and (3) misattributing to both sources when it was presented by only one source. As a result of study attrition and some instances of missing data, analyses were performed on 233 of the 251 participant witnesses' source memory data at Time 3.

Witness Source Memory. A 3 (interviewer type: correctly informed vs. incorrectly informed vs. blind) X 2 (instructions to avoid suggestive questions: yes vs. no) MANOVA examined the effect of interviewer and instruction type on the number of witnesses' correct, incorrect and don't know source memory decisions. Analyses revealed a significant effect of interviewer type on the number of witnesses correct decisions, $F(2$, $227)=3.58 p=.030, \eta_{\mathrm{p}}{ }^{2}=.031$ and don't know decisions $F(2,227)=3.81 p=.024, \eta_{\mathrm{p}}{ }^{2}=$ .033. Post-hoc comparisons revealed that witnesses of correctly informed interviewers made more correct source memory decisions $(M=17.18, S D=4.24)$ than witnesses of incorrectly informed interviewers $(M=15.35, S D=4.15)$. Witnesses of correctly informed interviewers also made significantly fewer don't know decisions $(M=9.04, S D$ $=4.93)$ compared to witnesses of both incorrectly informed interviewers $(M=11.35, S D$ $=6.09)$ and witnesses of blind interviewers $(M=10.85, S D=5.83)$. There was no difference between witnesses of blind and incorrectly informed interviewers with respect to correct decisions or don't know decisions. See Table 14 for means and standard deviations for witness source memory decisions and Table 15 for inferential statistics. 
Witness Source Memory Error Types. To examine further the effect of interviewer and instruction type on witnesses' source memory, another 3 X 2 MANOVA was conducted on the types of witness source memory errors: (1) the number of pure source confusions (e.g., attributing a detail to the video when it should be attributed to the interviewer or vice versa), (2) the number of misattributions to only 1 source (instead of correctly attributing to both), and (3) the number of misattributions to both sources (instead of correctly attributing to only one). Analyses revealed a significant effect of interviewers' pre-interview knowledge on the number of misattributions to both sources, $F(2,227)=6.91 p=.001, \eta_{\mathrm{p}}^{2}=.057$ and the number of pure source confusions, $F(2,227)$ $=2.90 p=.057, \eta_{\mathrm{p}}{ }^{2}=.025$. Witnesses of blind interviewers were less likely to make pure source confusion errors $(\mathrm{M}=0.02, \mathrm{SD}=0.16)$ than witnesses of both correctly informed interviewers $(M=0.17, S D=0.44)$ and incorrectly informed interviewers $(M=0.17, S D$ $=0.54)$. Witnesses of correctly informed interviewers were more likely to misattribute a detail to more than once source $(M=0.63, S D=1.16)$ compared to witnesses of both incorrectly informed interviewers $(M=0.27, S D=0.60)$ and blind interviewers $(M=$ $0.16, S D=0.50)$. There were no other significant main effects or interactions. See Table 14 for means and standard deviations and Table 15 for inferential statistics.

Table 14.

Means and standard deviations for witness source memory decisions.

\begin{tabular}{|l|l|l|l|l|}
\hline \multirow{1}{*}{$\begin{array}{c}\text { Witness Source } \\
\text { Memory Decisions }\end{array}$} & \multicolumn{1}{|c|}{$\begin{array}{c}\text { Suggestibility } \\
\text { Instruction }\end{array}$} & \multicolumn{1}{|c|}{ Interviewer Type } & Mean/36 & \multicolumn{1}{c|}{ SD } \\
\hline \multirow{4}{*}{$\begin{array}{l}\text { Number of correct } \\
\text { decisions }\end{array}$} & \multirow{3}{*}{ Yes } & Blind & 16.78 & 3.59 \\
\cline { 2 - 5 } & & Correct-Informed & 18.13 & 4.13 \\
\cline { 2 - 5 } & \multirow{2}{*}{ No } & Incorrect-Informed & 16.03 & 3.86 \\
\hline & & Blind & 16.46 & 4.52 \\
\cline { 3 - 5 } & & Correct-Informed & 17.19 & 4.24 \\
\cline { 3 - 5 } & Incorrect-Informed & 15.36 & 4.15 \\
\hline & Blind & 9.00 & 2.70 \\
\hline
\end{tabular}




\begin{tabular}{|c|c|c|c|c|}
\hline \multirow{5}{*}{$\begin{array}{l}\text { Number of incorrect } \\
\text { decisions }\end{array}$} & \multirow[t]{2}{*}{ Yes } & Correct-Informed & 10.05 & 4.19 \\
\hline & & Incorrect-Informed & 8.97 & 2.83 \\
\hline & \multirow{3}{*}{ No } & Blind & 8.39 & 3.39 \\
\hline & & Correct-Informed & 9.52 & 3.29 \\
\hline & & Incorrect-Informed & 9.57 & 4.21 \\
\hline \multirow{6}{*}{$\begin{array}{l}\text { Number of don't know } \\
\text { decisions }\end{array}$} & \multirow{3}{*}{ Yes } & Blind & 10.22 & 6.68 \\
\hline & & Correct-Informed & 7.82 & 4.74 \\
\hline & & Incorrect-Informed & 11.00 & 6.93 \\
\hline & \multirow{3}{*}{ No } & Blind & 11.45 & 6.68 \\
\hline & & Correct-Informed & 10.17 & 4.74 \\
\hline & & Incorrect-Informed & 11.64 & 6.93 \\
\hline \multirow{6}{*}{$\begin{array}{l}\text { Number of pure source } \\
\text { confusions }\end{array}$} & \multirow{3}{*}{ Yes } & Blind & 0.03 & 0.17 \\
\hline & & Correct-Informed & 0.18 & 0.45 \\
\hline & & Incorrect-Informed & 0.17 & 0.51 \\
\hline & \multirow{3}{*}{ No } & Blind & 0.03 & 0.16 \\
\hline & & Correct-Informed & 0.17 & 0.44 \\
\hline & & Incorrect-Informed & 0.17 & 0.58 \\
\hline \multirow{6}{*}{$\begin{array}{l}\text { Number of } \\
\text { misattributions to } 1 \\
\text { source }\end{array}$} & \multirow{3}{*}{ Yes } & Blind & 0.03 & 0.17 \\
\hline & & Correct-Informed & 0.18 & 0.45 \\
\hline & & Incorrect-Informed & 0.17 & 0.51 \\
\hline & \multirow{3}{*}{ No } & Blind & 0.03 & 0.16 \\
\hline & & Correct-Informed & 0.17 & 0.44 \\
\hline & & Incorrect-Informed & 0.17 & 0.58 \\
\hline \multirow{6}{*}{$\begin{array}{l}\text { Number of } \\
\text { misattributions to both } \\
\text { sources }\end{array}$} & \multirow{3}{*}{ Yes } & Blind & 0.16 & 0.48 \\
\hline & & Correct-Informed & 0.46 & 1.07 \\
\hline & & Incorrect-Informed & 0.28 & 0.61 \\
\hline & \multirow{3}{*}{ No } & Blind & 0.15 & 0.55 \\
\hline & & Correct-Informed & 0.79 & 1.22 \\
\hline & & Incorrect-Informed & 0.26 & 0.59 \\
\hline
\end{tabular}

Table 15.

$F$ values, $p$ values and effect sizes for witness source memory decisions.

\begin{tabular}{|c|c|c|c|c|c|c|}
\hline Witness Source Memory & \multicolumn{3}{|c|}{ Interview Type } & \multicolumn{3}{|c|}{ Instruction Type } \\
\hline & $F$ & $\begin{array}{l}p \\
* 020\end{array}$ & $\eta_{\mathrm{p}}^{2}$ & $\mathrm{~F}$ & $p$ & $\eta_{\mathrm{p}}^{2}$ \\
\hline rrect Decisions & & & & & & \\
\hline orrect Decisions & 1.86 & .158 & .016 & 0.15 & .700 & .001 \\
\hline n't Know Decisions & 3.81 & $* .024$ & .033 & 3.65 & .057 & .016 \\
\hline e Source Confusions & 2.90 & $* .06$ & 0.25 & 0.01 & .932 & .000 \\
\hline isattribute to Both Sourc & 6.91 & $* .001$ & .057 & 0.87 & .351 & .004 \\
\hline satt & 0.50 & .608 & .004 & 0.61 & .435 & .003 \\
\hline
\end{tabular}

Note. ${ }^{*}$ Denotes a significant or marginal difference at $p<.06$. 
Interviewer Source Memory. Of the final sample of 251 participant pairs, source memory questionnaires were completed by only those interviewers who had read pre-interview information. As a result of attrition and some instances of missing data, analyses were performed on the source memory decisions for 146 interviewers (73 correctly informed and 73 incorrectly informed). A 3 X 2 MANOVA examined the effect of interviewer and instruction type on the number of interviewers' correct, incorrect and don't know source memory decisions. Analyses revealed no significant effects of interviewer type, instruction type, and no interviewer type by instruction type interactions on any of the dependent measures. See Table 16 for means and standard deviations and Table 17 for inferential statistics.

Interviewer Source Memory Error Types. To examine further the possible effect of interviewer type on interviewer source memory, another 3 X 2 MANOVA was conducted on the types of interviewers' source memory errors: (1) the number of pure source confusions, (2) the number of misattributions to only 1 source, and (3) the number of misattributions to both sources. Analyses revealed a significant effect of interviewer type on misattributions to both sources, $F(1,142)=9.10 p=.003, \eta_{\mathrm{p}}{ }^{2}=.06$ and misattributions to only one source, $F(1,142)=4.45 p=.037, \eta_{\mathrm{p}}{ }^{2}=.03$. Post-hoc comparisons showed that correctly informed interviewers were more likely to misattribute the detail as coming from both sources $(M=0.86, \mathrm{SD}=1.13)$ than incorrectly informed interviewers $(M=0.38, S D=0.79)$. In contrast, incorrectly informed interviewers were more likely to misattribute a detail to only 1 source when it came from both sources $(M=2.92, S D=2.18)$ compared to incorrectly informed 
interviewers $(M=2.22, S D=1.91)$. There were no other main effects or interactions. See

Table 16 for means and standard deviations and Table 17 for inferential statistics.

Table 16.

Means and standard deviations for interviewer source memory decisions.

\begin{tabular}{|c|c|c|c|c|}
\hline $\begin{array}{l}\text { Interviewer Source } \\
\text { Memory Decisions }\end{array}$ & $\begin{array}{l}\text { Suggestibility } \\
\text { Instruction }\end{array}$ & Interviewer Type & Mean & SD \\
\hline \multirow{4}{*}{$\begin{array}{l}\text { Number of correct } \\
\text { decisions }\end{array}$} & \multirow[t]{2}{*}{ Yes } & Correct-Informed & 17.71 & 5.39 \\
\hline & & Incorrect-Informed & 17.18 & 4.82 \\
\hline & \multirow[t]{2}{*}{ No } & Correct-Informed & 17.11 & 5.03 \\
\hline & & Incorrect-Informed & 16.45 & 4.88 \\
\hline \multirow{4}{*}{$\begin{array}{l}\text { Number of incorrect } \\
\text { decisions }\end{array}$} & \multirow[t]{2}{*}{ Yes } & Correct-Informed & 12.03 & 4.37 \\
\hline & & Incorrect-Informed & 12.09 & 4.43 \\
\hline & \multirow[t]{2}{*}{ No } & Correct-Informed & 12.61 & 4.21 \\
\hline & & Incorrect-Informed & 13.35 & 4.43 \\
\hline \multirow{4}{*}{$\begin{array}{l}\text { Number of don't know } \\
\text { decisions }\end{array}$} & \multirow[t]{2}{*}{ Yes } & Correct-Informed & 6.26 & 6.62 \\
\hline & & Incorrect-Informed & 6.73 & 4.69 \\
\hline & \multirow[t]{2}{*}{ No } & Correct-Informed & 6.29 & 5.73 \\
\hline & & Incorrect-Informed & 6.20 & 4.84 \\
\hline \multirow{4}{*}{$\begin{array}{l}\text { Number of pure source } \\
\text { confusions }\end{array}$} & \multirow[t]{2}{*}{ Yes } & Correct-Informed & 0.89 & 1.05 \\
\hline & & Incorrect-Informed & 1.00 & 1.11 \\
\hline & \multirow[t]{2}{*}{ No } & Correct-Informed & 0.87 & 1.17 \\
\hline & & Incorrect-Informed & 1.43 & 1.68 \\
\hline \multirow{4}{*}{$\begin{array}{l}\text { Number of } \\
\text { misattributions to } 1 \\
\text { source }\end{array}$} & \multirow[t]{2}{*}{ Yes } & Correct-Informed & 2.06 & 1.85 \\
\hline & & Incorrect-Informed & 3.09 & 1.99 \\
\hline & \multirow{2}{*}{ No } & Correct-Informed & 2.37 & 1.98 \\
\hline & & Incorrect-Informed & 2.78 & 2.34 \\
\hline \multirow{4}{*}{$\begin{array}{l}\text { Number of } \\
\text { misattributions to both } \\
\text { sources }\end{array}$} & \multirow[t]{2}{*}{ Yes } & Correct-Informed & 1.06 & 1.26 \\
\hline & & Incorrect-Informed & 0.36 & 0.74 \\
\hline & \multirow[t]{2}{*}{ No } & Correct-Informed & 0.68 & 0.99 \\
\hline & & Incorrect-Informed & 0.40 & 0.84 \\
\hline
\end{tabular}

Table 17.

$F$ values, $p$ values and effect sizes for interviewer source memory decisions.

Interviewer

Source Memory Decisions

Correct Decisions

Incorrect Decisions

Don't Know Decisions

Pure Source Confusions

Misattribute to 1 Source

\begin{tabular}{ccc}
\multicolumn{4}{c}{ Interview Type } \\
\hline $\mathrm{F}$ & $p$ & $\eta_{\mathrm{p}}^{2}$ \\
0.51 & .478 & .004
\end{tabular}

$\begin{array}{lll}0.33 & .570 \quad .002\end{array}$

$0.04 \quad 836 \quad .000$

$\begin{array}{lll}2.44 & .120 \quad .017\end{array}$

$4.45 * .037 \quad .030$

\begin{tabular}{ccc}
\multicolumn{2}{c}{ Instruction Type } \\
\hline $\mathrm{F}$ & $p$ & $\eta_{\mathrm{p}}{ }^{2}$
\end{tabular}

$\begin{array}{lll}0.64 & .424 \quad .005\end{array}$

$\begin{array}{lll}1.68 & .197 \quad 012\end{array}$

$0.07 \quad .787 \quad .001$

$\begin{array}{lll}0.90 & .344 \quad .006\end{array}$

$\begin{array}{lll}0.00 & .995 \quad .000\end{array}$ 
$\begin{array}{lllllll}\text { Misattribute to Both Sources } & 9.10 & * .003 & .060 & 1.08 & .301 & .008\end{array}$

Note. * Denotes a significant effect at $p<.05$.

\section{Time 3: Post-experiment Questionnaire}

Witness Perceptions of the Interviewer. To examine witnesses' perceptions of the interviewers, all witnesses were asked to provide Likert-type ratings of the interviewers at Time 3 via the post-experiment questionnaire. Of the 251 witnesses who completed Part 2 of the study, 230 post-experiment questionnaires were completed and their data analyzed. A 3 (interviewer type: correctly informed vs. incorrectly informed vs. blind) X 2 (instructions to avoid suggestive questions: yes vs. no) MANOVA examined the effect of interviewer type and instruction type on witnesses' perceptions of the interviewer's (1) effectiveness, (2) listening skills, (3) level of comfort in the interview, and the (4) degree of pressure felt during the interview on a scale of 1 to $10(1=$ not at all to $10=$ extremely or completely). Analyses revealed no main effects of interviewer type or instruction type on witnesses' perceptions of the interviewer and no instruction type by interviewer type interaction. See Table 18 for means and standard deviations and Table 19 for inferential statistics.

Table 18.

Means and standard deviations (on a 1 to 10 scale) for witness perceptions of the interviewer.

\begin{tabular}{|l|l|l|l|l|}
\hline $\begin{array}{c}\text { Witness Perceptions of } \\
\text { Interviewer }\end{array}$ & \multicolumn{1}{|c|}{$\begin{array}{c}\text { Suggestibility } \\
\text { Instruction }\end{array}$} & \multicolumn{1}{|c|}{ Interviewer Type } & Mean & SD \\
\hline \multirow{4}{*}{ How effective? } & \multirow{3}{*}{ Yes } & Blind & 6.28 & 2.32 \\
\cline { 2 - 5 } & & Correct-Informed & 6.28 & 2.37 \\
\cline { 2 - 5 } & \multirow{2}{*}{ No } & Incorrect-Informed & 5.87 & 2.13 \\
\cline { 2 - 6 } & & Blind & 6.67 & 1.90 \\
\cline { 3 - 6 } & & Correct-Informed & 6.17 & 2.21 \\
\cline { 3 - 6 } & Incorrect-Informed & 6.02 & 2.68 \\
\hline & & Blind & 8.03 & 1.75 \\
\hline
\end{tabular}




\begin{tabular}{|c|c|c|c|c|}
\hline \multirow{5}{*}{ Good listener? } & \multirow[t]{2}{*}{ Yes } & Correct-Informed & 7.70 & 2.03 \\
\hline & & Incorrect-Informed & 7.76 & 2.03 \\
\hline & \multirow{3}{*}{ No } & Blind & 8.56 & 1.19 \\
\hline & & Correct-Informed & 7.87 & 1.88 \\
\hline & & Incorrect-Informed & 7.63 & 1.71 \\
\hline \multirow{6}{*}{ How comfortable? } & \multirow{3}{*}{ Yes } & Blind & 8.23 & 1.72 \\
\hline & & Correct-Informed & 7.77 & 1.96 \\
\hline & & Incorrect-Informed & 8.21 & 1.83 \\
\hline & \multirow{3}{*}{ No } & Blind & 8.59 & 1.19 \\
\hline & & Correct-Informed & 7.76 & 2.24 \\
\hline & & Incorrect-Informed & 7.71 & 1.78 \\
\hline \multirow{6}{*}{ How much pressure? } & \multirow{3}{*}{ Yes } & Blind & 5.59 & 2.63 \\
\hline & & Correct-Informed & 4.19 & 2.67 \\
\hline & & Incorrect-Informed & 4.21 & 2.69 \\
\hline & \multirow{3}{*}{ No } & Blind & 4.26 & 2.95 \\
\hline & & Correct-Informed & 4.54 & 2.66 \\
\hline & & Incorrect-Informed & 4.27 & 2.93 \\
\hline
\end{tabular}

Table 19.

$F$ values, $p$ values and effect sizes for witness perceptions of the interviewer.

\begin{tabular}{|c|c|c|c|c|c|c|}
\hline \multirow[t]{2}{*}{ Witness Perceptions of Interviewer } & \multicolumn{3}{|c|}{ Interview Type } & \multicolumn{3}{|c|}{ Instruction Type } \\
\hline & $\mathrm{F}$ & $p$ & $\eta_{\mathrm{p}}^{2}$ & $\mathrm{~F}$ & $p$ & $\eta_{\mathrm{p}}^{2}$ \\
\hline How effective? & 1.05 & .353 & .009 & 0.24 & .626 & .001 \\
\hline How good of listener? & 2.54 & .081 & .021 & 0.72 & .396 & .003 \\
\hline How comfortable? & 2.67 & .072 & .022 & 0.05 & .826 & .000 \\
\hline How much pressure? & 1.37 & .255 & .012 & 0.75 & .387 & .003 \\
\hline
\end{tabular}

Interviewers' perceptions of the witness. To examine interviewers' perceptions of the witnesses, all interviewers' were asked to provide Likert-type ratings of the witnesses at Time 3 via the post-experiment questionnaire. Of the 251 interviewers who completed Part 2 of the study, 230 post-experiment questionnaires were completed at Part 3 (due to attrition and missing data points). A 3 X 2 MANOVA examined the effects of interviewer type and instruction type on interviewers' perceptions of (1) how accurate they believe the witness to be and (2) how credible they believed the witness to be, on a scale of 1 to $10(1=$ not at all to $10=$ extremely or completely $)$. Analyses revealed a 
significant effect of instruction type on perceived witness credibility, $F(1,224)=5.85 p=$ $.016, \eta_{\mathrm{p}}^{2}=.03$. Post-hoc comparisons revealed that interviewers who received instructions to avoid suggestive questions believed that the witness was less credible $(M=6.36, S D=$ 1.98) compared to interviewers who did not receive the instructions $(M=6.99, S D=$ 1.96). There were no other main effects or interactions. See Table 20 for means and standard deviations and Table 21 for inferential statistics.

Perceptions of pre-interview information. For participant interviewers' perceptions of pre-interview information, data from a final sample of 158 participant interviewers in the pre-informed conditions was analyzed. To examine interviewers' perceptions and perceived use of the pre-interview information, a 3 (interviewer type: correctly informed vs. incorrectly informed vs. blind) X 2 (instructions to avoid suggestive questions: yes vs. no) MANOVA examined the effect of interviewer type and instruction type on interviewers' perceptions of (1) the accuracy of the pre-interview information, (2) the helpfulness of the pre-interview report, as well as their perceptions of (3) how much they were influenced by the report and (4) how much they used the preinterview report when conducting the interview, all on a scale of 1 to $10(1=$ not at all to $10=$ extremely or completely). Analyses revealed no effects of interviewer or instruction type on interviewers' perceptions of the pre-interview information, and no instruction type by interviewer type interaction. See Table 20 for means and standard deviations and Table 21 for inferential statistics. 
Table 20.

Means and standard deviations (on a 1 to 10 scale) for interviewer perceptions of the witness and pre-interview information.

\begin{tabular}{|c|c|c|c|c|}
\hline Interviewer Perceptions & $\begin{array}{l}\text { Suggestibility } \\
\text { Instruction }\end{array}$ & Interviewer Type & Mean & SD \\
\hline \multirow{6}{*}{$\begin{array}{l}\text { How accurate was } \\
\text { witness? }\end{array}$} & \multirow{3}{*}{ Yes } & Blind & 6.11 & 1.81 \\
\hline & & Correct-Informed & 6.00 & 1.87 \\
\hline & & Incorrect-Informed & 6.14 & 2.13 \\
\hline & \multirow{3}{*}{ No } & Blind & 6.47 & 1.90 \\
\hline & & Correct-Informed & 6.53 & 1.54 \\
\hline & & Incorrect-Informed & 6.46 & 2.06 \\
\hline \multirow{6}{*}{$\begin{array}{l}\text { How credible was } \\
\text { witness? }\end{array}$} & \multirow{3}{*}{ Yes } & Blind & 6.55 & 1.90 \\
\hline & & Correct-Informed & 6.38 & 1.85 \\
\hline & & Incorrect-Informed & 6.13 & 2.24 \\
\hline & \multirow{3}{*}{ No } & Blind & 7.39 & 1.90 \\
\hline & & Correct-Informed & 6.75 & 1.71 \\
\hline & & Incorrect-Informed & 6.81 & 2.19 \\
\hline \multirow{6}{*}{$\begin{array}{l}\text { How accurate was pre- } \\
\text { interview information? }\end{array}$} & \multirow{3}{*}{ Yes } & Blind & N/A & N/A \\
\hline & & Correct-Informed & 7.26 & 1.86 \\
\hline & & Incorrect-Informed & 7.47 & 1.96 \\
\hline & \multirow{3}{*}{ No } & Blind & N/A & N/A \\
\hline & & Correct-Informed & 7.62 & 1.66 \\
\hline & & Incorrect-Informed & 7.50 & 2.03 \\
\hline \multirow{6}{*}{$\begin{array}{l}\text { How helpful was pre- } \\
\text { interview information? }\end{array}$} & \multirow{3}{*}{ Yes } & Blind & $\mathrm{N} / \mathrm{A}$ & N/A \\
\hline & & Correct-Informed & 7.63 & 1.66 \\
\hline & & Incorrect-Informed & 7.50 & 1.96 \\
\hline & \multirow{3}{*}{ No } & Blind & $\mathrm{N} / \mathrm{A}$ & $\mathrm{N} / \mathrm{A}$ \\
\hline & & Correct-Informed & 7.07 & 1.98 \\
\hline & & Incorrect-Informed & 7.08 & 1.86 \\
\hline \multirow{6}{*}{$\begin{array}{l}\text { How much influenced } \\
\text { by information? }\end{array}$} & \multirow{3}{*}{ Yes } & Blind & $\mathrm{N} / \mathrm{A}$ & $\mathrm{N} / \mathrm{A}$ \\
\hline & & Correct-Informed & 7.31 & 2.25 \\
\hline & & Incorrect-Informed & 7.92 & 1.96 \\
\hline & \multirow{3}{*}{ No } & Blind & $\mathrm{N} / \mathrm{A}$ & N/A \\
\hline & & Correct-Informed & 8.10 & 2.20 \\
\hline & & Incorrect-Informed & 7.85 & 2.34 \\
\hline \multirow{6}{*}{$\begin{array}{l}\text { How much did you use } \\
\text { the information? }\end{array}$} & \multirow{3}{*}{ Yes } & Blind & $\mathrm{N} / \mathrm{A}$ & $\mathrm{N} / \mathrm{A}$ \\
\hline & & Correct-Informed & 6.05 & 2.74 \\
\hline & & Incorrect-Informed & 6.47 & 2.48 \\
\hline & \multirow{3}{*}{ No } & Blind & $\mathrm{N} / \mathrm{A}$ & $\mathrm{N} / \mathrm{A}$ \\
\hline & & Correct-Informed & 6.05 & 2.74 \\
\hline & & Incorrect-Informed & 6.47 & 2.48 \\
\hline
\end{tabular}

Table 21.

$F$ values, $p$ values and effect sizes for interviewer perceptions of the witness.

Interviewer Perceptions

How accurate was witness?

\begin{tabular}{ccccccc}
\multicolumn{2}{c}{ Interview Type } & & \multicolumn{3}{c}{ Instruction Type } \\
\cline { 1 - 2 } \cline { 5 - 7 } & $p$ & $\eta_{\mathrm{p}}{ }^{2}$ & & $\mathrm{~F}$ & $p$ & $\eta_{\mathrm{p}}{ }^{2}$ \\
5.85 & $* .016$ & .025 & & 2.63 & .106 & .012
\end{tabular}


How credible was witness?

$\begin{array}{llllll}0.01 & .993 & .000 & 1.37 & .257 & .012\end{array}$

How accurate was pre-interview

$\begin{array}{llllll}0.02 & .887 & .000 & 0.43 & .515 & .003\end{array}$ information?

How helpful was pre-interview

$\begin{array}{llllll}0.00 & .958 & .000 & 1.36 & .246 & .009\end{array}$

information?

How much influenced by information?

$\begin{array}{llllll}0.26 & .611 & .002 & 1.07 & .303 & .007\end{array}$

$\begin{array}{llllll}0.75 & .389 & .005 & 2.91 & .090 & .019\end{array}$

How much did they use the information?

\section{DISCUSSION}

The overarching goal of the present study was to critically examine whether reviewing case information prior to conducting a witness interview as recommended by the NIJ guidelines (Technical Working Group, 1999) is beneficial when eliciting adult eyewitness accounts. Specifically, the current study sought to expand upon the findings of Rivard and colleagues (under review), suggesting that blind interviewers (with no knowledge of case information) elicited more correct information from witnesses, than interviewers who had correct or incorrect information about the crime prior to the interview. The present study sought to expand this line of research on the effect of blind versus non-blind interviewing via 2 primary aims: (1) to investigate whether interviewer instructions to avoid suggestive interviewing techniques would moderate the effect of pre-interview information on witness memory and interviewer behavior (2) whether any possible effects of pre-interview information extend beyond the immediate context of the forensic interview. Thus the present study examined the impact of blind versus informed interviewing on witnesses' memory for the event at the time of the interview (1 week 
after witnessing the crime), witnesses' memory for the event 1 week after the interview ( 2 weeks after the crime), interviewers' memory for the witness interview 1 week after the interview, and witnesses' and interviewers' subsequent abilities to disentangle potentially competing sources of information.

Five central predictions were made in line with previous research findings and psychological theory: (1) Blind interviewers would perform better quality interviews (e.g. containing fewer suggestive questions and more open ended questions) compared to both correctly and incorrectly informed interviewers, (2) Witnesses interviewed by blind interviewers would be more accurate than witnesses of incorrectly informed interviewers, (3) Witnesses of blind interviewers would provide more information than both incorrectly and correctly informed interviewers, (4) Interviewers instructed to avoid suggestive questions would ask fewer suggestive questions, and (5) after a brief delay, (a) Blind interviewers would have more accurate and detailed memories of the witness' account compared to correctly and incorrectly informed interviewers and (b) witnesses whose interviewers were blind would also have more accurate and detailed memories of the originally witnessed event compared to witnesses of incorrectly and more detailed memories than witnesses of correctly informed interviewers. See Appendix A for a summary of the research questions.

\section{Time 2 Interview}

Consistent with previous literature and partially supporting prediction 3 , the effects of blind interviewing were observed via the quantity (but not the accuracy) of witness recall during the witness interview. Witnesses of blind interviewers tended to recall more details overall than informed interviewers, but only when those interviewers 
had reviewed incorrect case facts. This finding is consistent, in part, with Rivard et al.'s (under review) findings that witnesses of blind interviewers recalled more information than both correctly and incorrectly informed interviewers. Surprisingly, in both studies, the veracity of case information had no bearing on witness recall quantity or accuracy during the witness interview. That is, there were no differences in witness recall between the two informed interviewing groups, suggesting that the mere knowledge of case facts, and not the quality of the case facts, may influence the amount of information interviewers obtained. Although it was hypothesized that pre-interview information would influence the accuracy of witness recall (prediction 2), the similar accuracy rates across groups are not entirely surprising given that (a) Rivard et al. (under review) reported similar findings in terms of overall accuracy rates across groups, and (b) there were no differences in the level of interviewer suggestiveness as a function of preinterview knowledge. Thus, witnesses of informed interviewers were not induced to be more inaccurate by the informed interviewers. In the absence of suggestive questioning, the benefit of blind interviewing may lie in the increased quantity of information gathered via other venues.

Contrary to prediction 1 , whether or not interviewers had information prior to the interview did not influence the type or quality of the questions they asked. Specifically, interviewers with prior knowledge of case facts were not more likely to ask more specific, that is yes/no, multiple-choice or cued questions, or interject information into the interview compared to those with no such knowledge. In fact, the questioning strategies across groups were relatively consistent, apart from the tendency of interviewers to ask fewer suggestive questions and to conduct longer interviews when 
instructed to avoid suggestive questions. These findings suggest that the instructions were successful in reducing the number of suggestive questions asked (supporting prediction 3) but that the benefit of blind interviewing was not necessarily a function of reducing interviewer bias or influence. In fact, Rivard et al. (under review) found that the key difference between blind and informed interviewers was in the type and quality of the interviewers' first question. Thus, the pre-interview information likely guided how interviewers set the stage for the interview task. In addition, the pre-interview information may have guided the content of interviewers' questions (e.g., confirming details already known), thereby restricting the amount of information gathered (MacCoun, 1998; Nisbett \& Ross, 1980). Future analyses will explore this possibility by examining (a) the content of interviewers' questions (e.g., relevance to pre-interview reports) and (b) the first question type (e.g., beginning the interview with an open vs. closed ended question or a suggestive vs. non-suggestive question).

Interestingly, despite the fact that overall question type/quality did not differ as a function of pre-interview knowledge, witnesses of blind interviewers still tended to report more information than witnesses of incorrectly informed interviewers. Since correctly informed interviewers arguably represent the best-case scenario in real-world interviews, the failure to observe a difference between blind interviewing and correctly informed interviewing, suggests that reviewing accurate case facts may not actually promote superior, more "efficient" interviewing. In fact, there were no differences in the length of the interviews as a function of interviewer type, suggesting that informed interviewing did not allow interviewers to use their time more efficiently. These data further suggest that interviewer influence (in the form of number of overall suggestive questions asked) 
may not be the (only) potential problem associated with the non-blind interviewing approach. In line with a plethora of research on confirmation bias, interviewers' preconceptions about the event may fundamentally alter their questioning strategies beyond the mere type of questions, for example, by narrowing the scope of questions asked (Kassin et al., 1996; Synder \& Swann, 1978) or by altering the opening question of the interview (Rivard et al., under review). As such, interviewers may ask "good", nonsuggestive questions (preserving accuracy) and yet still engage in a potentially damaging confirmatory questioning strategy. Future research should address experimentally the relevance of the information contained within the pre-interview case summaries to explore whether the specific characteristics of the pre-interview information (e.g., relevance, depth, source, novelty) influence interviewer behavior and subsequent witness memory.

\section{The Delayed Impact of Pre-interview Information}

The second aim of the study was to examine whether pre-interview information influenced witness and interviewer memory beyond the context of the investigative interview, that is, after a 1-week delay. I predicted that witnesses of blind interviewers would have more accurate memories of the originally witnessed event compared to witnesses of correctly and incorrectly informed interviewers. Consistent with this prediction, witnesses of blind interviewers recalled a higher proportion of accurate details (i.e., higher accuracy rate) one week after the interview than witnesses of incorrectly informed interviewers, but only when interviewers did not receive instructions to avoid suggestive questions. When those instructions were given, the accuracy rates did not differ across groups. Thus, being interviewed by a pre-informed interviewer at Time 2 
was detrimental to witnesses' overall accuracy at Time 3 when the pre-interview information was incorrect and interviewers were untrained in avoiding suggestive questions. Somewhat surprisingly, although misinformed interviewers were not interjecting information during the interview itself, witnesses still displayed a type of misinformation effect when recalling at a later time, suggesting that other aspects of the post-event interaction with the incorrectly informed interviewers influenced their memories for the original event.

Being interviewed by an informed interviewer also affected witnesses' subsequent source-monitoring decisions: when witness source memory was directly tested, witnesses were more likely to confuse the source of a detail (e.g., claiming it came from the mock crime video when it came from the interviewer and vice versa) when they were interviewed by an informed versus a blind interviewer. In addition, witnesses were more likely to correctly identify the source of a detail when they were interviewed by a correctly versus an incorrectly informed interviewer. These inaccuracies and source confusions associated with non-blind interviewing are consistent with previous literature demonstrating that post-event information can have a powerful effect on individuals' memory for the original event (e.g. Loftus \& Palmer, 1974; Loftus 1975; Loftus et al., 1978; McCloskey \& Zaragoza, 1985). However, the current findings suggest that even if misinformation is not directly evidenced in the form of leaking information into an interview via suggestive questions, its indirect effects may still be evidenced in the form of memory and source-monitoring errors at a later time. As suggested by Rivard et al. (under review), blind and informed interviewers may differ with respect to their initial approach to the witness (e.g., suggestiveness of the first question), which serves to alter 
the witness' output criteria. That is, informed interviewers may be communicating that they are already knowledgeable about the event, thereby influencing how witnesses report the event during the interview and then re-evaluate the event at a later recall attempt. In addition, it is possible that subtle, less detectible sources of influence are at play that were not fully captured by the variables coded thus far, such as interviewers' non-verbal behavior, tone of voice, or opening question, possibly influencing what information witnesses chose to report during the interview. This notion is in line with past research demonstrating that venues via which expectations can have powerful, yet indirect, effects on the outcome of interpersonal interactions remain somewhat elusive (Rosenthal \& Rubin, 1978; Rosenthal, 1994; Snyder \& Swann, 1978). For example, research on double-blind lineup administration has shown that non-blind administrators can influence eyewitness lineup decisions in the absence of overt cues of such influence but rather, in the form of subtle changes in eye-contact, speech emphasis, facial expressions, and body language (Garrioch \& Brimacombe, 2001).

Interestingly, pre-interview information also influenced interviewers' memories of the witness interview after a 1-week delay. Consistent with predictions, interviewers who were blind to case information had more accurate memories of the witness interviews compared to both correctly informed and incorrectly informed interviewers. In addition, incorrectly informed interviewers made more report-related errors during recall, confusing information they had read in the report with what they had heard from the witness during the interview itself by either (a) supplementing the witness narrative with pre-interview information or (b) modifying the witnesses' account to be more in line with what they read prior to the interview. This confusion was also evident in interviewers' 
source memory decisions. Correctly informed interviewers were more likely than incorrectly informed interviewers to misattribute a detail to both sources, perhaps because they encountered very few inconsistencies between the witnesses' account and the preinterview information. In contrast, incorrectly informed interviewers were more likely than correctly informed interviewers to forget a source, or to misattribute a detail to only one source when they actually learned it from both sources (pre-interview information and witness).

This pattern of findings is in line with research and theory on the constructive nature of memory. As such, the pre-informed interviewers' knowledge about the case facts and expectations during the witness interview likely influenced how they attended to, interpreted, and stored the information witnesses provided (Neisser, 1996). That is, the pre-interview reports may have activated schema-driven processing in which interviewers' attention was filtered through top-down processing. As such, witness information gathered was interpreted through the lens of their pre-existing knowledge about the crime (MacCoun, 1998; Nisbett \& Ross, 1980). Specifically, interviewers may have paid more attention to information consistent with the report, while ignoring information that contradicted the information. Interviewers' memories also appeared to suffer as evidenced by an increase in source memory confusions for informed interviewers, similar to the effects of misinformation on subsequent source-monitoring performance found in past research (e.g., Johnson et al., 1993; McCloskey \& Zaragoza, 1985). Future analyses of the current data will explore whether interviewers tended to recall more accurately witness statements that were consistent with the pre-interview information compared to statements inconsistent with pre-interview information, 
supporting the hypothesis that interviewers engaged in selective attention and processing during the interview.

The observed differences in interviewer accuracy at time 3 also have important implications for real-world interviews, particularly since interviewers rarely video-record their cooperative witness interviews. In cases where interviews are not recorded, interviewers must rely on their reconstructive memories of the interview in order to generate an accurate summary of the witness' statement at a later time. The present study's findings suggest that if interviewers summarize witness statements after a delay without the help of a recording, they may misremember details if they have reviewed case information prior to the interview. However, in contrast to real world interviewers, interviewers in the present study were not allowed to take notes during the witness interview. The availability of interview notes (or recordings) may have arguably improved the quality of interviewer recall of a prior interviewer. There is reason to assume that interviewer notes may still be an insufficient remedy for informed interviewing as previous research on interviewer note-taking suggests that interviewers' notes are often incomplete and the accuracy of those notes are influenced by the quality of the interview conducted (Hyman Gregory, Schreiber Compo, Vertefeuille \& Zambruski, 2012; Köhnken, Thürer, \& Zoberbier, 1994; Schreiber Compo, Hyman Gregory, \& Fisher, 2012). Future research should investigate if and to what extent interviewers' note-taking is influenced by pre-interview knowledge and how this notetaking guides later recall of the witness interview. 


\section{Implications}

The present findings extend the existing literature on the applied significance of confirmation bias in witness interviewing by demonstrating that interviewers' prior knowledge of case facts can influence (a) the output elicited during an eyewitness interview in a controlled laboratory setting (b) the accuracy of eyewitness accounts over time, and (c) interviewers' later memories for the witnesses' accounts. Although this laboratory setting differed in several ways from real-world investigative interviewing settings, the current study's findings replicate an earlier study comparing blind versus informed interviewing with adult witnesses and provide an important initial test of the delayed effects of blind versus non-blind interviewing. To inform policies for real world investigations, the present findings need to be replicated using experienced interviewers and more realistic procedures (e.g., allowing interviewers to take notes). Still, the resulting data should at minimum, stimulate a critical discussion about blind interviewing as a viable option in cooperative witness interviews. The present data suggest that interviewers should be comfortable conducting blind interviews in some circumstances, saving valuable time reviewing case information. Arguably, there are beneficial and suboptimal ways to prepare for an interview, for example, by avoiding particular pieces of case information, but reviewing other critically helpful details. However, blind interviewing may be challenging with certain (vulnerable) witness groups, such as witnesses who are unable to provide a detailed account or are reluctant to provide information in response to general prompting (Saywitz et al., 1991). The appropriateness of a blind interviewing approach may therefore depend on (a) the purpose of the interview and (b) the characteristics of the interviewee. Exploring the strengths and 
limitations of various interview preparation techniques remains an important topic for future research.

\section{Limitations}

One inherent limitation to the current study was its use of student rather than professional interviews. Despite being incentivized to thoroughly question the witnesses, these lay interviewers may have had little vested interest in the outcome of the interview. However, this was true for all interviewers across conditions; the fact that significant differences emerged despite this limitation suggests that mere knowledge of case facts, independent of and without motivation to solve a case can have an important effect on witness and interviewer recall. As such, the present experiment likely underestimated the effect of prior knowledge in a more naturalistic setting.

Although one could argue that professional interviewers may have used more appropriate (open-ended) questions improving the overall quality of interviews and the subsequent information collected, past research suggests that this is unlikely (Fisher, Geiselman, \& Raymond, 1987; Schreiber Compo et al., 2012). Real-world interviewers may have also differed in their training and knowledge about the use of suggestive questions. However, there were few differences in interviewer suggestiveness and question types across conditions, suggesting that interviewing skill and training is only one of many variables that may potentially moderate this effect. Future research should examine the effectiveness of blind versus informed interviewing with real world interviewers to examine whether and to what extent pre-interview preparation assists experienced interviewers in the context of a true police investigation in which 
interviewers take notes and are asked to summarize the witness interview to be evidence in subsequent court settings.

Finally, it should be noted that informed interviewers spent an estimated 30 to 40 seconds reading the summarized case report prior to conducting the interviews whereas blind interviewers did not. A filler task for the blind condition would have been considered if there had been a reasonable task/time delay between interviewer instructions and interview. Due to the facts that a 30 second filler task would have been difficult to administer (arguably an instruction for such task would have taken as long as the filler task itself), the time difference between informed and blind interviewing conditions was kept to a minimum, and any time difference would mimic real-world interviewing (not reading a case summary would result in a more timely interview than reading it), the present design and findings are arguably an adequate test of blind interviewing. In other words, such a negligible amount of variability was unlikely to have significantly altered the pattern of results.

\section{Conclusions and Future Directions}

In summary, the current study replicates and expands upon the findings of Rivard et al. (under review) demonstrating that informed interviewing is not only not a superior method, but in some circumstances, may actually be inferior to a blind interviewing approach in terms of gathering plentiful information within the context of an investigative interview and in fostering accurate witness and interviewer memory over time. Consistent with the findings of Rivard and colleagues (under review), the slight advantage of blind interviewing in the interviewing phase of the present study is not easily explained by poor interviewing or other biases on the part of the pre-informed interviewers. Instructions to 
avoid suggestive questions did not moderate the effect of blind versus non-blind interviewing and importantly, there were no differences between blind and informed interviewers in the length or total number of questions asked. Future exploratory analyses of the present data will investigate whether blind and informed interviewers differ with respect to non-verbal behavior (e.g., smiling, eye contact, body posture) and/or the sequence of questions asked in combination with the types of questions asked (e.g., beginning with open-ended questions regarding what happened, followed by closed questions about specific people or portions of the event).

The present study was the first to demonstrate that the potential danger of preinterview information extends beyond the immediate context of the investigative interview, influencing how both witnesses and interviewers consolidated, stored and retrieved information from memory on a later date. In light of the current findings, additional research is thus needed to explore the utility of interviewer preparation as recommended by the NIJ guidelines. The present experiment is an important step in assessing the effect of pre-interview case knowledge on the outcome of witness interviews and highlights the critical need for follow-up studies further examining the advantages and disadvantages of blind versus informed interviewing. Specifically, additional research is needed to replicate the present findings with well-controlled, high quality field studies with additional populations, both interviewer and interviewee, relevant to investigative settings. 


\section{REFERENCES}

Alba, J. W. \& Hasher, L. (1983). Is memory schematic? Psychological Bulletin, 93(2), 203-231. doi:10.1037/0033-2909.93.2.203.

Baddeley, A. D. (2001). Is working memory still working? American Psychologist, 56, 851-864. doi:10.1027//1016-9040.7.2.85.

Baddeley, A. D., \& Hitch, G. J. (1974). Working memory. In G. Bower (Ed.), Recent advances in learning and memory (Vol. 8, pp. 47-90). New York; Academic Press.

Bruck, M. \& S. J. Ceci. (1995). Amicus brief for the case of State of New Jersey v. Michaels presented by Committee of Concerned Social Scientists, Psychology, Public Policy, and Law, 1, 272-322. doi:10.1037/1076-8971.1.2.272.

Cantlon, J., G. Payne G., Erbaugh, C. (1996). Outcome-based practice: Disclosure rates of child sexual abuse comparing allegation blind and allegation informed structured interviews, Child Abuse and Neglect, 20, 1113-1120. doi:10.1016/0145-2134(96)001007.

Dror, I. E., Péron, A. E., Hind, S., Charlton, D. (2005). When emotions get the better of us: The effect of contextual top-down processing on matching fingerprints, Applied Cognitive Psychology, 19, 799-809. doi:10.1002/acp.1130.

Fisher, R. P., Geiselman, R. E., \& Raymond, D. S. (1987). Critical analysis of police interviewing techniques. Journal of Police Science and Administration, 15, 291-297.

Garrioch, L. \& Brimacombe, C.A. E. (2001). Lineup administrators' expectations: Their impact on eyewitness confidence. Law and Human Behavior, 25, 299-315. doi:10.1023/A:1010750028643.

Hyman Gregory, A., Schreiber Compo, N., Vertefeuille, L., \& Zambruski, G. (2012). A comparison of U.S. police interviewers' notes with their subsequent reports. Journal of Investigative Psychology and Offender Profiling, 8, 203-214.

Idaho v. Wright, 497 U.S. 805. (1990).

Jones, M. \& Sugden, R. (2001). Positive confirmation bias in the acquisition of information. Theory and Decision, 50, 59-99. doi:10.1023/A:1005296023424.

Johnson, M. K., Hashtroudi, S., Lindsay, D. S. (1993). Source monitoring. Psychological Bulletin, 114, 3-28. doi:10.1037/0033-2909.114.1.3. 
Kassin, S. M., Goldstein, C. C., Savitsky, K. (2003). Behavioral confirmation in the interrogation room: The dangers of presuming guilt. Law and Human Behavior, 27,187203.

Köhnken, G., Thürer, C., \& Zoberbier, D. (1994). The cognitive interview: Are the interviewers' memories enhanced, too? Applied Cognitive Psychology, 8, 13-24.

Loftus, E. F. (1975). Leading questions and the eyewitness report. Cognitive Psychology, 7, 560-572. doi:10.1016/0010-0285(75)90023-7.

Loftus, E. F. \& Palmer, J. C. (1974). Reconstruction of automobile destruction: An example of the interaction between language and memory. Journal of Verbal Learning and Verbal Behavior, 13, 585-589. doi:10.1016/S0022-5371(74)80011-3.

Loftus, E. F., Miller, D. G., Burns, H. J. (1978). Semantic integration of verbal information into visual memory. Journal of Experimental Psychology: Human Learning and Memory, 4, 19-31. doi:10.1037/0278-7393.4.1.19

McCloskey, M. \& Zaragoza, M. (1985). Misleading postevent information and memory for events: Arguments against memory impairment hypotheses. Journal of Experimental Psychology: General, 114, 1-16. doi:10.1037/0096-3445.114.1.1.

MacCoun, R. J. (1998). Biases in the interpretation and use of research results. Annual Review of Psychology, 49, 259-287. doi:10.1146/annurev.psych.49.1.259.

Neisser, U. (1967). Cognitive Psychology. New York: Appleton-Century-Crofts.

Nickerson, R. S. (1998). Confirmation bias: A ubiquitous phenomenon in many guises. Review of General Psychology, 2, 175-220. doi:10.1037/1089-2680.2.2.175.

Nisbett, R. E. \& Ross, L. (1980). Human Inference: Strategies and Shortcomings of Social Judgment. Englewood Cliffs, NJ: Prentice-Hall.

Pettit, F., Fegan, M., Howie, P. (1990). Interviewer effects on children's testimony. Paper presented at International Congress on Child Abuse and Neglect, Hamburg, Germany.

Phillips, M. R., McAuliff, B.D., Bull Kovera, M., Cutler, B. (1999). Double-blind photoarray administration as a safeguard against investigator bias. Journal of Applied Psychology, 85, 2. doi:10.1037/0021-9010.84.6.940.

Poole, D. A., Lamb, M. E. (1998). Investigative Interviews of Children: A Guide for Helping Professionals. American Psychological Association: London. 
Rivard, J. R., Schreiber Compo, N., \& Pena, M. M. (under review) 'Blind' interviewing: Is ignorance bliss?

Rivard, J. R. \& Schreiber Compo, N. (in preparation). Survey of forensic interviewers: Current techniques and perspectives from the field.

Rosenthal, R. (1994). Interpersonal expectancy effects: a 30 year perspective. Current Directions in Psychological Science, 3(6), 176-179. doi:10.1111/14678721.ep10770698.

Rosenthal, R., Rubin, D. B. (1978). Interpersonal expectancy effects: The first 345 studies. Behavioral and Brain Sciences, 1, 377-145. doi:10.1017/S0140525X00075506.

Saywitz, K. J., Goodman, G. S., Nicholas, E., Moan, S. F. (1991). Children's memories of a physical examination involving genital touch: Implications for reports of child sexual abuse. Journal of Consulting and Clinical Psychology, 59, 682-691. doi:10.1037/0022006X.59.5.682.

Schreiber Compo, N., Hyman Gregory, A. R., \& Fisher, R. P. (2012). Interviewing behaviors in police investigators: A field study of a current U.S. sample. Psychology, Crime and Law, 18 (3-4), 359-375. doi:10.1080/1068316X.2010.494604.

Synder, M. \& Swann, W. B. (1978). Behavioral confirmation in social interaction: From social perception to social reality. Journal of Experimental and Social Psychology, 14, 148-162. doi:10.1016/0022-1031(78)90021-5.

Teasdale, J.D., Dritschel, B. H., Taylor, M. J., Lloyd, C. A., Nimmo-Smith, I., Baddely, A. D. (1995). Stimulus-independent thought depends on central executive resources, Memory \& Cognition, 23, 551-559.

Technical Working Group: Eyewitness Evidence (1999). Eyewitness evidence: A guide for law enforcement. U.S. Department of Justice, Office of Justice Programs, National Institute of Justice. NCJ 178240

Tversky, A. \& Khaneman, D. (1973). Availability: A heuristic for judging frequency and probability. Cognitive Psychology, 5, 207-232. doi:10.1016/0010-0285(73)90033-9.

Wason, P.C. (1968). Reasoning about a rule. The Quarterly Journal of Experimental Psychology, 20, 273-281. doi:10.1080/14640746808400161.

Wells, G. L., Small, M., Penrod, S., Malpass, R. S., Fulero, S. M., Brimacombe, C. A. E. (1998). Eyewitness identification procedures: Recommendations for lineups and photospreads. Law and Human Behavior, 22, 1998. doi:10.1023/A:1025750605807. 
Vrij, A., Granhag, P. A., Mann, S., Leal, S. (2011). Outsmarting the liars: Toward a cognitive lie detection approach. Current Directions in Psychological Science, 20, 28-32. doi:10.1177/0963721410391245 


\title{
APPENDICES
}

\author{
Appendix A
}

\section{Research Questions, Hypotheses and Summary of Key Findings}

\begin{tabular}{|c|c|c|c|}
\hline & $\begin{array}{l}\text { Research } \\
\text { Questions }\end{array}$ & Hypotheses & Findings \\
\hline & $\begin{array}{l}\text { Does pre- } \\
\text { interview } \\
\text { information } \\
\text { influence } \\
\text { interviewer and } \\
\text { witness behavior? }\end{array}$ & 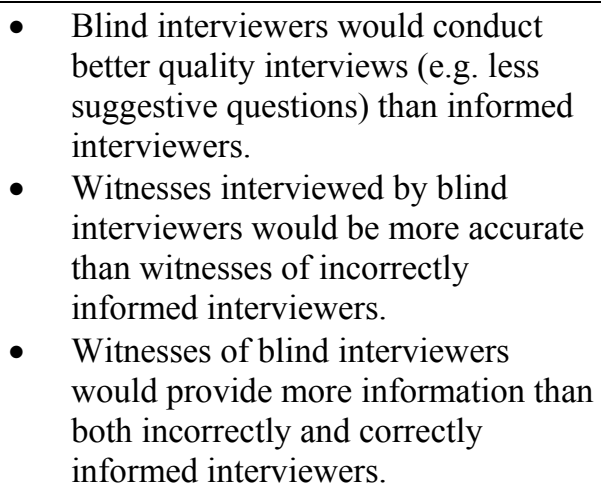 & $\begin{array}{l}\text { Partially supported: There was } \\
\text { no effect of pre-interview } \\
\text { information on interviewers' } \\
\text { use of suggestive questions. } \\
\text { Not supported: Witnesses } \\
\text { interviewed by blind } \\
\text { interviewers were not more } \\
\text { accurate but they reported } \\
\text { more information overall } \\
\text { during the witness interview } \\
\text { than witnesses of incorrectly } \\
\text { informed interviewers. }\end{array}$ \\
\hline & $\begin{array}{l}\text { Do cautionary } \\
\text { instructions } \\
\text { moderate the } \\
\text { effect of pre- } \\
\text { interview } \\
\text { information on } \\
\text { interviewer and } \\
\text { witness behavior? }\end{array}$ & $\begin{array}{l}\text { Interviewer instructions would } \\
\text { decrease the amount of suggestive } \\
\text { questions asked and increase witness } \\
\text { accuracy. } \\
\text { Interviewer instructions would lead } \\
\text { to a larger difference in suggestive } \\
\text { questions between blind and non- } \\
\text { blind interviewers compared to no } \\
\text { instructions. }\end{array}$ & $\begin{array}{l}\text { - Partially supported: } \\
\text { Interviewer instructions } \\
\text { decreased interviewers' use of } \\
\text { suggestive questions but did } \\
\text { not increase witness accuracy. } \\
\text { Not supported: There was no } \\
\text { interviewer by instruction } \\
\text { interaction. Interviewers asked } \\
\text { very few suggestive questions } \\
\text { overall, regardless of } \\
\text { interviewer condition or } \\
\text { instructions to avoid } \\
\text { suggestive questions. }\end{array}$ \\
\hline & $\begin{array}{l}\text { Do the effects of } \\
\text { pre-interview } \\
\text { information } \\
\text { extend beyond the } \\
\text { context of the } \\
\text { interview at a later } \\
\text { recall attempt? }\end{array}$ & $\begin{array}{l}\text { - Blind interviewers would have more } \\
\text { accurate and detailed memories of } \\
\text { the witness' account compared to } \\
\text { informed interviewers, regardless of } \\
\text { instruction type. } \\
\text { Witnesses whose interviewers were } \\
\text { blind would have more accurate } \\
\text { memories of the originally witnessed } \\
\text { event than witnesses of incorrectly } \\
\text { informed interviewers and more } \\
\text { detailed memories than witnesses of } \\
\text { both correctly and incorrectly } \\
\text { informed interviewers. }\end{array}$ & $\begin{array}{l}\text { - Supported: Blind interviewers } \\
\text { had more accurate memories } \\
\text { of the witness interview than } \\
\text { both correctly and incorrectly } \\
\text { informed interviewers, } \\
\text { regardless of instruction type. } \\
\text { Partially supported: Witnesses } \\
\text { of blind interviewers were } \\
\text { more accurate than witnesses } \\
\text { of incorrectly informed } \\
\text { interviewers when instructions } \\
\text { to avoid suggestive questions } \\
\text { were not given. }\end{array}$ \\
\hline
\end{tabular}




\section{Appendix B}

Video Details Contained in the Reports

\begin{tabular}{|c|c|c|c|}
\hline \multicolumn{2}{|r|}{ Detail Type } & \multicolumn{2}{|c|}{ Same in Both Videos } \\
\hline & Crime type & \multicolumn{2}{|l|}{ Theft } \\
\hline & Item stolen & \multicolumn{2}{|l|}{ Laptop } \\
\hline & Suspect gender & \multicolumn{2}{|l|}{ Male } \\
\hline & Suspect action & \multicolumn{2}{|l|}{ Entered room } \\
\hline & Suspect hair color & \multicolumn{2}{|l|}{ Brown } \\
\hline & Suspect Ethnicity & \multicolumn{2}{|l|}{ Hispanic } \\
\hline & Victim gender & \multicolumn{2}{|l|}{ Female } \\
\hline & Victim & \multicolumn{2}{|l|}{ Left room } \\
\hline & Setting & \multicolumn{2}{|c|}{ Bystander present in the room } \\
\hline & Bystander gender & \multicolumn{2}{|l|}{ Male } \\
\hline & Bystander first name & \multirow{2}{*}{\multicolumn{2}{|c|}{$\begin{array}{l}\text { Mike } \\
\text { Called security }\end{array}$}} \\
\hline & Bystander action 2 & & \\
\hline \multicolumn{2}{|r|}{ Detail Type } & Video 1 & Video 2 \\
\hline \multirow[t]{8}{*}{ Who } & Suspect age & 20 & 21 \\
\hline & Suspect height & 5,8, & $57^{\prime \prime}$ \\
\hline & Suspect weight & 140 & 190 \\
\hline & Suspect Hair length & Short & Average length \\
\hline & Suspect facial hair & Goatee & None mentioned \\
\hline & Suspect shirt color & Black & Black \& gray striped \\
\hline & Suspect pants & Khaki shorts & Blue jeans \\
\hline & Carrying & Over-the-shoulder bag & Backpack \\
\hline What & No. of items stolen & 1 (laptop only) & 2 (laptop \& cell phone) \\
\hline \multirow[t]{2}{*}{ When } & Time of Day & $12 \mathrm{pm}$ & $6 \mathrm{pm}$ \\
\hline & Time of Year & Around New Years & Around Halloween \\
\hline \multirow[t]{4}{*}{ How } & Bystander sequence & Bystander enters first & Bystander enters 2nd \\
\hline & Bystander exit & Does not exit & Exits room \\
\hline & Calling security & Campus phone & Cell phone \\
\hline & Suspect action & Shuts off light & none \\
\hline
\end{tabular}


Appendix C

Demographic Questionnaire

Which role have you been assigned? Check one: Interviewer Witness

\section{Please provide the following demographic information:}

1. What is your age?

2. What is your gender?
Years

Check one:

Male Female

3. Which of the following categories best reflects your ethnic/racial identity? (check only one)

$\begin{array}{lll}\text { African American } & \text { Asian/Pacific Island } \\ \text { Caucasian: Non-Hispanic } & \longrightarrow \text { Hispanic } \\ \text { Native American } & \quad \text { Other }\end{array}$

4. What is the highest education level you have completed?

high school graduate freshman year in college sophomore year in college junior year in college

senior year in college

graduate school

Other

5. Is English your primary/native language?

Yes

If no, how long have you spoken English fluently?

If English is not your native language, what is your native language?

6. What is your occupation?

7. Do you know the other person who you participated with today? Yes No 
If yes how do you know them?

Witness only:

8. Do you know or recognize any of the actors in the crime video? Yes No

If yes which actor(s) and how do you know them? 


\section{Appendix D}

Time 3 Cued Memory Questionnaire (Witness version)

\section{For the following questions, please fill in the blanks as completely as possible based} on your memory of the video you watched 2 weeks ago:

1. Please describe exactly what the suspect was wearing:
a. Shirt:
b. Pants:
c. Other:

2. Please describe the suspect's physical appearance:
a. Height
b. Weight
c. Hair color
d. Hair length
e. Facial hair
f. Ethnicity
g. Skin color
h. Other:

3. Please describe the stolen item(s):
a. Color:
b. Size:
c. Type:
d. Other:

4. Please describe the room characteristics:

a. Items in the room

b. Arrangement of items

c. Room type

d. Room number

e. Floor number

f. Building name

g. Decorations

h. Other: 
5. Please describe exactly what the bystander was wearing:
a. Shirt:
b. Pants:
c. Other:

6. Please describe the bystander's physical appearance:
a. Height
b. Weight
c. Hair color
d. Hair length
e. Facial hair
f. Ethnicity
g. Skin color
h. Other:

7. Please describe the exact sequence of events

a. Sequence of entering and leaving the room:

b. Victim actions:

c. Bystander actions:

d. Suspect actions: 
e. Other:

8. The bystander's name was: 


\section{Appendix E}

\section{Time 3 Source Memory Questionnaire (Witness Version)}

On the following pages, you will be asked about specific pieces of information. For each piece of information, please check the appropriate box reflecting whether and from what source you saw or heard this information. Please indicate whether you saw or hear the information: (a.) "In the video only" and not mentioned by the interviewer. (b.) "Mentioned by the interviewer only" and not in the video. (c.) Both "In the video AND mentioned by the interviewer" (d.) "Neither in the video NOR mentioned by the interviewer" or (e). "I don't know"

1. The suspect was wearing shorts. This information was:
a. $\square$ In the crime video only
b. Mentioned by the interviewer only
c. In the crime video and mentioned by the interviewer
d. Neither in the crime video nor mentioned by the interviewer
e. I don't know

2. Music was coming from the room next door. This information was:
a.

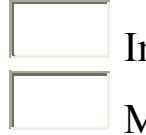 In the crime video only
b. Mentioned by the interviewer only
c. In the crime video and mentioned by the interviewer
d. Neither in the crime video nor mentioned by the interviewer
e. I don't know

3. The crime occurred around New Years. This information was:
a.<smiles>C1=[In]C1</smiles> In the crime video only
b. Mentioned by the interviewer only
c. In the crime video and mentioned by the interviewer
d. Neither in the crime video nor mentioned by the interviewer
e. I don't know 
4. The crime occurred in room 201. This information was
a. $\quad$ In the crime video only
b. Mentioned by the interviewer only
c. In the crime video and mentioned by the interviewer
d. Neither in the crime video nor mentioned by the interviewer
e. I don't know

5. The crime occurred around $12 \mathrm{pm}$. This information was:
a. $\square$ In the crime video only
b. Mentioned by the interviewer only
c. In the crime video and mentioned by the interviewer
d. Neither in the crime video nor mentioned by the interviewer
e. I don't know

6. The suspect has short hair. This information was:
a. $\square$ In the crime video only
b. $\square$ Mentioned by the interviewer only
c. In the crime video and mentioned by the interviewer
d. Neither in the crime video nor mentioned by the interviewer
e. I don't know

7. The bystander's name was Mike Ramirez. This information was:
a. $\quad$ In the crime video only
b. Mentioned by the interviewer only
c. In the crime video and mentioned by the interviewer
d. $\square$ Neither in the crime video nor mentioned by the interviewer
e. $\square$ I don't know

8. The bystander called security on his cell phone. This information was:

a. $\quad$ In the crime video only 

b. $\square$ Mentioned by the interviewer only
c. In the crime video and mentioned by the interviewer
d. Neither in the crime video nor mentioned by the interviewer
e. I don't know

9. The suspect is approximately 140 pounds. This information was:
a. In the crime video only
b. Mentioned by the interviewer only
c. In the crime video and mentioned by the interviewer
d. Neither in the crime video nor mentioned by the interviewer
e. I don't know

10. The crime occurred around Halloween. This information was:
a. $\square$ In the crime video only
b. Mentioned by the interviewer only
c. In the crime video and mentioned by the interviewer
d. Neither in the crime video nor mentioned by the interviewer
e. I don't know

11. The victim entered the room where the bystander was sitting. This information was:
a. $\square$ In the crime video only
b. Mentioned by the interviewer only
c. In the crime video and mentioned by the interviewer
d. Neither in the crime video nor mentioned by the interviewer
e. I don't know

12. The crime occurred around $6 \mathrm{pm}$. This information was:
a. In the crime video only
b. Mentioned by the interviewer only
c. In the crime video and mentioned by the interviewer 


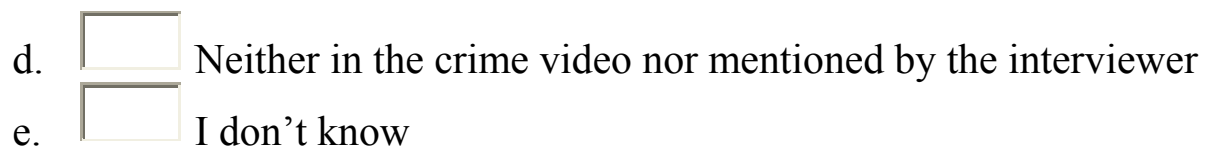

13. The suspect stole the victim's laptop. This information was:
a.
$\square$ In the crime video only
b. Mentioned by the interviewer only
c. In the crime video and mentioned by the interviewer
d. Neither in the crime video nor mentioned by the interviewer
e. I don't know

14. The suspect was wearing an over the shoulder bag. This information was:
a. $\quad$ In the crime video only
b. Mentioned by the interviewer only
c. In the crime video and mentioned by the interviewer
d. Neither in the crime video nor mentioned by the interviewer
e. I don't know

15. The suspect stole the victim's cell phone. This information was:
a. $\square$ In the crime video only
b. Mentioned by the interviewer only
c. In the crime video and mentioned by the interviewer
d. Neither in the crime video nor mentioned by the interviewer
e. I don't know

16. The suspect turned off the lights. This information was:
a. $\quad$ In the crime video only
b. Mentioned by the interviewer only
c. In the crime video and mentioned by the interviewer
d. Neither in the crime video nor mentioned by the interviewer
e. I don't know 
17. There was a coffee maker in the room. This information was:
a. In the crime video only
b. Mentioned by the interviewer only
c. In the crime video and mentioned by the interviewer
d. Neither in the crime video nor mentioned by the interviewer
e. I don't know

18. The bystander left the room before calling security. This information was:
a. $\square$ In the crime video only
b. Mentioned by the interviewer only
c. In the crime video and mentioned by the interviewer
d. Neither in the crime video nor mentioned by the interviewer
e. I don't know

19. The bystander's name was Mike Rodriguez. This information was:
a. $\square$ In the crime video only
b. Mentioned by the interviewer only
c. In the crime video and mentioned by the interviewer
d. Neither in the crime video nor mentioned by the interviewer
e. I don't know

20. The crime occurred in room 301. This information was
a. $\quad$ In the crime video only
b. Mentioned by the interviewer only
c. In the crime video and mentioned by the interviewer
d. Neither in the crime video nor mentioned by the interviewer
e. $\quad$ I don't know

21. The wall color was green. This information was:

a. $\quad$ In the crime video only 

b. $\square$ Mentioned by the interviewer only
c. In the crime video and mentioned by the interviewer
d. Neither in the crime video nor mentioned by the interviewer
e. I don't know

22. The suspect was wearing a solid black t-shirt. This information was:
a. In the crime video only
b. Mentioned by the interviewer only
c. In the crime video and mentioned by the interviewer
d. Neither in the crime video nor mentioned by the interviewer
e. I don't know

23. The bystander called security from a campus phone. This information was:
a. In the crime video only
b. Mentioned by the interviewer only
c. In the crime video and mentioned by the interviewer
d. Neither in the crime video nor mentioned by the interviewer
e. I don't know

24. The suspect has average length hair. This information was:
a. $\quad$ In the crime video only
b. Mentioned by the interviewer only
c. In the crime video and mentioned by the interviewer
d. Neither in the crime video nor mentioned by the interviewer
e. I don't know

25. The suspect tripped on his way out. This information was:
a. In the crime video only
b. Mentioned by the interviewer only
c. $\square$ In the crime video and mentioned by the interviewer
d. Neither in the crime video nor mentioned by the interviewer 

e. I don't know

26. The suspect has a goatee. This information was:
a. $\quad$ In the crime video only
b. Mentioned by the interviewer only
c. In the crime video and mentioned by the interviewer
d. Neither in the crime video nor mentioned by the interviewer
e. I don't know

27. The suspect is approximately 5'7. This information was:
a. $\square$ In the crime video only
b. Mentioned by the interviewer only
c. In the crime video and mentioned by the interviewer
d. Neither in the crime video nor mentioned by the interviewer
e. I don't know

28. The bystander immediately called security. This information was:
a. $\square$ In the crime video only
b. Mentioned by the interviewer only
c. In the crime video and mentioned by the interviewer
d. Neither in the crime video nor mentioned by the interviewer
e. I don't know

29. The suspect has brown hair. This information was:
a. In the crime video only
b. Mentioned by the interviewer only
c. In the crime video and mentioned by the interviewer
d. Neither in the crime video nor mentioned by the interviewer
e. I don't know 
30. The suspect is approximately 190 pounds. This information was:
a. $\square$ In the crime video only
b. Mentioned by the interviewer only
c. In the crime video and mentioned by the interviewer
d. Neither in the crime video nor mentioned by the interviewer
e. I don't know

31. The bystander entered the room where the witness was sitting. This information was:
a. $\square$ In the crime video only
b. Mentioned by the interviewer only
c. In the crime video and mentioned by the interviewer
d. Neither in the crime video nor mentioned by the interviewer
e. I don't know

32. The suspect was wearing a striped t-shirt. This information was:
a. $\square$ In the crime video only
b. Mentioned by the interviewer only
c. In the crime video and mentioned by the interviewer
d. Neither in the crime video nor mentioned by the interviewer
e. I don't know

33. The suspect is approximately 5'8. This information was:
a. $\square$ In the crime video only
b. Mentioned by the interviewer only
c. In the crime video and mentioned by the interviewer
d. Neither in the crime video nor mentioned by the interviewer
e. I don't know

34. The suspect was wearing jeans. This information was:

a. In the crime video only 

b. $\square$ Mentioned by the interviewer only
c. In the crime video and mentioned by the interviewer
d. Neither in the crime video nor mentioned by the interviewer
e. I don't know

35. The bystander was coughing heavily. This information was:
a. $\quad$ In the crime video only
b. Mentioned by the interviewer only
c. In the crime video and mentioned by the interviewer
d. Neither in the crime video nor mentioned by the interviewer
e. I don't know

36. The suspect was wearing a backpack. This information was:
a. $\square$ In the crime video only
b. Mentioned by the interviewer only
c. In the crime video and mentioned by the interviewer
d. Neither in the crime video nor mentioned by the interviewer
e. I don't know 


\section{Appendix F}

\section{Witness Post-experiment Questionnaire}

1. In your opinion, how effective was the interviewer in obtaining a detailed and accurate description of the event you witnessed?

$\begin{array}{llllllllll}1 & 2 & 3 & 4 & 5 & 6 & 7 & 8 & 9 & 10\end{array}$

Not at all Effective

Extremely Effective

2. In your opinion, how good of a listener was the interviewer?

$\begin{array}{llllllllll}1 & 2 & 3 & 4 & 5 & 6 & 7 & 8 & 9 & 10\end{array}$

Not good at all

Extremely Good

3. How comfortable did the interviewer make you feel?

$\begin{array}{llllllllll}1 & 2 & 3 & 4 & 5 & 6 & 7 & 8 & 9 & 10\end{array}$

Not at all Comfortable

Completely Comfortable

4. How much pressure did you feel during the interview to provide details you didn't remember?

$\begin{array}{llllllllll}1 & 2 & 3 & 4 & 5 & 6 & 7 & 8 & 9 & 10\end{array}$

None at all

Extreme Pressure

5. How difficult was it for you to place yourself in the shoes of an actual crime witness?

$\begin{array}{llllllllll}1 & 2 & 3 & 4 & 5 & 6 & 7 & 8 & 9 & 10\end{array}$

Not at all Difficult

Extremely Difficult 
6. What percentage of your interview questions do you think were (must add up to $100 \%)$ :

Open ended (required a narrative answer, e.g. "What happened?")

$\%$

Yes/No (could only be answered by yes or no, e.g. "Did he have long hair?")

$\%$

Multiple Choice (gave the witness several options, e.g. "Was it in the morning, afternoon or night?")

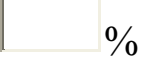

Detail/Cued Questions (required a specific answer, e.g. "How did he steal it?”) $\%$

7. Do you feel that the interviewer had prior knowledge of the crime video you witnessed?

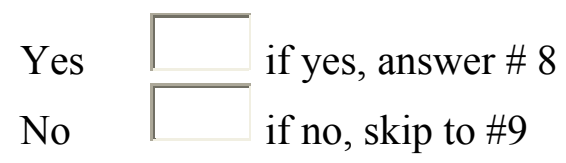

8. In your opinion, how accurate was the information provided to the interviewer?

$\begin{array}{llllllllll}1 & 2 & 3 & 4 & 5 & 6 & 7 & 8 & 9 & 10\end{array}$

Not at all Accurate

Completely Accurate 


\section{Appendix G}

Interviewer Post-Experiment Questionnaire (Informed Conditions)

1. What strategy did you use to interview the witness? (What types of questions did you ask, what information did you want to know first etc.)

2. What percentage (must add up to $100 \%$ ) of your interview questions do you think were:

Open ended (required a narrative answer, e.g. "What happened?")

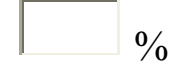

Yes/No (could only be answered by yes or no, e.g. "Did he have long hair?") \%

Multiple Choice (gave the witness several options, e.g. "Was it in the morning, afternoon or night?")

$\%$

Detail/Cued Questions (required a specific answer, e.g. "How did he steal it?”) $\%$

4. How accurate did you believe the witness to be?

$\begin{array}{llllllllll}1 & 2 & 3 & 4 & 5 & 6 & 7 & 8 & 9 & 10\end{array}$

Not at all Accurate

Completely Accurate

5. How credible did you believe the witness to be?

$\begin{array}{llllllllll}1 & 2 & 3 & 4 & 5 & 6 & 7 & 8 & 9 & 10\end{array}$

Not at all Credible

Completely Credible 
6. How accurate did you believe the information in the report to be?

$\begin{array}{llllllllll}1 & 2 & 3 & 4 & 5 & 6 & 7 & 8 & 9 & 10\end{array}$

Not at all Accurate

Completely Accurate

7. How helpful was the information in the police report when conducting your interview?

$\begin{array}{llllllllll}1 & 2 & 3 & 4 & 5 & 6 & 7 & 8 & 9 & 10\end{array}$

Not at all Helpful

Extremely Helpful

8. How much do you think your interviewing strategy was influenced by the information in the police report?

$\begin{array}{llllllllll}1 & 2 & 3 & 4 & 5 & 6 & 7 & 8 & 9 & 10\end{array}$

Not Influenced all

Strongly Influenced

9. How much did you incorporate the information provided in the police report into the questions you asked the witness?

$\begin{array}{llllllllll}1 & 2 & 3 & 4 & 5 & 6 & 7 & 8 & 9 & 10\end{array}$

Not used at all

Used A Lot

10. Why did or didn't you incorporate the information from the report in your interview? 
11. Do you think you introduced information into the interview?

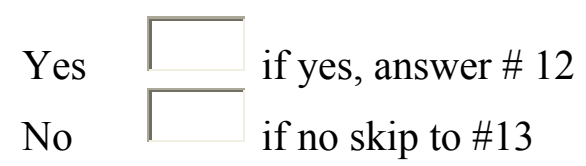

12. Which pieces of information do you think you introduced into the interview (please list them)?

13. Which of the following instructions did you receive before interviewing the witness at Time 2:
a. Gather as much information as possible
b. Avoid leading or suggestive questions
c. Both $a$ and $b$
d. None of the above

14. Assume you know nothing about a crime other than one occurred. Which of the following is an example of a suggestive question given that you have no information?
a. $\quad$ When did this occur?
b. Who was there?
c. How did he steal the laptop?
d. What was the suspect wearing? 
Appendix $\mathrm{H}$

Debriefing Questionnaire

Please answer the following questions as accurately as possible.

Role (check one): Interviewer: Witness:

1. How seriously did you take your role (interviewer/witness) in this study?

$\begin{array}{cccccccccc}1 & 2 & 3 & 4 & 5 & 6 & 7 & 8 & 9 & 10 \\ \text { Not seriously at all } & & & & & & & & \text { Extremely seriously }\end{array}$

2. Did you speak to the other participant about this study or the crime in between appointments?

2a. If YES, when?:

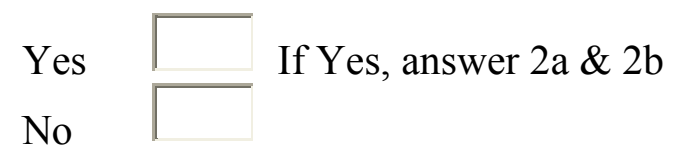

$2 \mathrm{~b}$. How often did you speak to the other participant about this study or the crime in between appointments?

2c. What did you discuss?

3. Were any of the instructions confusing?

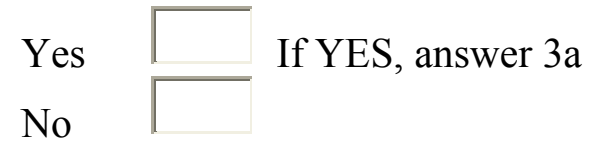

3a. If YES, what parts were confusing?

\section{Interviewer only:}

4. How much effort did you put into conducting your interview according to the instructions you received?

$\begin{array}{cccccccccc}1 & 2 & 3 & 4 & 5 & 6 & 7 & 8 & 9 & 10 \\ \text { No effort at all } & & & & & & & & & \text { Maximum effort }\end{array}$


5. How motivated were you to conduct the best interview possible?

$\begin{array}{ccccccccc}1 & 2 & 3 & 4 & 5 & 6 & 7 & 8 & 9 \\ \text { Not motivated at all } & & & & & & & \text { Extremely motivated }\end{array}$

6. How concerned were you about having your interview evaluated by the research team?

$\begin{array}{ccccccccc}1 & 2 & 3 & 4 & 5 & 6 & 7 & 8 & 9 \\ \text { Not concerned at all } & & & & & & & \text { Extremely concerned }\end{array}$

7. How concerned were you about gathering accurate information?

$\begin{array}{ccccccccc}1 & 2 & 3 & 4 & 5 & 6 & 7 & 8 & 9 \\ \text { Not concerned at all } & & & & & & & \text { Extremely concerned }\end{array}$

8. How concerned were you about gathering a lot of information?

$\begin{array}{ccccccccc}1 & 2 & 3 & 4 & 5 & 6 & 7 & 8 & 9 \\ \text { Not concerned at all } & & & & & & & \text { Extremely concerned }\end{array}$

9. Did you believe that you would have to write a 200 word essay if you failed to conduct a good interview?

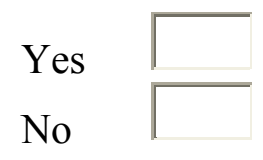

10. How concerned were you about having to potentially write a 200 word explanation?

$\begin{array}{ccccccccc}1 & 2 & 3 & 4 & 5 & 6 & 7 & 8 & 9 \\ \text { Not concerned at all } & & & & & & & \text { Extremely concerned }\end{array}$

11. How motivated were you to earn the extra credit point for conducting a good interview?

$\begin{array}{ccccccccc}1 & 2 & 3 & 4 & 5 & 6 & 7 & 8 & 9 \\ \text { Not motivated at all } & & & & & & & \text { Extremely motivated }\end{array}$


Appendix I

\section{Interviewer Instructions Part I (Instruction Group):}

Put yourself in the shoes of a police investigator who is in charge of solving this crime. Your goal is to (1) gather as much information as possible - any detail counts - and (2) avoid leading or suggestive questions that can introduce new information into the interview. A question is leading if it suggests the answer to the question (e.g. You drove to school today, didn't you?). A suggestive question provides information that has not yet been mentioned by the witness (e.g. What color is your car? - when the witness has not mentioned he/she has a car).

\section{Interviewer Instructions Part I (Instruction Group):}

A crime occurred and you are about to interview a witness to that crime. Put yourself in the shoes of a police investigator who is in charge of solving this crime. Your goal is to gather as much information as possible - any detail counts.

\section{Interviewer Instructions Part II (All Groups):}

As you interview the witness, you will need to find out what type of crime took place and the details of the crime, when and where exactly the crime took place, the sequence of events, who exactly was involved, a detailed description of all people involved, and any other details you feel are important to successfully solve this crime. Please take as much time as you need to gather the most detailed and informative statement possible. At the conclusion of the study your interview will be reviewed and you can earn an extra credit point if the research team concludes you have conducted a good interview and have obtained sufficient information to further investigate this crime. If your interview and report do not meet the criteria, you will need to explain to my supervisor why you failed and may be asked to write a 200 word essay outlining this explanation. 
Appendix $\mathbf{J}$

\section{Interviewer Instruction Comprehension Quiz}

1. Your goal as an interviewer is to do what?

a.

b.

2. How much time do you have to complete the interview?

a.

3. What makes a question suggestive?

a.

b.

4. What are the categories of information you should obtain from the witness?

a.

b.

c.

d.

e.

5. What happens if you do not perform a good interview and obtain sufficient information from the witness?

a.

b.

6. What happens if you perform a good interview and obtain sufficient information? 
Appendix K

Relevant Detail List: Time 2 Interview and Time 3 Recall

\section{Room/Setting Characteristics}

Wall color

Room type

Room number

Decorations

Items in room

Time of day

Time of year

Building

Other

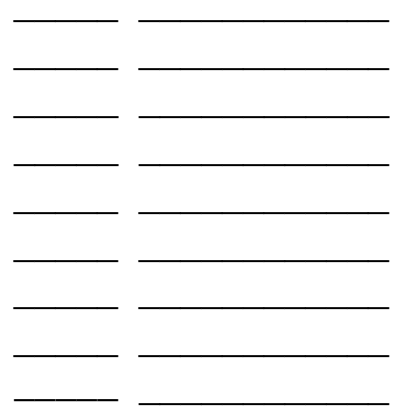

Perpetrator Characteristics:

Age

Hair color

Hair length

Hair style

Facial hair

Eye Color

Race/Ethnicity

Skin Color

Facial shape

Build

Height

Weight

Shirt type

Shirt color

Pants/Shorts Type

Pants/Shorts Color

Shoes Type

Shoes Color

Bag Type

Bag color

Gender

Other:

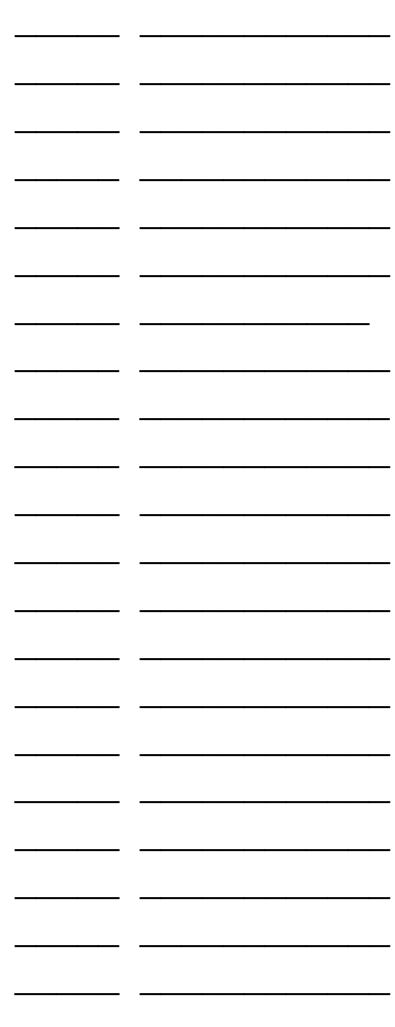

Perpetrator Actions:

What stolen

How stole it

Where put it

Lights

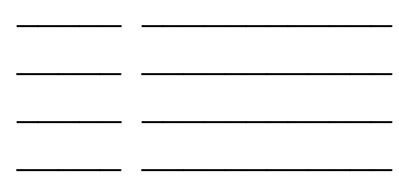


Stolen Laptop Characteristics:

Type

Color

Victim Cell Phone Characteristics:

Type:

Color:

Victim Characteristics:

Age:

Hair color

Hair length

Hair style

Eye Color

Race/Ethnicity

Skin Color

Facial shape

Build

Height

Weight

Shirt

Pants/Shorts

Shoes

Glasses

Accessories

Gender

Other:

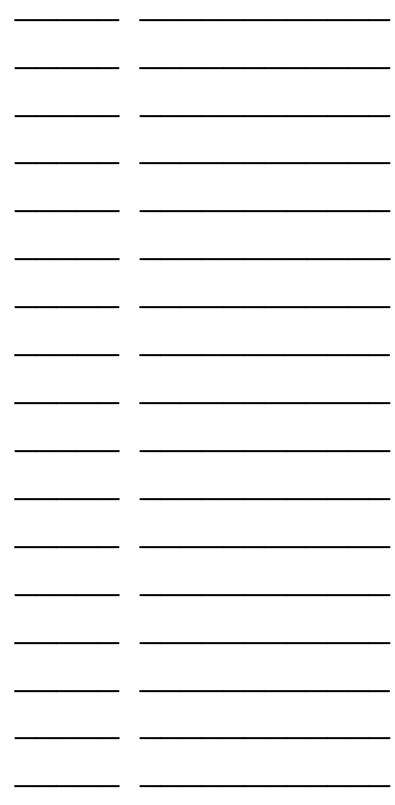

Bystander Characteristics:

Age:

First name

Last name

Hair color

Hair length

Hair style

Facial hair

Eye Color

Race/Ethnicity

Skin Color

Facial shape

Build

Height

Weight

Shirt Type

Shirt Color

Pants/Shorts

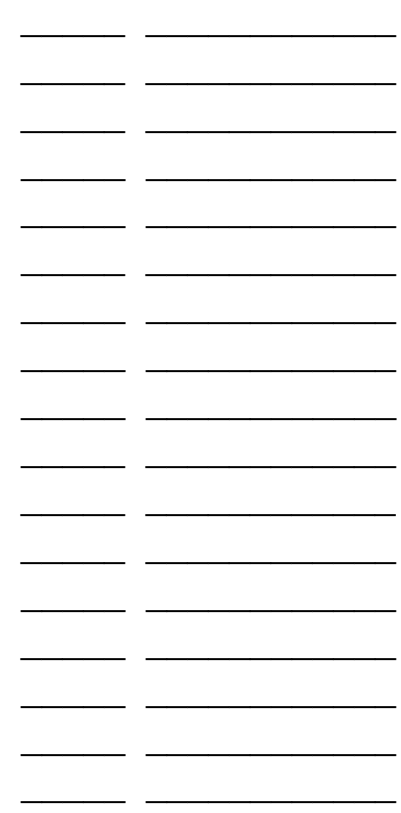


Shoes

Bag Type

Bag color

Laptop type

Laptop color

Gender

Other:

\section{Bystander Actions:}

Enter Sequence

Plug in computer

Called security/police

Type of phone used 
VITA

JILLIAN R. RIVARD

Born: Gloversville, New York

2003

B.A., Psychology

Ithaca College

Ithaca, New York

2009

M.A., Forensic Psychology

Roger Williams University

Bristol, RI

2011-2014

Doctoral Candidate

Florida International University

Miami, FL

\section{PUBLICATIONS AND PRESENTATIONS}

Fisher, R. P., Schreiber Compo, N., Rivard, J. R., \& Hirn, D. (2014) Interviewing witnesses. In Perfect, T. \& Lindsay, D. S. (Eds). The Sage Handbook of Applied Memory. Stamford, CT: Cenveo Inc.

Rivard, J. R., Fisher R. P., Robertson, B. \& Hirn Mueller, D. (in press) Testing the cognitive interview with professional interviewers: Enhancing recall of specific details of recurring events. Applied Cognitive Psychology.

Fisher, R. P., Leins, D., Pludwinski, L., Rivard, J. R., \& Robertson, B. (in press) Interviewing protocols to facilitate HUMINT sources' recollections of meetings.

Rivard, J. R., Benson, S., \& Schreiber Compo, N. (2014). The effects of blind versus informed interviewing on eyewitness source memory. Paper presented at the $7^{\text {th }}$ International Conference of Psychology and Law, New Orleans, LA.

Rivard, J. R., Schreiber Compo, N., Puertas, L., Castellon, S., Ferreira, L., Benitez, Y., Garcia, B., Mikaiel, C., Pena, M., Campbell, I. (2014). Confirmation bias in witness interviewing: The delayed effects of pre-interview knowledge. Paper presented at the $7^{\text {th }}$ International Conference of Psychology and Law, New Orleans, LA.

Malloy, L. C., Mugno, A. P., Rivard, J. R., Lyon, T. D, Quas, J. (2014). A detailed investigation of recanted child sexual abuse cases. Paper presented at the $7^{\text {th }}$ International Conference of Psychology and Law, New Orleans, LA. 
LaPaglia, J, A., Wilford, M. M., Rivard, J. R., Chan, J. C. K., \& Fisher. R. P. (2013). Misleading suggestions can alter later memory reports even following an investigative interview. Applied Cognitive Psychology. doi: 10.1002/acp.2950

LaPlaglia, J., Wilford, M., Rivard, J. R., Chan, J., Fisher, R. P. (2013) The memorial benefits of the cognitive interview come at a cost of enhanced suggestibility. Paper presented at the 6th International Conference of Psychology and Law, Portland, OR.

Fisher, R. P., Rivard, J.R., Robertson, B., Hirn, D. (2013). Testing the cognitive interview with professional interviewers. Paper presented at the 6th International Conference of Psychology and Law, Portland, OR.

Rivard, J. R. \& Schreiber Compo, N. (2012). Investigative interviewing: Is ignorance bliss? Paper presented at the $5^{\text {th }}$ Annual Conference of the International Investigative Interviewing Research Group, Toronto, Canada.

Fisher, R. P., Rivard, J. R., Leins, D. \& Pludwinski, L. (2012). Can good interviewing overcome poor witnessing conditions? Paper presented at the $5^{\text {th }}$ Annual Conference of the International Investigative Interviewing Research Group, Toronto, Canada.

Leins, D., Fisher, R. P., Pludwinski, L., Robertson, B., Rowback, J. (2012). Consistency as reflective of question type rather than memory strength. Poster presented at the $5^{\text {th }}$ International Conference of Psychology and Law, San Juan, Puerto Rico.

Fisher, R. P., Leins, D., Pludwinski, L., Rowback, J. (2012). Interviewing protocols to enhance detainees' recollections of meetings with terrorists. Paper presented at $5^{\text {th }}$ International Conference of Psychology and Law, San Juan, Puerto Rico.

Rowback, J. \& Schreiber Compo, N. (2011). The effects of pre-interview information on eyewitness recall. Poster presented at the $4^{\text {th }}$ International Conference of Psychology and Law, Miami, FL.

Cahill, B., Fisher, R. P. \& Rowback, J. (2011). Catching liars with cartoons. Paper presented at the $4^{\text {th }}$ International Conference of Psychology and Law, Miami, FL.

Rowback, J., Small, R., Platania, J. (2009). The role of individual differences in explaining the acceptability of prosecutorial misconduct. Paper presented at the $2^{\text {nd }}$ International Conference of Psychology and Law, San Antonio, TX.

Rowback, J. \& Platania, J. (2008). The interacting effects of death qualification and perceptions of confessions. Poster Presented at the $20^{\text {th }}$ Congress of the Association for Psychological Science, Chicago, IL. 